\title{
Modeling Photosynthesis and Carbon Partitioning
}

\author{
held at the \\ 90th ASHS Annual Meeting \\ Nashville, Tennessee \\ 28 July 1993
}

sponsored by the
Cropping Efficiency and Photosynthesis Working Group

published by the

American Society for Horticultural Science

Alexandria, VA 22314-2824

as a special insert in

HortScience 29(12), December 1994 


\title{
Workshop Papers and Authors
}

\author{
Presiding: Bharat P. Singh
}

Modeling Photosynthesis and Carbon Partitioning: Introduction to the Workshop

Bharat P. Singh

Mechanics of Model Building

James M. McKinion and Ronaldo A. Sequeira

Response of Crop Photosynthesis to Carbon Dioxide, Temperature, and Light: Experimentation and Modeling

V.R. Reddy, L.B. Pachepsky, and B. Acock

Modeling Photosynthesis of Row Crop Canopies

K.J. Boote and N.B. Pickering

\section{A Supply and Demand Approach to Modeling Annual Reproductive and Vegetative Growth of Deciduous Fruit Trees}

Theodore M. DeJong and Yaffa L. Grossman

\section{Modeling Photosynthesis and Carbon Partitioning: Introduction to the Workshop}

\author{
Bharat P. Singh \\ Agricultural Research Station, Fort Valley State College, Fort Valley, GA 31030
}

This workshop was organized to provide concise guidelines for those contemplating modeling photosynthesis or $\mathrm{C}$ partitioning and a useful reference for those already involved in modeling.

The concept of modeling to provide a simplified representation of a real-world process is not new. The complex nature of plant and soil systems, however, made their description through models difficult until the advent of modern computers. During the last 3 decades, interest in developing crop models has gradually intensified, and models to evaluate plant and soil systems are now available. Simulation models have been developed to quantify physiological processes in several crops and determine the effects of environmental and management factors on these processes. Models have been used to test hypotheses, plan experiments, and identify areas where knowledge is lacking. They are also useful for practical purposes such as controlling insects and disease, scheduling irrigation, and making other cropmanagement decisions. Simulation models that predict the growth and development of diverse crops such as citrus, grains, and feed crops have been developed during the past decade.

Practically all dry matter of higher plants originates from photosynthesis. The oxidation-reduction reaction of $\mathrm{H}_{2} \mathrm{O}$ and $\mathrm{CO}_{2}$ during photosynthesis to produce carbohydrate occurs against existing energy gradients. Leaf chlorophyll absorbs energy from certain wavelengths of solar radiation to provide the additional energy needed to reduce $\mathrm{CO}_{2}$. The extent to which a plant absorbs the incident solar radiation depends on its leaf area index and on leaf age, turgidity, shape, size, and positioning. In the visible wavelengths, a typical leaf absorbs $75 \%$, reflects $15 \%$, and transmits $10 \%$ of incident sunlight (Gates, 1965). Leaves are usually at an angle that permits some radiation energy to reach the lower canopy without being intercepted by the top leaves. Competition for solar energy may occur between plants, when one plant casts a shadow on another, or within a plant,

The cost of publishing this paper was defrayed in part by the payment of page charges. Under postal regulations, this paper therefore must be hereby marked advertisement solely to indicate this fact. when top leaves shade the bottom leaves.

Earth's atmospheric $\mathrm{CO}_{2}$ concentration is not optimal for the maximum photosynthesis rate (Bonner, 1962). It is difficult to increase the $\mathrm{CO}_{2}$ level in a field crop canopy, but $\mathrm{CO}_{2}$ fertilization in greenhouses has been used advantageously in high-value vegetable and flower production. In a $\mathrm{CO}_{2}$-stable crop canopy, the internal leaf $\mathrm{CO}_{2}$ concentration may vary considerably as a result of differing resistance to $\mathrm{CO}_{2}$ diffusion into the leaves. Leaf stomatal resistance to diffusion is affected by such factors as leaf temperature, air vapor pressure, and plant water status.

Not all C fixed by photosynthesis is converted to dry matter. Part of it is lost through respiration to provide energy to maintain the living complex and synthesize compounds that form the final dry matter. Also, in agricultural crops, much of the synthesized dry matter is translocated to the plant organ harvested for use.

Most photosynthesis and C-partitioning models have been developed to establish quantitative relationships between the environmental factors, crop canopy characteristics, ontogeny, and the rates of photosynthesis and photosynthate partitioning to various plant organs. These relationships are then used to describe how photosynthesis rate and the amount of dry-matter production and translocation to yieldproducing organs would be affected in particular situations. Whisler et al. (1986) have tabulated the names of prominent research groups and institutions that have developed models dealing with photosynthesis and $\mathrm{C}$ partitioning, their test species, and the names of these models.

Since there are fewer models available for horticultural crops than agronomic crops, it is our hope that this workshop will generate interest in developing crop-simulation models for photosynthesis, $\mathrm{C}$ partitioning, and other yield-determining processes in horticultural crops. Because most horticultural crops are intensively managed and of high value, models of these crops may be a valuable tool in selecting cultural options that produce the highest economic yield.

McKinion and Sequeira discuss the requirements for building a sound model: an appropriate database, adherence to a minimum set of design features, calibration and validation of the model, and continued 
subsequent validations. Boote and Pickering describe the essential components of a row crop photosynthesis model. The available $\mathrm{C}$ supply and the demand by different plant $\mathrm{C}$ sinks are used by DeJong and Grossman to develop a model for annual vegetative and reproductive growth in deciduous fruit trees.

The $\mathrm{CO}_{2}$ level in the atmosphere is expected to double in the next 50 to 100 years, resulting in a 2 to $3 \mathrm{C}$ increase in Earth's temperature (Gates, 1983). How this will affect life processes, including photosynthesis, is of great concern. Reddy, Pachepsky, and Acock describe a model that can be used to simulate the effect of $\mathrm{CO}_{2}$ and temperature on canopy photosynthesis.
Literature Cited

Bonner, J. 1962. The upper limit of crop yield. Science 137:11-15.

Gates, D.M. 1965. Radiant energy, its receipt and disposal, p. 1-26. In: P.E. Waggoner (ed.). Agricultural meteorology. Meteorol. Monogr. 6. Amer. Meteorol. Soc., Boston.

Gates, D.M. 1983. An overview, p. 7-20. In: E.R. Lemon (ed.). $\mathrm{CO}_{2}$ and plants. Westview Press, Boulder, Colo.

Whisler, F.D., B. Acock, D.N. Baker, R.E. Fye, H.F. Hodges, J.R. Lambert, H.E. Lemmon, J.M. McKinion, and V.R. Reddy. 1986. Crop simulation models in agronomic systems. Adv. Agron. 40:141-208.

\title{
Mechanics of Model Building
}

\author{
James M. McKinion and Ronaldo A. Sequeira \\ Crop Simulation Research Unit, Agriculture Research Service, Mississippi State University, MS 39762-5367
}

In the late 1960s, with the advent of wide availability of the digital computer, it became possible by applying systems theory to build simulation models of biological entities. In production agriculture, scientists have built models for various field crops: cotton (Gossypium hirsutum L.), corn (Zea mays L.), wheat (Triticum aestivum L.), soybean [Glycine max (L.) Merr.], and alfalfa (Medicago sativa L.). In most of the models built to date, crop phenology is simulated directly with detailed aspects of crop physiology. Some models also rely on principles of soil physics to some degree. This paper addresses the methodology of constructing process-level, physiologically based crop simulation models that possess detailed descriptions of plant physiological and soil physical mechanisms and proposes a minimum set of design features.

\section{THE DATABASE}

Data availability largely determines the type of model of a physiological process, or an entire crop, that a modeler can develop. Unfortunately, most field-crop experiments are designed to determine either differences between means or the significance of specific treatments, not an understanding of the cause of treatment differences. As a result, one cannot determine from field data which external events caused responses in the biological-physical system. If a model is developed from such a data set, that model will be valid only for data conditions at that site for the years over which the data were collected and cannot reliably be extended to other sites or other years.

In a simulation model, detailed information must be available on all exogenous variables that can affect the process or crop being studied. For example, if one were modeling leaf growth and development, many variables would have to be known to build a comprehensive leaf model: date the leaf was initiated and the change in leaf size, $\mathrm{N}$ concentration, water potential, temperature, exposure to solar radiation, dry weight, stomatal conductance, and photosynthesis rate. Of course, most of these variables would have to be measured from leaf initiation through senescence. If significant information is missing from this data set, the type of model one can construct is limited. If temperature data were missing, the job would become very difficult. If leaf $\mathrm{N}$ concentration data are missing, a leaf model could be built, but the model would be confounded by the unknown leaf $\mathrm{N}$ status under which the data set was collected.

In applying systems methodology to modeling biological systems, experiments are designed to determine cause and effect and measure external variables pertinent to the system being studied. Even when one strives to be comprehensive in field research experiments, certain classes of experiments cannot be conducted in the field. For example,

A contribution of the U.S. Dept. of Agriculture-Agricultural Research Service Crop Simulation Research Unit in cooperation with the Agronomy Dept., Mississippi State Univ., and the Mississippi Agricultural and Forestry Experiment Station. The cost of publishing this paper was defrayed in part by the payment of page charges. Under postal regulations, this paper therefore must be hereby marked advertisement solely to indicate this fact. determining the isolated effect of temperature on the rate of single leaf area expansion would be almost impossible to do in the field. The first problem is the range of temperatures the leaf would experience at a particular site. The second problem is the confounding effect of $\mathrm{N}$ variation under field conditions. A third problem is the confounding effect of water stress on a field crop. Any model built describing leaf area development from such a set of field-collected data would have these confounding effects built into the model.

If one had enough resources, land, and time, field experiments could be conducted across the ecological range of the crop under variable conditions of temperature, solar radiation, water regimes, and plant nutrition so that one could unravel cause and effect in fieldcollected data sets. These would have to be replicated over sites and years in hundreds of locations for each crop being modeled. However, there is a better way that is much more efficient and much more accurate for collecting data for building process-level models.

Naturally sunlit-controlled-environment plant growth chambers have been used to collect data for constructing process-level crop models since the mid-1970s (McKinion, 1986; Phene et al., 1978). These soil-plant-atmosphere-research (SPAR) chambers are used to control all external independent variables except solar radiation.

Methodology has been developed with these SPAR chambers to run appropriate experiments and collect process data to parameterize process-level crop growth models that require only 3 years of experiments. Such models have all primary and secondary plant processes described and calibrated. Some tertiary effects may also be addressed, but additional controlled-environment experiments are required to address crop-specific processes to complete the model.

\section{MODEL-BUILDING METHODOLOGY}

The methodology we have developed for calculating photosynthesis in cotton, wheat, and soybean is based on plant canopy geometry. The experimental method for acquiring these data involves using SPAR chambers in which these crops have been grown in a row-crop configuration (McKinion, 1986; Parson et al., 1980; Phene et al., 1978). Solar radiation is allowed to vary naturally, but air temperature, $\mathrm{CO}_{2}$ concentration, and soil conditions are controlled. Thus, we measure apparent photosynthesis under various air temperature, soil moisture, and soil N regimes (McKinion and Baker, 1982; Reddy et al., 1992). We also measure light, maintenance, and growth respiration rates so that, given crop biomass, we can calculate net photosynthesis. Statistically, the equations derived from this experimental approach and database have an $R^{2}$ of 0.92 or better for cotton and wheat.

The methodology we use for building dynamic simulation models of field crops has led us to propose a minimum set of design features:

1) The model will be a materials balance accounting for dry-matter production and organ senescence.

2) The model will calculate photosynthate production separately from respiration (since the forcing functions in the two processes are different and the ratios change). 
3) Photosynthesis and transpiration will be based on canopy light interception.

4) Daily canopy light interception will be calculated on a plant or row element and on canopy density rather than on a leaf area index, per se.

5) Nutrient uptake will include the process of nutrient entrainment in the transpiration stream.

6) Physiological stress will be calculated in a function containing metabolite and nutrient supply and demand.

7) Decisions about the abortion of fruiting structures will be based on physiological stress.

8) Morphogenetic rates will be stated as temperature functions that are reduced by physiological stress.

9) Water stress will be considered an environmental resultant that determines physiological stress. Plant-water relations will determine the turgor levels of growing points and, thus, indirectly, the demand for nutrients and metabolites. Plant-water relations will also determine photosynthesis and transpiration rates. Thus, water stress will indirectly determine morphogenetic rates or the abortion of fruiting parts.

10) Plant-water relations will be determined partly by the relative location of roots and soil water in the soil profile. Root distribution will respond to soil penetration resistance and to $\mathrm{O}_{2}$ and nutrient gradients. Soil water distribution will be considered a function of soil hydrological properties.

From the design features mentioned above used with the SPAR experimental facility and high-speed desktop computers, the methodology outlined in this paper for building causal, process-oriented, physiological crop models is based on a rational, scientific approach.

\section{SYSTEMS ANALYSIS AND MODEL VALIDATION}

By applying the principles outlined above and tenets of system analysis, one can arrive at a collection of many processes in which the individual process has been transformed from a nonlinear system into a linear, mathematically tractable system. The use of the Taylor series expansion of a nonlinear partial differential equation about a defined region is an example of transforming a system from nonlinear to linear. Many biological processes are nonlinear. The fact that we can describe many of these processes in terms of mechanistic models is good, but it is not enough to aggregate a collection of linearized mechanisms into a simulation model. Biological systems have many feedback paths between processes. The more closely we can identify and code these feedback paths into the simulation model, the more robust the model becomes (Swartzman and Kaluzny, 1987). At the same time, the simulation model becomes more nonlinear. Synergistic, agonistic, and n-way interactions are common. Individual parts of the system can be described in terms of mechanism and tested in terms of test data sets. The soil physics in GOSSYM (Baker et al., 1983) is an example. Currently there are $>400$ cotton-producing soils in our database. These soils are identified by soil series and name. The soil physical properties are stored in the database for each soil layer down to $2 \mathrm{~m}$. The data for each layer are the soil water retention curve; bulk density; percent sand and clay content; and initial moisture, organic matter, ammonia, and nitrate content. The operation of the soil hydrology code using these data is tested for each new soil type before it is added to the database. However, the model is more than a linear combination or sum of its parts. This implies that another step beyond combining individually studied model components is needed. This additional step is wholemodel calibration and validation.

The model should be calibrated with data sets that are independent from the data sets with which validation tests are made. In calibrating the GOSSYM (Boone et al., 1993) model, we typically use $\approx 25$ calibration data sets. For validation we use $\approx 80$ data sets, with another 100 data sets reserved for odd circumstances. Until now, the only way to deal with this problem has been iterative and heuristic.

Model calibration will continue to be necessary in the near future. It is therefore imperative to consider procedures that can automate the parameterization process. We have developed genetic algorithm (GA) techniques that permit the implementation of self-correcting, selfmaintaining simulation models.

\section{MODEL CALIBRATION AND GENETIC ALGORITHMS}

There are several reasons for parameterizing or recalibrating a model. Variable response under different environments and varietal idiosyncrasies are often noted as sources of variability, and much experimental research relies on the ability to control these factors (Fye et al., 1984; Reddy et al., 1985). System parameterization is a welldefined, straightforward procedure, given that a model whose processes have been validated exists (Curry and Feldman, 1987). However, biological systems are not perfectly controllable or observable, as defined by Schultz and Melsa (1967). Curry and Feldman (1987) noted that even a good model must be recalibrated for different situations, but there are no systems with an identified mechanism by which this recalibration can be automated. This constant recalibration requirement is due to missing aspects in the model that fail to capture the differential response across all environments or situations. Recalibration is a necessary trade-off between the expense of further model refinement and an iterative correcting procedure. Further, Shannon (1976) noted that, due to the accumulation of measurement errors, adding new variables or processes will not necessarily increase prediction ability. Vansteenkiste and Spriet (1982) summarize some of the special constraints presented by biological systems and the resulting need for parameterization.

GAs are search procedures based on the biological mechanisms of selection and the transmittal and evolution of genetic information. They were developed by J. Holland (1992) and constitute one of the fastest growing areas of emergent computation research. GAs use biological evolution metaphors to find optimal, naturally evolved solutions in artificial systems. Software that can learn and adapt to new conditions is a revolutionary development in modeling and in the broader area of software engineering and hardware design. Heretofore, static computer systems have required constant maintenance to respond to changes in the problem domain. The emulation by computer programs of evolutionary processes that lead to increased fitness will enable them to be resilient to changes in their targeted environments (Goldberg, 1989). A methodology has been established for implementing GAs that is problem-independent (Davis, 1991; Goldberg, 1989; Goldberg and Richardson, 1987). GAs use strings (chromosome analogs) to represent the structural elements whose overall performance is of interest. A string is constructed in a manner analogous to DNA encodings in cellular nuclei. Strings are composed of genes, each of which describes an attribute of the desired solution. A GA works by reproducing chromosomes iteratively over multiple generations while applying genetic operators, which modify the informational content of the strings. Strings reproduce at a rate that is proportional to the fitness of the solution they encode. Thus, a population of strings (each of which represents a solution) becomes gradually more fit (i.e., the average solution gets more optimal). Generally, the difference in the average fitness between consecutive generations decreases and the population tends toward high fitness. It is said the population converges toward a solution at this time. Because of string or chromosome reproduction, their rearrangement, and subsequent evaluation and selection, a GA makes it possible to explore many potential solutions. The ability of a GA to search a massive statespace of alternatives simultaneously to a defined problem is greater than for other search algorithms (Goldberg and Richardson, 1987; Liepins et al., 1987).

We developed a GA $\left(\mathrm{GA}_{\text {Gossym }}\right)$ to automate the parameterization of GOSSYM (McKinion et al., 1989; Whisler et al., 1986). Data first used by Reddy et al. (1985) in the GOSSYM validation were used to develop our GA. A better overall fit was observed when compared to manual or heuristic parameterization (Sequeira et al., 1993). Phenological event timing, organ generation, and mass accretion were predicted better by $\mathrm{GA}_{\text {Gossym }}$ than by the model calibrated by Reddy et al. (1985). Notably, about a $20 \%$ improvement in the prediction of the number of green bolls (as measured by the sum of the absolute deviations) was obtained. Similarly improved predictions of peak leaf weight timing and, of particular interest to producers, a $40 \%$ improve- 
ment in the prediction of overall fruit mass accretion were obtained by $\mathrm{GA}_{\text {Gossym }}$. Running $\mathrm{GA}_{\text {Gossym }}$ with the full parameter set resulted in an overall fitness improvement of $\approx 25 \%$ over all output types normally used to assess fit.

Our discovery of the potential of GAs to derive improved parameter sets from high-level data will have profound implications on the speed at which we can develop locality-specific systems and on the accuracy of these systems to perform at that specific site. The GA was restricted to investigate parameter ranges that were within the realm of the field-observed variability. That is, parameters continued to maintain the original biological interpretations. We have demonstrated that we can develop a fine-tuned system that responds to local environments optimally given logical constraints on parameter ranges and functional forms.

GOSSYM is currently used throughout U.S. cotton-growing regions. A self-correcting feature was developed that allowed the model to rederive its parameters when field data indicated that forecasts were beyond an arbitrarily set threshold of acceptability. The process of finding the optimal configuration of parameter sets has been completely automated. The process of model correction thus depends only on the model's perceived goodness of fit. If it does not fit data well, it will invoke its associated GA and evolve a better set of parameters. This research implies that models may be applicable and have improved forecast efficacy over a wider range of conditions than is presently the case. This improvement in performance and applicability will affect natural resource management.

\section{CONCLUSIONS}

The level of detail used in a biological simulation model depends on its objectives and the accuracy or fidelity with which processes are simulated. Hierarchy theory states that if one is simulating at the whole-plant level, then details must be included at least two levels of abstraction down from the whole-plant level. It has been our experience that, as one increases the level of scientific mechanism in crop models, the system becomes more robust and less brittle. One must validate, validate, validate! Mechanisms that on the surface seem to be perfectly reasonable and plausible to put in a model may actually not function properly. The only way to find out is to integrate the mechanism, calibrate the model, and run validation tests. Verification tests at the component level do not always tell the story. New methodology is being developed to aid in model calibration. This new methodology uses GAs from the field of artificial intelligence. Our first efforts in this arena have given very promising results.

Literature Cited

Baker, D.N., J.R. Lambert, and J.M. McKinion. 1983. GOSSYM: A simulator of cotton growth and yield. South Carolina Agr. Expt. Sta. Tech. Bul. 1089.
Boone, M.Y.L.,D.O Porter, and J.M. McKinion. 1993. Calibration of GOSSYM: Theory and practice. Computers Electronics Agr. 9:193-203.

Curry, G.L. and R.M. Feldman. 1987. Mathematical foundations of population dynamics. Texas A\&M Univ. Press, College Station.

Davis, L. 1991. Handbook of genetic algorithms. Van Nostrand Reinhold, New York.

Fye, R.E., V.R. Reddy, and D.N. Baker. 1984. Validation of GOSSYM: Part I. Arizona conditions. Agr. Systems 14:85-105.

Goldberg, D.E. 1989. Genetic algorithms in search, optimization, and machine learning. Addison-Wesley, Reading, Mass.

Goldberg, D.E. and J. Richardson. 1987. Genetic algorithm with sharing for multimodal function optimization, p. 41-49. In: J.J. Grefenstette (ed.). Genetic algorithms and their applications. Proc. 2nd Intl. Conf. Genet. Algorithms. L. Erlebaum Assoc. Publishers, Hillsdale, N.J.

Holland, J.H. 1992. Adaptation in natural and artificial systems. MIT Press, Cambridge, Mass.

Liepins, G.E., M.R. Hilliard, M. Palmer, and M. Morrow. 1987. Greedy genetics, p. 90-99. In: J.J. Grefenstette (ed.). Genetic algorithms and their applications. Proc. 2nd Intl. Conf. Genet. Algorithms. L. Erlebaum Assoc. Publishers, Hillsdale, N.J.

McKinion, J.M. 1986. SPARNET: A data acquisition, analysis computer network. Computers Electronics Agr. 1:31-40.

McKinion, J.M. and D.N. Baker. 1982. Modeling experimentation, verification, and validation: Closing the feedback loop. Trans. Amer. Soc. Agr. Eng. 25(3):647-653.

McKinion, J.M., D.N. Baker, F.D. Whisler, and J.R. Lambert. 1989. Application of the GOSSYM/COMAX system to cotton crop management. Agr. Systems 31:55-65.

Parsons, J.E., J.L. Dunlap, J.M. McKinion, C.J. Phene, and D.N. Baker. 1980. Microprocessor-based data acquisition and control software for plant growth chambers (SPAR system). Trans. Amer. Soc. Agr. Eng. 23(3):589-595.

Phene, C.T., D.N. Baker, J.R. Lambert, and J.M. McKinion. 1978. SPAR-A soil-plant-atmosphere-research system. Trans. Amer. Soc. Agr. Eng. 21:924-930.

Reddy, K.R., H.F. Hodges, and J.M. McKinion. 1992. Cotton response to global climate change. World Resources Rev. 4(3):348-365.

Reddy, K.R., H.F. Hodges, and J.M. McKinion. 1993. A temperature model for cotton phenology. Biotronics 2:47-59.

Reddy, V.R., D.N. Baker, and J.N. Jenkins. 1985. Validation of GOSSYM: Part II. Mississippi conditions. Agr. Systems 17:133-154.

Schultz, D.G. and J.L. Melsa. 1967. State functions and linear control systems. McGraw-Hill, New York.

Sequeira, R.A., R. Olson, and J. McKinion. 1993. Self-correction of simulation models using genetic algorithms. Intl. Joint Conf. Artificial Intelligence (IJCAI'93), AI Applications in Natural Resources, Chambery, France. p. 77-87.

Shannon, R. 1976. Simulation: The art and the science. Prentice Hall, New York.

Swartzman, G.L. and S.P. Kaluzny. 1987. Ecological simulation. MacMillan, New York.

Vansteenkiste, G.C. and J.A. Spriet. 1982. Modelling ill-defined systems. In: F.E. Cellier (ed.). 1982. Progress in modelling and simulation. Academic, New York.

Whisler, F.D., B. Acock, D.N. Baker, R.E. Fye, H.F. Hodges, J.R. Lambert, H.E. Lemmon, J.M. McKinion, and V.R. Reddy. 1986. Crop simulation models in agronomic systems. Adv. Agron. 40:142-208.

\title{
Response of Crop Photosynthesis to Carbon Dioxide, Temperature, and Light: Experimentation and Modeling
}

\author{
V.R. Reddy, L.B. Pachepsky, and B. Acock \\ U.S. Department of Agriculture, Agricultural Research Service, Natural Resources Institute, Systems Research \\ Laboratory, Building 007, Room 008, Beltsville Agricultural Research Center-West, Beltsville, MD 20705
}

Interest in the response of crop photosynthesis to atmospheric $\mathrm{CO}_{2}$ concentration $\left(\left[\mathrm{CO}_{2}\right]\right)$, temperature, and light is growing in ecophysiological research and practical agriculture. Horticulturists are interested because greenhouses often have elevated $\mathrm{CO}_{2}$. Agronomists and ecologists have to take into account in their crop development and productivity predictions that ambient $\left[\mathrm{CO}_{2}\right]$ is increasing, which is expected to increase global air temperature.

The cost of publishing this paper was defrayed in part by the payment of page charges. Under postal regulations, this paper therefore must be hereby marked advertisement solely to indicate this fact.
Canopy photosynthesis models have been proposed, but a method to validate, compare, and choose the most suitable model for a particular application is needed. Such a method is presented here and is used to show that a hyperbolic model is adequate for describing the effects of light, $\left[\mathrm{CO}_{2}\right]$, and air temperature on canopy photosynthesis.

The hyperbolic model was fitted to experimental data on cotton (Gossypium hirsutum L.) canopy $\mathrm{CO}_{2}$ exchange obtained in daylit controlled-environment chambers in a range of $\left[\mathrm{CO}_{2}\right]$ and air temperatures. Canopy light-use efficiency depended on temperature, while canopy conductance to $\mathrm{CO}_{2}$ transfer was a function of air temperature and $\left[\mathrm{CO}_{2}\right]$. The complete model of cotton canopy photosynthesis 
contains seven parameters that can be determined from canopy $\mathrm{CO}_{2}-$ exchange data. Methods and results of photosynthesis model parameterization with data on canopy and leaf $\mathrm{CO}_{2}$ exchange are also compared.

Photosynthetic light response curves have been studied for various plant species during the last several decades. Carbon dioxide and temperature dependencies of canopy $\mathrm{CO}_{2}$ exchange have become the object of intensive study only during the last 15 years. Carbon dioxide response curves were developed as a result of research into photosynthesis mechanisms (Laisk, 1977) and they have been used in greenhouse horticulture for optimizing $\left[\mathrm{CO}_{2}\right]$ control. Recently, this area of research has become the center of interest for a wide circle of researchers. Increasing atmospheric $\mathrm{CO}_{2}$ is expected to result in a $\left[\mathrm{CO}_{2}\right]$ of $600 \mu \mathrm{l} \cdot \mathrm{liter}^{-1}$ by about the middle of the 21 st century. This increase will likely affect global climate primarily by increasing air temperature 3 to $6 \mathrm{C}$ (Wetherald, 1989). Data on light, $\left[\mathrm{CO}_{2}\right]$, and temperature response of photosynthesis are also necessary for assessing the use of crops for human life-support in closed habitats envisioned for space. Results of such measurements can be used to model the use of plants to remove $\mathrm{CO}_{2}$, produce $\mathrm{O}_{2}$, and evaporate water for controlled ecological life-support systems (Wheeler et al., 1993).

The increasing need to predict crop growth at elevated $\left[\mathrm{CO}_{2}\right]$ and temperature has made simulation models essential tools for integrating information across levels of organization and for making quantitative predictions. Five approaches for predicting canopy assimilation using a submodel of leaf photosynthesis are described by Boote and Loomis (1991). The first and simplest approach is to multiply leaf photosynthesis by leaf area index (LAI), which is correct only for LAIs <1.0. This method overestimates canopy photosynthesis at higher LAIs and high light flux densities. The second approach is the big-leaf approach, in which the plant canopy is treated as a single leaf. It often underestimates canopy assimilation. A third approach, proposed by Sinclair (1991), is based on two leaf classes: those exposed to direct solar radiation and those that are shaded. A fourth approach, proposed by Denison and Loomis (1989), includes numerical integration through several leaf layers. This method is very complex, but the prediction can be excellent.

A fifth approach, proposed by Acock et al. (1978), uses a hyperbolic analytical description of photosynthesis and the variation in leaf photosynthetic characteristics with canopy depth. In this approach, canopy properties are accounted for by three parameters that depend on environmental factors.

Many models have been developed to describe leaf photosynthesis. Parameters of these models are usually determined from experimental data (Acock, 1991; Evans and Farquhar, 1991). However, validating models with experimental data is still not a common procedure. Model adequacy is sometimes estimated by visually comparing calculated and measured data, but the model usually is not analyzed quantitatively over the entire range of conditions. Methods for analyzing models quantitatively were developed long ago and have been used successfully, for instance, in chemical technology (Himmelblau, 1968).

The essential difference between laboratory and field data is that the latter are more variable as a result of environmental variability. The data obtained from daylit controlled-environment chambers are affected by variable light, as in the field, but they are measured at stable, controlled values of $\left[\mathrm{CO}_{2}\right]$ and air temperature. Such data are more reliable then field data for parameterizing a photosynthesis model developed to predict plant responses to elevated $\left[\mathrm{CO}_{2}\right]$ and temperature.

This study presents 1 ) the results of cotton and tomato (Lycopersicon esculentum Mill.) $\mathrm{CO}_{2}$-exchange measurements in a wide range of $\left[\mathrm{CO}_{2}\right]$ at various air temperatures, 2) the validation of a canopy photosynthesis model and comparison with a leaf photosynthesis model, and 3) the analysis of dependencies of the main model parameters on $\left[\mathrm{CO}_{2}\right]$ and temperature compared with the same parameters for a single leaf.

\section{TEST PROCEDURES}

General. 'DPL 50' cotton seeds were sown on wet filter paper at 28/ $23 \mathrm{C}$ (day/night). Germinating seeds were selected for uniformity and planted in naturally irradiated controlled-environment plant growth chambers in 11 rows with five plants per row on 15 May 1989 near Starkville, Miss. (lat. $30.5^{\circ} \mathrm{N}$ ). Row length was $0.5 \mathrm{~m}$ and row width was $0.18 \mathrm{~m}$. The initial plant population was 55 plants $/ \mathrm{m}^{2}$. The chambers consisted of a steel bin containing the rooting medium and measuring $1.0 \mathrm{~m}$ high $\times 2.0 \mathrm{~m}$ long $\times 0.5 \mathrm{~m}$ wide. An acrylic base on top of this soil bin held the aerial parts of the plants and measured 2.0 $\mathrm{m}$ high $\times 2.0 \mathrm{~m}$ long $\times 1.5 \mathrm{~m}$ wide. The growing medium was a mixture of 3 sand : 1 vermiculite $(\mathrm{v} / \mathrm{v})$, with slow-release micronutrients added at $88 \mathrm{mg} \cdot$ liter $^{-1}$ before the soil bins were filled. Six plant rows were harvested 23 days after emergence (DAE) and two more rows were harvested $35 \mathrm{DAE}$ to reduce light competition. At final harvest, there were three rows that corresponded to 15 plants $/ \mathrm{m}^{2}$. Air in the chambers was maintained at 28/23C (day/night) during seedling emergence and until 14 DAE. At $15 \mathrm{DAE}$, various temperatures and $\left[\mathrm{CO}_{2}\right]$ treatments were imposed.

Temperature and $\left[\mathrm{CO}_{2}\right]$. In Expt. 1, air in 10 growth chambers was maintained at 15/7, 20/12, 25/17, 30/22, and 35/27C (day/night). Carbon dioxide was maintained at 350 or $700 \mu \mathrm{l} \cdot \mathrm{liter}^{-1}$ at each temperature level. Day temperature was initiated $1 \mathrm{~h}$ after sunrise and night temperature was initiated $1 \mathrm{~h}$ after sunset. In Expt. 2, $\left[\mathrm{CO}_{2}\right]$ was maintained in five chambers at $350,450,600,750$, or $900 \mu 1 \cdot$ liter $^{-1}$. The day/night temperature of the chambers was maintained at 30/18C. Air temperature, $\left[\mathrm{CO}_{2}\right]$, and irrigation in the chambers were computer controlled and monitored. Graded shadecloths were hung around the chamber sides up to plant height to simulate the decreased light intensity normally caused by adjacent plants in field conditions. Baffles were installed in the chambers for air mixing, and continuous air circulation controlled the temperature uniformly throughout the chamber. The chambers were sealed, and $\left[\mathrm{CO}_{2}\right]$ of the air was monitored at 10 -sec intervals and averaged for each 900 -sec period. Carbon dioxide content of the air in each chamber was monitored with a dedicated conductimetric analyzer. The conductimetric analyzers were checked with an infrared gas analyzer for calibration every 15 min, after which a computer adjusted the calibration curves when necessary. To maintain $\left[\mathrm{CO}_{2}\right]$ in the chambers, pure $\mathrm{CO}_{2}$ was injected through a solenoid valve and a calibrated flowmeter. Each flowmeter was calibrated with a gas-displacement meter (Brooks; Emerson Electric Co., Hatfield, Pa.) at the beginning and end of each experiment. Carbon dioxide flow rates were recorded three times per day. Each night, the leakage rate of each chamber was determined using the procedure described by Acock and Acock (1989). Canopy interception of solar radiation was measured with a radiation sensor (model LI1915B; LI-COR, Lincoln, Neb.) 63 DAE for the various day/night temperatures and 83 to $102 \mathrm{DAE}$ for the $\left[\mathrm{CO}_{2}\right]$ noted. The amount of $\mathrm{CO}_{2}$ injected, air chamber volume, atmospheric pressure, chamber temperature, and chamber leakage rate were used to calculate plant photosynthesis during the day and respiratory rates during the night over each 15-min interval.

Model comparison. To compare a canopy photosynthesis model with a single-leaf photosynthesis model, data from a laboratory experiment by Stanghellini and Bunce (1993) have been analyzed. In this experiment, 'Rutgers Large Red' tomato $\mathrm{CO}_{2}$-exchange rates for single attached leaves were determined by gas-exchange techniques at three leaf temperatures as functions of short-term variation in $\left[\mathrm{CO}_{2}\right]$ and light. The experiments were conducted on fully expanded leaves of plants grown in vermiculite-filled pots, flushed daily with a nutrient solution, at $\left[\mathrm{CO}_{2}\right]$ of either 350 or $700 \mu l \cdot$ liter $^{-1}$. The conditions during growth were air temperature $25 \mathrm{C}$, relative humidity $70 \%$, photosynthetic photon density $500 \mu \mathrm{mol} \cdot \mathrm{m}^{-2} \cdot \mathrm{s}^{-1}$, and photoperiod $14 \mathrm{~h}$.

At the beginning of each measurement (27 to 31 days after sowing), a side leaflet (of either the fourth or the fifth leaf) was enclosed in a gasexchange chamber in which $\left[\mathrm{CO}_{2}\right]$, light, air temperature, and humidity could be manipulated continuously. Carbon dioxide exchange rates were measured at four $\left[\mathrm{CO}_{2}\right]$ of the incoming air-100, 350, 700, and $1000 \mu \mathrm{l} \cdot$ liter $^{-1}$. Light was supplied by incandescent lamps through a water filter at fluxes of 50,100, 150, 500, 800, 1100, 1400, 1700, and $2000 \mu \mathrm{mol} \cdot \mathrm{m}^{-2} \cdot \mathrm{s}^{-1}$. Measurements were taken at three temperatures $(18,25$, and 32C).

Data analysis. Gross canopy $\mathrm{CO}_{2}$ exchange rate of cotton vs. irradiance was fitted to Model [1]: 
where $P$ is gross canopy $\mathrm{CO}_{2}$ exchange rate $\left(\mathrm{mg} \cdot \mathrm{m}^{-2} \cdot \mathrm{s}^{-1}\right) ; I$ is the light flux density incident on the canopy $\left(\mathrm{W} \cdot \mathrm{m}^{-2}\right) ; C$ is $\left[\mathrm{CO}_{2}\right]$ in the air $\left(\mathrm{mg} \cdot \mathrm{m}^{-3}\right) ; \alpha_{c}$ is canopy light-use efficiency $\left(\mathrm{mg} \mathrm{CO}_{2} / \mathrm{W}\right) ; \tau_{c}$ is canopy conductance to $\mathrm{CO}_{2}$ transfer $\left(\mathrm{m} \cdot \mathrm{s}^{-1}\right)$; and $\beta$ is a matching term $\left(\mathrm{mg} \cdot \mathrm{m}^{-2} \cdot \mathrm{s}^{-1}\right)$. Gross canopy $\mathrm{CO}_{2}$ exchange rate was calculated by adding the dark respiration rate measured at the daytime temperature during the first hour of the night to all net photosynthesis rate values for the previous day. Since $P$ is gross canopy $\mathrm{CO}_{2}$-exchange rate, $\beta$ is not dark respiration; it can be considered as a term introduced to increase the accuracy of the model by adjusting for photorespiration.

Single-leaf, $\mathrm{CO}_{2}$-exchange rate of tomato vs. irradiance was fitted to a three-parameter model of the same kind as Model [1]:

Model [2]

and to Farquhar's model (Evans and Farquhar, 1991)

Model [3]
In Models [2] and [3], $P_{1}$ is photosynthesis ( $\mu \mathrm{mol} \mathrm{CO} / \mathrm{m}^{2}$ per sec), $R$ is respiration ( $\mu \mathrm{mol} \mathrm{CO} \mathrm{CO}_{2} / \mathrm{m}^{2}$ per sec), $I$ is light flux density at the leaf surface ( $\mu \mathrm{mol}$ photons $/ \mathrm{m}^{2}$ per sec), $C$ is $\left[\mathrm{CO}_{2}\right]$ in air $\left(\mu \mathrm{mol} \cdot \mathrm{m}^{-3}\right), \alpha$ is leaf light-use efficiency ( $\mu \mathrm{mol} \mathrm{CO} / / \mu \mathrm{mol}$ photons), $\tau$ is leaf conductance to $\mathrm{CO}_{2}$ transfer $\left(\mathrm{m} \cdot \mathrm{s}^{-1}\right)$, and $\theta$ is a dimensionless curvature factor $(0 \leq \theta \leq 1)$. Model 3 has four parameters: $\alpha, \tau, R$, and $\theta$.

Cotton canopy light response curves for every combination of $\left[\mathrm{CO}_{2}\right]$ and temperature were fitted with Model [1] and tomato leaf light response curves for all $\mathrm{CO}_{2}$ and temperature treatments were fitted with Models [2] and [3]. For all models, a modified Marquardt algorithm (Marquardt, 1963; Pachepsky et al., 1982) has been used for fitting. This method allows the calculation of the parameter values and their statistical characteristics, i.e., SDS, confidence intervals, residuals, correlation coefficients of residuals, and Student's criteria.

The values of $\alpha_{c}, \tau_{c}$, and $\beta$ and $\alpha, \tau, R$, and $\theta$ were calculated for every treatment, and the dependencies of these parameters on environmental factors were analyzed. The adequacy of the model was assessed by $\mathrm{F}$ test, analysis of residuals, and autocorrelation coefficient $(\kappa)$ test (Haflon, 1985; Himmelblau, 1968).

Model adequacy. All of the data, regardless of their scatter, were successfully fitted by Model [1]. Results for six combinations of $\left[\mathrm{CO}_{2}\right]$ and temperature show that the scatter in the photosynthesis data was significantly higher at the lower day/night temperatures-15/7C (Fig.
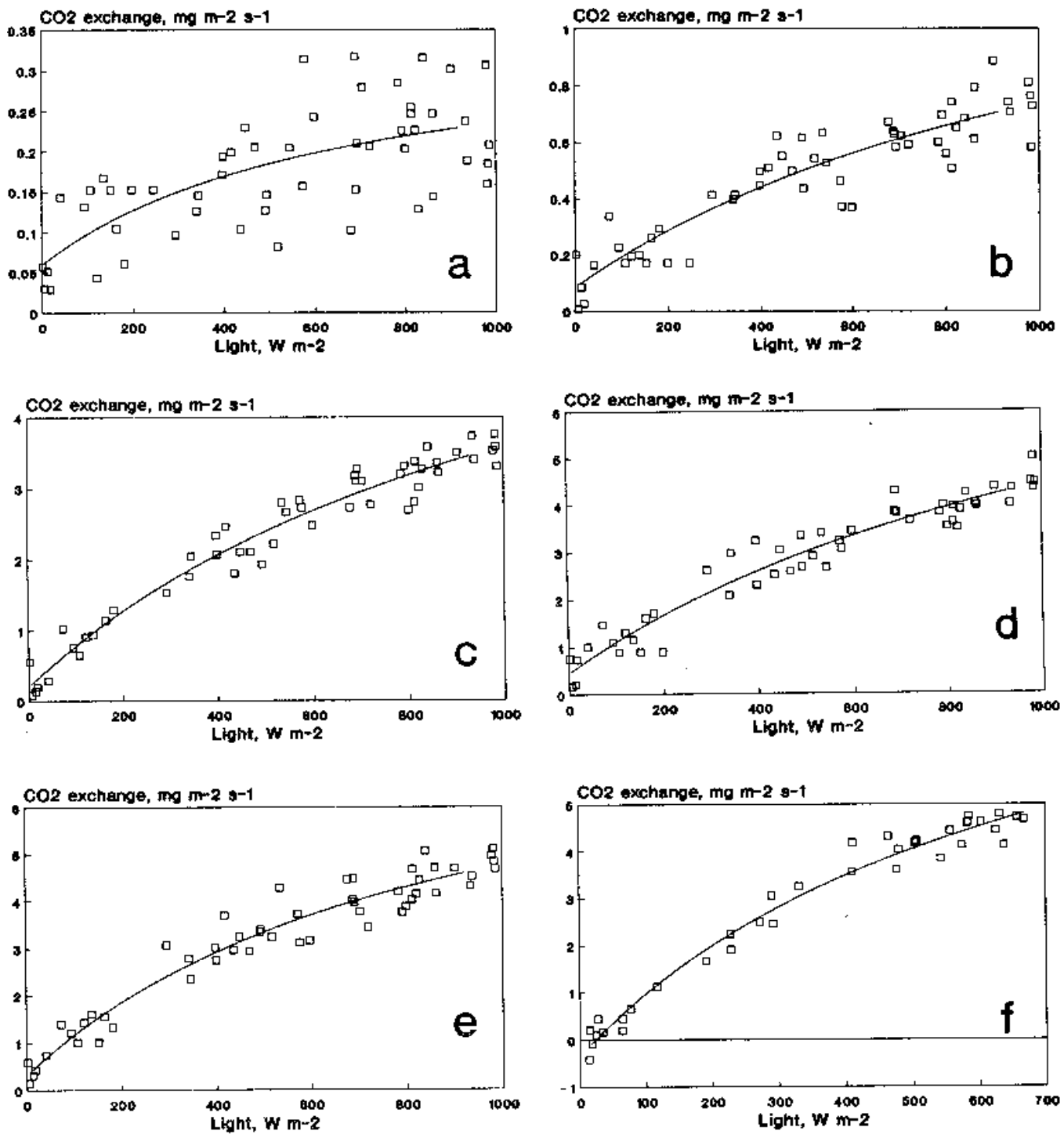

Fig. 1. Photosynthesis light response curves for a cotton canopy 63 days after emergence (DAE) at $\left[\mathrm{CO}_{2}\right]$ of $350 \mu 1 \cdot$ liter ${ }^{-1}$ and at various day/night temperatures ( ${ }^{\circ} \mathrm{C}$ ): (a) 15/7, (b) 20/12, (c) 25/17, (d) 30/22, (e) 35/27, and (f) $93 \mathrm{DAE}, 30 / 18 \mathrm{C}$, and $\left[\mathrm{CO}_{2}\right]$ at $900 \mu 1 \cdot \mathrm{liter}^{-1}$. Measured points and fitted curves are shown. 
1a) and 20/12C (Fig. 1b). The substantial scatter was caused by the smaller signal : noise ratio than at higher temperatures. Parameters for all 15 photosynthetic light response curves are shown in Table 1.

Model 1 was adequate quantitatively according to the $F$ test for all combinations of environmental factors (Table 2). The model's qualitative adequacy was tested by the analysis of residuals, which were randomly distributed with respect to light (Fig. 2). Values of $\kappa$ were less than $\kappa_{c r}$ in 13 cases, and only in two cases (Table 2) were the $\kappa$ values higher than the critical values of 0.339 and 0.288 , respectively, at $P \leq 0.05$ (Gomez and Gomez, 1983).

The three-parameter hyperbolic Model [1] for modeling $\mathrm{CO}_{2}$ exchange in a cotton canopy is therefore adequate for describing data obtained in daylit controlled-environment chambers. Including additional parameters in the model cannot improve model quality because of the scatter in the data.

For the data on tomato leaf $\mathrm{CO}_{2}$ exchange obtained in a leaf chamber with much lower scatter, the more complicated four-parameter Farquhar's Model [3] was better than the three-parameter Model [2]. The hyperbolic Model [2] was not adequate qualitatively for all treatments of the tomato leaf experiment.

Light response curves. The cotton canopy $\mathrm{CO}_{2}$-exchange rate at light saturation, $P_{s}\left(P_{s}=\tau_{c} C\right)$, varied from $0.293 \mathrm{mg} \cdot \mathrm{m}^{-2} \cdot \mathrm{s}^{-1}$ at $15 / 7 \mathrm{C}$ and $\left[\mathrm{CO}_{2}\right]$ at $350 \mu \mathrm{l} \cdot \mathrm{liter}^{-1}$ to $12.810 \mathrm{mg} \cdot \mathrm{m}^{-2} \cdot \mathrm{s}^{-1}$ at $35 / 27 \mathrm{C}$ and $\left[\mathrm{CO}_{2}\right]$ at $700 \mu \mathrm{l} \cdot \mathrm{liter}^{-1}$ (Table 1 ). Light saturation was actually reached in only 4 of the 15 treatments, at $15 / 7$ and $20 / 12 \mathrm{C}$ for $\left[\mathrm{CO}_{2}\right]$ at 350 and $700 \mu \mathrm{l} \cdot$ liter $^{-1}$.

Figure 3 shows light response curves $30 / 18 \mathrm{C}$ and five $\left[\mathrm{CO}_{2}\right]$ values. The higher $\left[\mathrm{CO}_{2}\right]$ gave higher $\mathrm{CO}_{2}$-exchange rates when irradiance exceeded $200 \mathrm{~W} \cdot \mathrm{m}^{-2}$. Light-saturated photosynthesis was not reached for these treatments, but the light response curves show that the maximal $\mathrm{CO}_{2}$-exchange rate depends on $\left[\mathrm{CO}_{2}\right]$. The nonlinear dependence of $\mathrm{CO}_{2}$-exchange rate on temperature (Figs. 4 and 5) is evident at 350 and $700 \mu l \cdot l i t e r^{-1}$. At both $\left[\mathrm{CO}_{2}\right]$, the saturated $\mathrm{CO}_{2}$-exchange rate was higher at higher temperatures. Analogous results have been published for soybeans [Glycine $\max$ (L.) Merr.] (Acock et al., 1985).

The dependencies we observed for cotton are not necessarily valid for other species. Studies for a single leaf show that various species react to elevated $\mathrm{CO}_{2}$ in different ways. Sage et al. (1989) studied the effect of $\mathrm{CO}_{2}$ enrichment on gas-exchange characteristics and found that there were different reaction patterns to elevated $\left[\mathrm{CO}_{2}\right]$. For some species (Solanum tuberosum L.), the initial slope of the $\mathrm{CO}_{2}$ response curve was unaffected, but the photosynthetic rate increased with increasing $\left[\mathrm{CO}_{2}\right]$, as observed in this cotton study. For other species (Chenopodium album L., Phaseolus vulgaris L.), with increasing $\left[\mathrm{CO}_{2}\right]$, the initial slope decreased and the $\mathrm{CO}_{2}$-saturated photosynthesis rate was affected very little. For Brassica oleracea $\mathrm{L}$. and $S$. melongena $\mathrm{L}$., the initial slopes and the $\mathrm{CO}_{2}$-saturated rate decreased with increasing $\left[\mathrm{CO}_{2}\right]$. We can compare the parameters $\alpha$ and $\tau$ for these species, considering $\mathrm{CO}_{2}$ and light response curves as hyperbolic functions. Analyzing these parameters calculated from the data in Sage et al. (1989) reveals that these parameters vary in different ways, depending on species. Light-use efficiency, $\alpha$, grew after acclimation for $S$. tuberosum and C. album; $\alpha$ was not affected by higher $\left[\mathrm{CO}_{2}\right]$ for $P$. vulgaris and it was significantly lower for acclimated $B$. oleracea plants. Conductance, $\tau$, did not change during acclimation for $S$. tuberosum, but it was lower for high $\left[\mathrm{CO}_{2}\right]$-acclimated C. album, $P$. vulgaris, and B. oleracea plants.

Sage et al. (1989) emphasized that no two species exhibited identical quantitative responses to $\mathrm{CO}_{2}$ enrichment and that no species exhibited an idealized acclimation response at the biochemical level. At the same time, the acclimation to high $\mathrm{CO}_{2}$ develops first at the biochemical level and appears to be complicated and controversial. Various explanations are possible for the effect of long-term high $\left[\mathrm{CO}_{2}\right]$ on photosynthesis. The different character of S. tuberosum reactions on one hand and of the other considered species on the other hand can be explained at the level of source-sink relationships. A

Table 1. Parameter values of Model [1] for cotton for various combinations of environmental conditions.

\begin{tabular}{|c|c|c|c|c|c|c|}
\hline Treatment & $\begin{array}{c}{\left[\mathrm{CO}_{2}\right]} \\
\left(\mu 1 \cdot \cdot \text { liter }^{-1}\right)\end{array}$ & $\begin{array}{c}\text { Temp }\left({ }^{\circ} \mathrm{C}\right) \\
\text { day/night }\end{array}$ & $\begin{array}{c}\alpha_{c} \\
\left(\mathrm{mg} \cdot \mathrm{W}^{-1}\right)\end{array}$ & $\begin{array}{c}\tau_{c} C \\
\left(\mathrm{mg} \cdot \mathrm{m}^{-2} \cdot \mathrm{s}^{-1}\right)\end{array}$ & $\begin{array}{c}\tau_{c} 10^{3} \\
\left(\mathrm{~m} \cdot \mathrm{s}^{-1}\right)\end{array}$ & $\begin{array}{c}\beta \\
\left(\mathrm{mg} \cdot \mathrm{m}^{-2} \cdot \mathrm{s}^{-1}\right)\end{array}$ \\
\hline 1 & 350 & $30 / 18$ & 0.00915 & 8.156 & 10.022 & 0.290 \\
\hline 2 & 450 & $30 / 18$ & 0.01057 & 9.179 & 15.776 & 0.308 \\
\hline 3 & 600 & $30 / 18$ & 0.01110 & 12.260 & 15.803 & -0.038 \\
\hline 4 & 750 & $30 / 18$ & 0.01290 & 10.120 & 10.436 & -0.224 \\
\hline 5 & 900 & $30 / 18$ & 0.01485 & 10.670 & 9.169 & -0.334 \\
\hline 6 & 350 & $15 / 7$ & 0.00044 & 0.293 & 0.647 & 0.060 \\
\hline 7 & 350 & $20 / 12$ & 0.00115 & 1.498 & 3.310 & 0.088 \\
\hline 8 & 350 & $25 / 17$ & 0.00615 & 7.501 & 16.575 & 0.214 \\
\hline 9 & 350 & $30 / 22$ & 0.00694 & 9.414 & 20.802 & 0.452 \\
\hline 10 & 350 & $35 / 27$ & 0.00944 & 8.404 & 18.570 & 0.318 \\
\hline 11 & 700 & $15 / 7$ & 0.00267 & 0.465 & 0.514 & -0.153 \\
\hline 12 & 700 & $20 / 12$ & 0.00329 & 0.785 & 0.868 & 0.053 \\
\hline 13 & 700 & $25 / 17$ & 0.00754 & 9.037 & 9.985 & 0.166 \\
\hline 14 & 700 & $30 / 22$ & 0.01180 & 10.630 & 11.745 & 0.342 \\
\hline 15 & 700 & $35 / 27$ & 0.01183 & 12.810 & 14.153 & 0.205 \\
\hline
\end{tabular}

Table 2. Results of Model [1] for cotton validation by $\mathrm{F}$ test $\left(\mathrm{F}<\mathrm{F}_{k-p, N-k}\right)$ and autocorrelation coefficient test $\left(\kappa<\kappa_{c r}\right)$.

\begin{tabular}{|c|c|c|c|c|c|c|}
\hline Treatment & $\begin{array}{c}{\left[\mathrm{CO}_{2}\right]} \\
\left(\mu 1 \cdot \text { liter-1 }^{-1}\right) \\
\end{array}$ & $\begin{array}{c}\text { Temp }\left({ }^{\circ} \mathrm{C}\right) \\
\text { day/night }\end{array}$ & $\mathrm{F}_{k-p, N-k}$ & $\mathrm{~F}$ & $\kappa_{c r}$ & $|\kappa|$ \\
\hline 1 & 350 & $30 / 18$ & 2.98 & 1.79 & 0.339 & 0.368 \\
\hline 2 & 450 & $30 / 18$ & 2.84 & 1.18 & 0.329 & 0.021 \\
\hline 3 & 600 & $30 / 18$ & 2.93 & 0.59 & 0.329 & 0.259 \\
\hline 4 & 750 & $30 / 18$ & 2.17 & 0.64 & 0.339 & 0.188 \\
\hline 5 & 900 & $30 / 18$ & 3.07 & 1.15 & 0.329 & 0.079 \\
\hline 6 & 350 & $15 / 7$ & 2.47 & 2.33 & 0.273 & 0.268 \\
\hline 7 & 350 & $20 / 12$ & 2.47 & 0.84 & 0.260 & 0.211 \\
\hline 8 & 350 & $25 / 17$ & 2.47 & 0.96 & 0.273 & 0.114 \\
\hline 9 & 350 & $30 / 22$ & 2.63 & 1.12 & 0.273 & 0.079 \\
\hline 10 & 350 & $35 / 27$ & 2.63 & 1.17 & 0.273 & 0.007 \\
\hline 11 & 700 & $15 / 7$ & 2.54 & 1.98 & 0.288 & 0.387 \\
\hline 12 & 700 & $20 / 12$ & 2.63 & 1.38 & 0.273 & 0.097 \\
\hline 13 & 700 & $25 / 17$ & 2.63 & 1.17 & 0.273 & 0.256 \\
\hline 14 & 700 & $30 / 22$ & 2.63 & 1.58 & 0.273 & 0.073 \\
\hline 15 & 700 & $35 / 27$ & 2.54 & 1.12 & 0.273 & 0.148 \\
\hline
\end{tabular}


Residuals, mg m-2 s-1

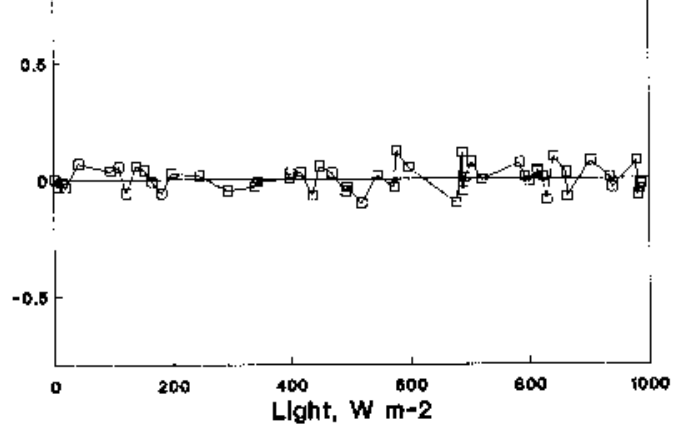

Regiduals, ma m-2 g-1

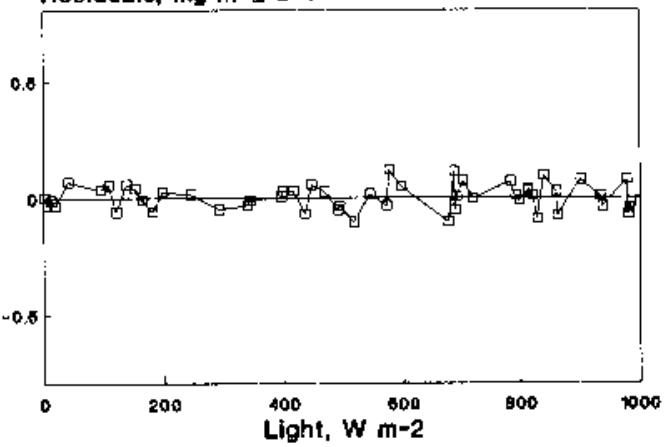

$25 / 17$ G, $350 \mathrm{~mL} L-1[\mathrm{CO} 2]$

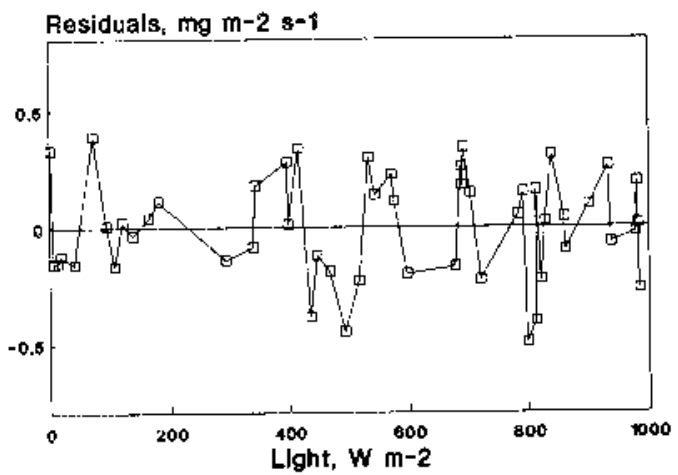

$30 / 22 \mathrm{C}, 360 \mathrm{mLL} /-1$ [CO2]

Residuals, $\mathrm{mg} \mathrm{m-2} \mathrm{s}-1$

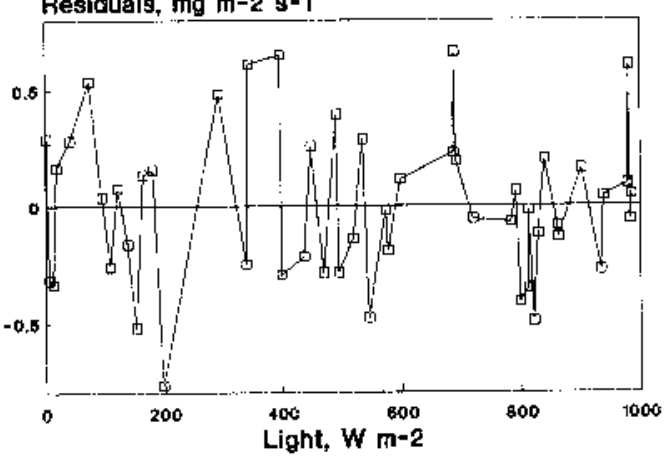

35/27 C. 350 mLL L-1 [CO2]

Residuals, $m g m-2 \mathrm{~g}-1$

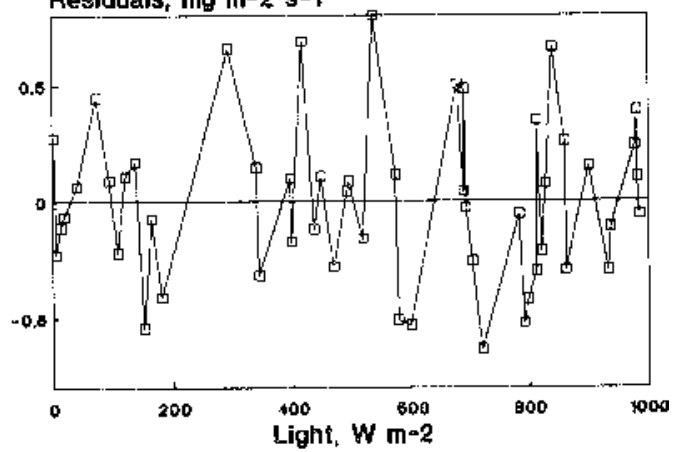

Fig. 2. Residuals for Model [1] at $\left[\mathrm{CO}_{2}\right]$ of $350 \mu l \cdot l i t e r^{-1}$.

higher demand for carbohydrates from an S. tuberosum tuber can facilitate acclimation by unloading extra starch from the chloroplast. The other species do not have such a sink for carbohydrates, and their acclimation can develop over a longer period than the duration of the experiment. Cotton plants in the current study positively affected by high $\mathrm{CO}_{2}$ have several assimilate sinks that can also positively affect cotton acclimation to elevated $\mathrm{CO}_{2}$.

Model 1 parameters. Cotton canopy light-use efficiency, $\alpha_{c}$, the initial slope of the canopy light response curve, varied from 0.00044 to $0.01485 \mathrm{mg} \cdot \mathrm{W}^{-1}$ (Table 1 ). The $\alpha_{c}$ at a given $\left[\mathrm{CO}_{2}\right]$ depended significantly on temperature (Fig. 6a). Linear regression of $\alpha_{c}$ on temperature provided the best fit with a correlation coefficient of 0.625. A similar relationship has been reported by Reddy et al. (1991). There were no statistically significant differences between $\alpha_{c}$ values for different $\left[\mathrm{CO}_{2}\right]$ at a constant temperature (Table 1), although $\alpha_{c}$ values were usually higher for higher $\left[\mathrm{CO}_{2}\right]$ at the same temperature.

Parameter $\beta$ did not depend on $\left[\mathrm{CO}_{2}\right]$, but the linear regression on temperature had a correlation coefficient of 0.714 (Fig. 6b). The canopy conductance to $\mathrm{CO}_{2}$ transfer, $\tau_{c}$, was strongly affected by temperature and $\left[\mathrm{CO}_{2}\right]$ (Table 1). The dependence on temperature was nonlinear (Fig. 7a), and the best fit to the data was obtained with Model [4] (Fig. 8a):

Model [4]

The same model was tested for tomato leaf conductance to $\mathrm{CO}_{2}$ transfer (Fig. 8b). This model gave a better fit to the tomato leaf data because the data were much less scattered than for the cotton canopy. The dependence of leaf and canopy conductance to $\mathrm{CO}_{2}$ transfer on $\left[\mathrm{CO}_{2}\right]$ and temperature has been shown in other studies (Boote and Loomis, 1991; Jarvis and Morison, 1981; Mansfield et al., 1981).

Ball et al. (1987) used much existing data on leaf conductance and developed an empirical model. They observed linear relationships between stomatal conductance and assimilation rate, relative humidity, and $\left[\mathrm{CO}_{2}\right]$. According to Ball's model, conductance declines with increasing $\left[\mathrm{CO}_{2}\right]$. Values of single-leaf stomatal conductance for 


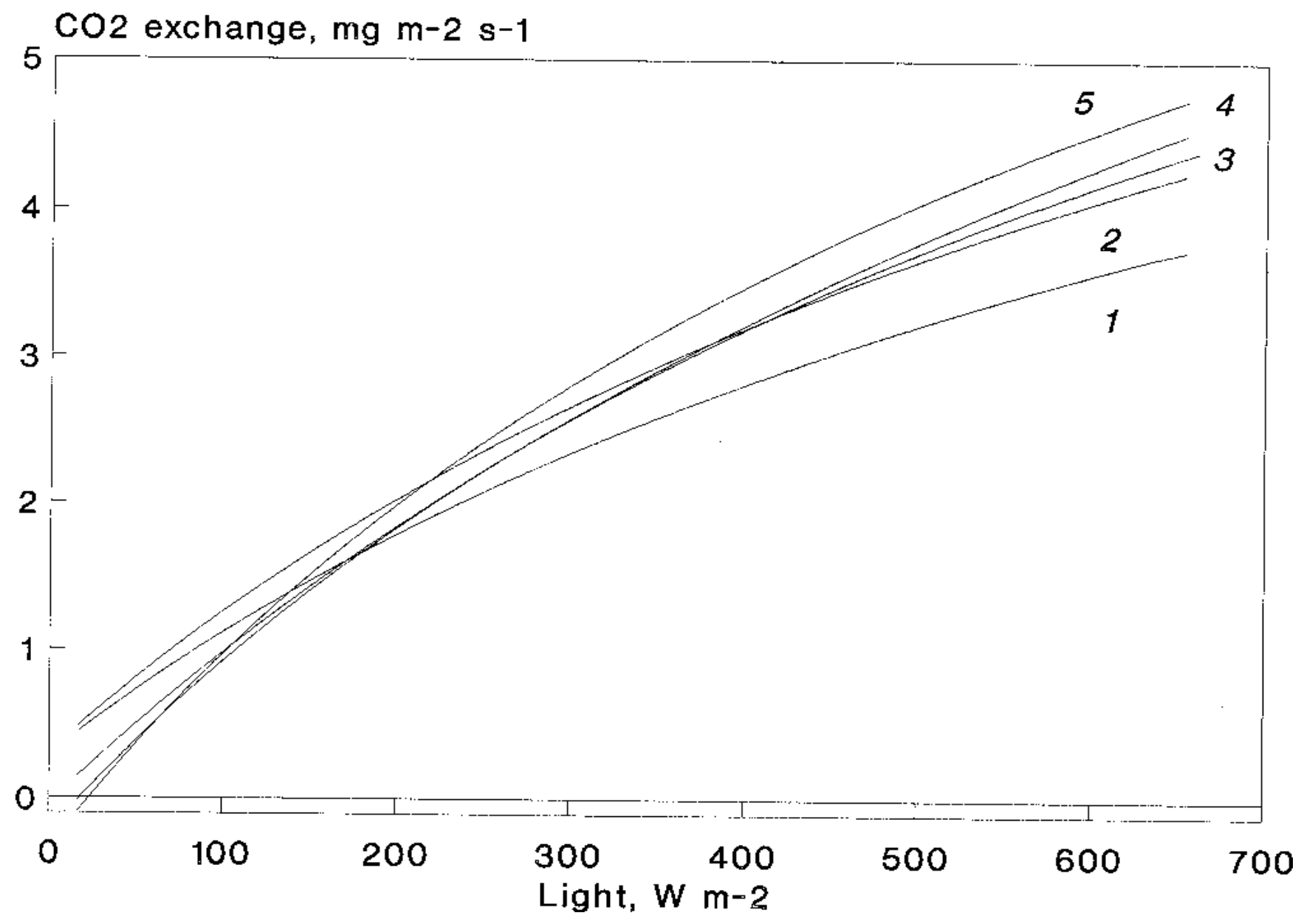

Fig. 3. Fitted photosynthesis light response curves for a cotton canopy 93 days after emergence, 30/18C, and various $\left[\mathrm{CO}_{2}\right]\left(\mu 1 \cdot 1\right.$ iter $\left.\left.\left.\left.{ }^{-1}\right): 1\right) 350,2\right) 450,3\right) 600$, 4) 750,5$) 900$.

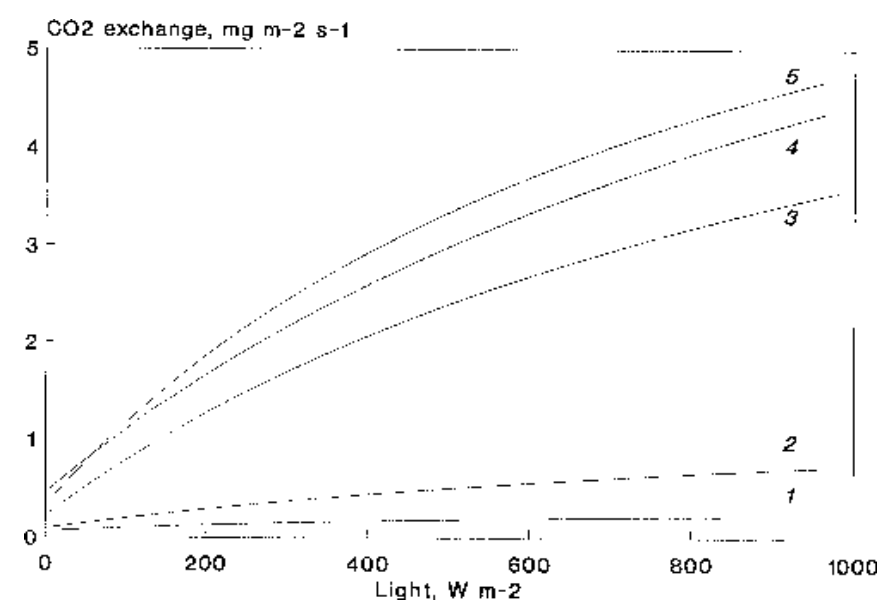

Fig. 4. Fitted photosynthesis light response curves for a cotton canopy 63 days after emergence at $\left[\mathrm{CO}_{2}\right] 350 \mu \mathrm{l} \cdot$ liter ${ }^{-1}$, and various day/night temperatures $\left({ }^{\circ} \mathrm{C}\right):$ 1) $15 / 7,2$ ) 20/12, 3) $25 / 17$, 4) 30/22, 5) 35/27.

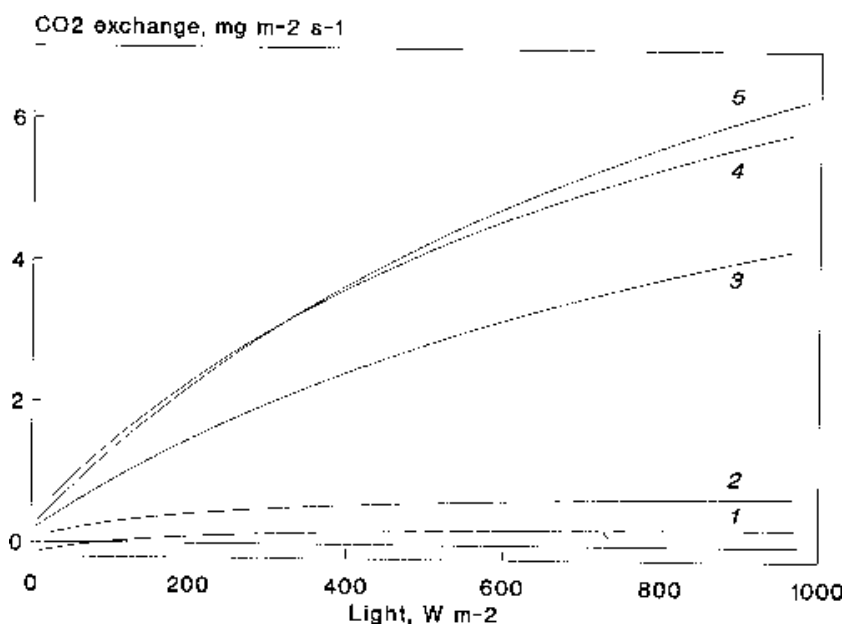

Fig. 5. Fitted photosynthesis light response curves for a cotton canopy 63 days after emergence at $\left[\mathrm{CO}_{2}\right] 700 \mu 1 \cdot 1$ iter ${ }^{-1}$, and various day/night temperatures $\left({ }^{\circ} \mathrm{C}\right):$ 1) $15 / 7,2$ ) 20/12, 3) $25 / 17$, 4) 30/22, 5) 35/27. 

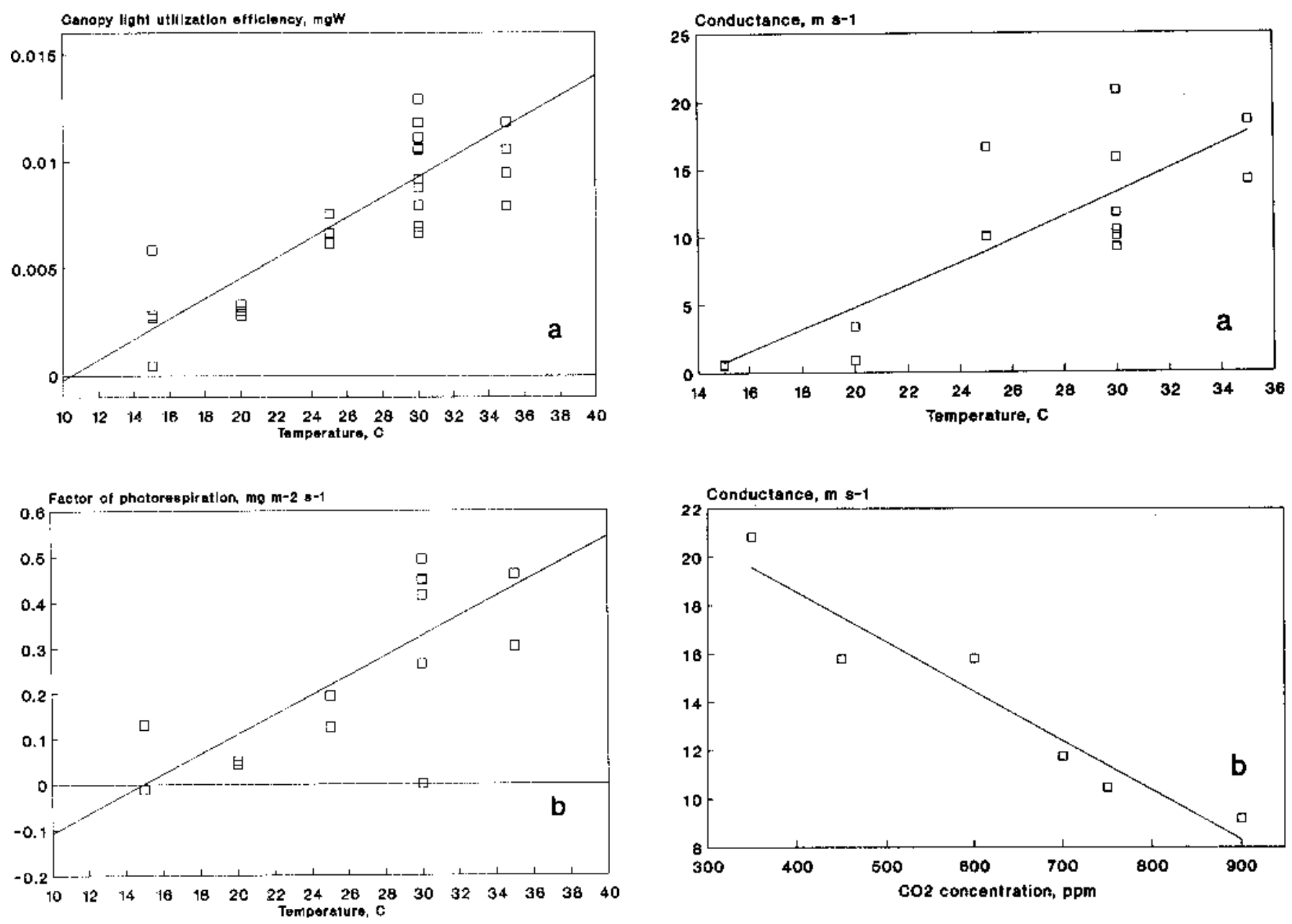

Fig. 6. Dependencies of (a) cotton canopy light-use efficiency $(\alpha=0.479 \cdot T E M P$ $5.11) \cdot 10^{-3}, r=0.625$, and $(\mathbf{b})$ matching factor $(\beta=0.022 \cdot T E M P-0.325, r=$ 0.714 ) on temperature.

Fig. 7. Dependencies of cotton canopy conductance on (a) temperature $(\tau=$ $95.48 \cdot \exp (0.0074 \cdot \boldsymbol{T E M P})-10.59, r=0.82$, and $(\mathbf{b}) \mathrm{CO}_{2}$ concentration $(\tau=-0.0205 \cdot C+26.75, r=0.95)$.
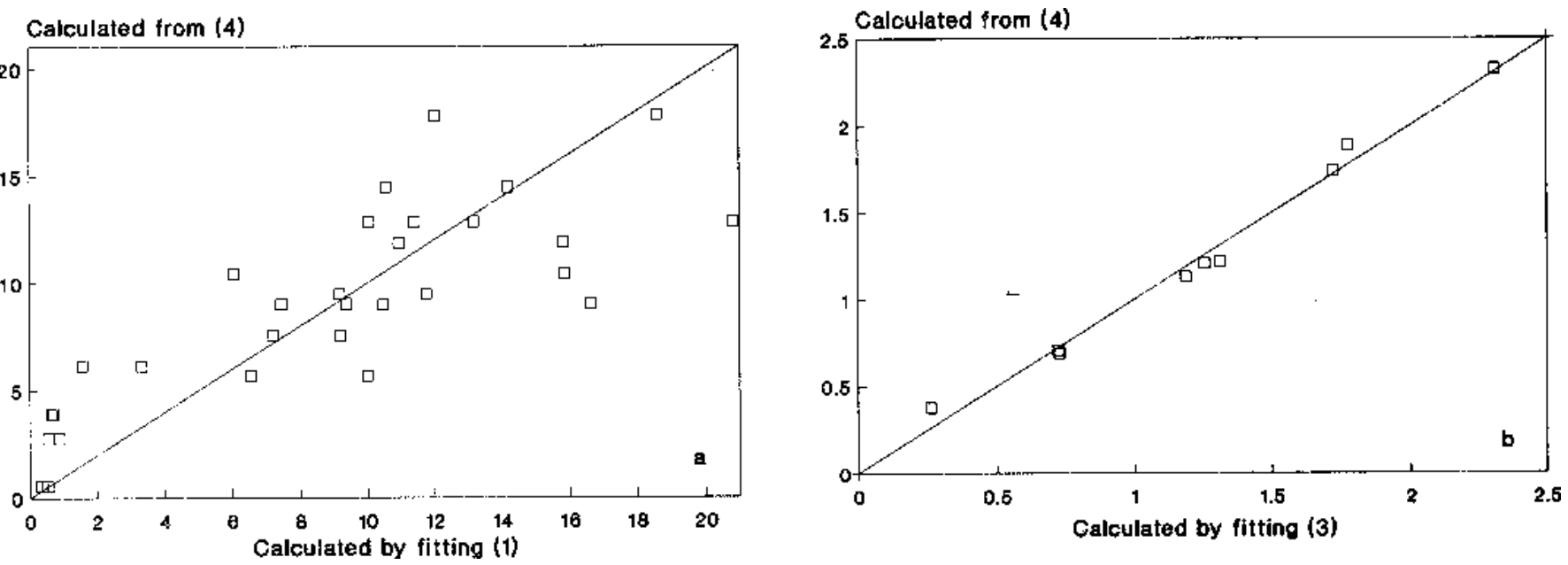

Fig. 8. Conductance for $\mathrm{CO}_{2}$ transfer obtained (a) for a cotton canopy by fitting Model [1] compared with predictions by Model [4], correlation coefficient $r=0.817$, and (b) for tomato leaf by fitting Model [3] compared with predictions by Model [2], $r=0.993$. Parameter values for Model [4]:

$\begin{array}{lll} & \text { Cotton } & \text { Tomato } \\ b_{1} & 3.228 & 0.23 \\ b_{2} & 0.0537 & 0.07 \\ b_{3} & 0.01 & 0.005\end{array}$


Eucalyptus grandis $\mathrm{Sw}$. calculated with this model combined with Farquhar's model of photosynthesis (Farquhar and von Caemmerer, 1982) were 0 to $0.01716 \mathrm{~m} \cdot \mathrm{s}^{-1}$ (Leuning, 1990). Values of canopy conductance from the experimental data for cotton in our study were within the same range. Conductance decreased linearly with increasing $\left[\mathrm{CO}_{2}\right]$ and increased exponentially with increasing temperature.

\section{THE COMPLETE MODEL}

The complete model for describing the dependence of cotton canopy $\mathrm{CO}_{2}$ exchange on light, $\left[\mathrm{CO}_{2}\right]$, and temperature contains seven parameters: $a_{1}, a_{2}, b_{1}, b_{2}, b_{3}, d_{1}$, and $d_{2}$ :

Parameter $a_{1}$ is the rate of increase of the canopy light-use efficiency with temperature, and $b_{2}$ shows the rate of increase of canopy conductance for $\mathrm{CO}_{2}$ transfer with temperature. Parameter $b_{1}$ defines the maximal $\tau_{c}$ value. Parameter $b_{3}$ indicates the rate of decrease of $\tau_{c}$ with increasing $\left[\mathrm{CO}_{2}\right]$. Parameter $d_{1}$ indicates the increase of photorespiration rate with increasing $\left[\mathrm{CO}_{2}\right]$. Parameters $a_{2}$ and $d_{2}$ are intercepts for corresponding relationships. This model can be used for closed cotton canopies because the experimental data on which the model is based were obtained for closed canopies 60 to 120 DAE. For other species and treatments, parameter values can be determined with the same technique as described above.

\section{CONCLUSIONS}

The empirical model for canopy $\mathrm{CO}_{2}$ exchange has been developed from experimental data on cotton in daylit chambers with controlled air temperature and $\left[\mathrm{CO}_{2}\right]$. The model contains seven parameters whose values can be determined with experimental data using the technique described above. The validation of the canopy $\mathrm{CO}_{2}$-exchange model can be effectively performed using the $\mathrm{F}$ test, analysis of residuals, and autocorrelation coefficient.

Every canopy light response curve for a particular combination of temperature and $\left[\mathrm{CO}_{2}\right]$ can be described adequately by a threeparameter hyperbolic model. The leaf light response curves need a four-parameter model for adequate description.

Canopy light-use efficiency, $\alpha_{c}$, and a photorespiration factor, $\beta$, increased linearly with increasing temperature. The dependence of these parameters on $\left[\mathrm{CO}_{2}\right]$ was not significant. Canopy and leaf conductance to $\mathrm{CO}_{2}$ transfer, $\tau_{c}$, strongly depended on temperature (exponentially) and $\left[\mathrm{CO}_{2}\right]$ (linearly).

Cotton canopy $\mathrm{CO}_{2}$-exchange rate increased with increasing $\left[\mathrm{CO}_{2}\right]$ at irradiance values higher than $200 \mathrm{~W} \cdot \mathrm{m}^{-2}$. The $\mathrm{CO}_{2}$ exchange rate showed a nonlinear increase with increasing temperature.

\section{Literature Cited}

Acock, B. 1991. Modeling canopy photosynthetic response to carbon dioxide, light interception, temperature, and leaf traits, p. 41-56. In: K.J. Boote and R.S. Loomis (eds.). Modeling crop photosynthesis-From biochemistry to canopy. Crop Sci. Soc. Amer. Spec. Publ. 19. Crop Sci. Soc. Amer., Amer. Soc. Agron, Madison, Wis.

Acock, B. and M.C. Acock. 1989. Calculating air leakage rates in controlledenvironment chambers containing plants. Agron. J. 81:619-623.
Acock, B., D.A. Charles-Edwards, D.J. Fitter, D.W. Hand, L.J. Ludwig, J. Warren Wilson, and A.C. Withers. 1978. The contribution of leaves from different levels within a tomato crop to canopy net photosynthesis: An experimental examination of two canopy models. J. Expt. Bot. 29:815-827.

Acock, B., V.R. Reddy, H.F. Hodges, D.N. Baker, and J.M. McKinion. 1985. Photosynthetic response of soybean canopies to full-season carbon dioxide enrichment. Agron. J. 77:942-947.

Ball, J.T., I.E. Woodrow, and J.A. Berry. 1987. A model predicting stomatal conductance and its contribution to the control of photosynthesis under different environmental conditions, p. 221-224. In: J. Biggins (ed.). Progress in photosynthesis research. vol. 4. Martinus Nijhoff, Dordrecht, The Netherlands.

Boote, K.J. and R.S. Loomis. 1991. The prediction of canopy assimilation, p. 109-140. In: K.J. Boote and R.S. Loomis (eds.). Modeling crop photosynthesis-From biochemistry to canopy. Crop Sci. Soc. Amer. Spec. Publ. 19. Crop Sci. Soc. Amer., Amer. Soc. Agron., Madison, Wis.

Denison, R.F. and R.S. Loomis. 1989. An integrative physiological model of alfalfa growth and development. Bul. Div. Agr. Natural Resources, Univ. of California, Oakland.

Evans, J.R. and G.D. Farquhar. 1991. Modeling canopy photosynthesis from the biochemistry of the $\mathrm{C}_{3}$ chloroplast, p. 1-16. In: K.J. Boote and R.S. Loomis (eds.). Modeling crop photosynthesis-From biochemistry to canopy. Crop Sci. Soc. Amer. Spec. Publ. 19. Crop Sci. Soc. Amer., Amer. Soc. Agron., Madison, Wis.

Farquhar, G.D. and S. von Caemmerer. 1982. Modelling of photosynthetic response to environmental conditions, p. 550-588. In: O.L. Lanhe, P.S. Nobel, C.B. Osmond, and H. Ziegler (eds.). Physiological plant ecology II. Encyclopedia of plant physiology new series. vol. 12B. Springer-Verlag, Berlin.

Gomez, K.A. and A.A. Gomez. 1983. Statistical procedures for agricultural research. 2nd ed. Wiley, New York.

Halfon, E. 1985. Is there a best model structure? III. Testing the goodness of fit. Ecol. Modelling 27:15-23.

Himmelblau, D.M. 1968. Process analysis by statistical methods. Wiley, New York.

Jarvis, P.G. and J.I.L. Morison. 1981. The control of transpiration and photosynthesis by the stomata, p. 247-279. In: P.G. Jarvis and T.A. Mansfield (eds.). Stomatal physiology. Cambridge Univ. Press, Cambridge, U.K.

Laisk, A. 1977. Kinetics of photosynthesis and photorespiration in $\mathrm{C}_{3}$ plants. Nauka, Moscow.

Leuning, R. 1990. Modelling stomatal behaviour and photosynthesis of Eucalyptus grandis. Austral. J. Plant Physiol. 17:159-175.

Mansfield, T.A., A.J. Travis, and R.G. Jarvis. 1981. Responses to light and carbon dioxide, p. 119-135. In: P.G. Jarvis and T.A. Mansfield (eds.). Stomatal physiology. Cambridge Univ. Press, Cambridge, U.K.

Marquardt, D.W. 1963. An algorithm for last-squares estimation on nonlinear parameters. Soc. Industrial Applied Mathematics J. 11:431-441.

Pachepsky, Ya.A., E.V. Mironrnko, R.V. Galiulin, and M.S. Sokolov. 1982. Statistical models of the dynamics of pesticides and their metabolites content in soils. Ecological Software 8. Acad. Sci. USSR, Pushchino.

Reddy, V.R., D.N. Baker, and H.F. Hodges. 1991. Temperature effects on cotton canopy growth, photosynthesis, and respiration. Agron. J. 83:699704.

Sage, R.F., T.D. Sharkey, and J.R. Seeman. 1989. Acclimation of photosynthesis to elevated $\mathrm{CO}_{2}$ in five $\mathrm{C}_{3}$ species. Plant Physiol. 89:590-596.

Sinclair, T.R. 1991. Canopy carbon assimilation and crop radiation-use efficiency dependence on leaf nitrogen content, p. 95-107. In: K.J. Boote and R.S. Loomis (eds.). Modeling crop photosynthesis-From biochemistry to canopy. Crop Sci. Soc. Amer. Spec. Publ. 19. Crop Sci. Soc. Amer., Amer. Soc. Agron., Madison, Wis.

Stanghellini, C. and J.A. Bunce. 1993. Response of photosynthesis and conductance to light, $\mathrm{CO}_{2}$, temperature, and humidity in tomato plants acclimated to ambient and elevated $\mathrm{CO}_{2}$. Photosynthetica 29:487-497.

Wetherald, R.T. 1989. Changes of temperature and hydrology caused by an increase of atmospheric carbon dioxide as predicted by general circulation models, p. 1-19. In: R.L. Wyman (ed.). Global climate change and life on earth. Routledge, Chapman and Hall, New York.

Wheeler, R.M., K.A. Corey, J.C. Sager, and W.M. Knott. 1993. Gas exchange characteristics of wheat stands in a closed, controlled environment. Crop Sci. 33:161-168. 


\title{
Modeling Photosynthesis of Row Crop Canopies
}

\author{
K.J. Boote ${ }^{1}$ and N.B. Pickering ${ }^{2}$ \\ Agronomy Department, University of Florida, Gainesville, FL 32611
}

Most field and horticultural crops are grown in rows rather than in horizontally uniform stands. Thus, it is important to be able to predict light interception and photosynthesis of incomplete hedgerow crops. With improved knowledge of the biochemistry of single-leaf photosynthesis, particularly in response to temperature and $\mathrm{CO}_{2}$ concentration, it is now possible to model canopy assimilation based on singleleaf characteristics.

The complexity of plant responses to climatic and management factors makes a mechanistic modeling approach attractive for predicting such responses reliably (Reynolds and Acock, 1985). Important plant processes include leaf photochemistry, leaf and canopy gas exchange, growth, and assimilate partitioning. Most efforts to model canopy photosynthesis mechanistically have applied only to closed horizontally uniform crop stands (Denison and Loomis, 1989; de Wit, 1965; Duncan et al., 1967; Norman and Arkebauer, 1991). Horticultural production could benefit from models that predict optimum spacing for fruit and nut tree crops, yield response to various hedgerow arrangements for trellised vineyards or staked tomatoes (Lycopersicon esculentum Mill.), and effects of various spacings on productivity of field and greenhouse commodities.

In this paper we describe a light interception-canopy photosynthesis approach that calculates absorption of direct and diffuse irradiance by incomplete hedgerow canopies as a function of canopy height, canopy width, leaf area index (LAI), leaf angle, row direction, latitude, day of year, and time of day. A sunlit and shaded LAI approach was used to simulate absorption of photosynthetic photon flux density (PFD) by sunlit and shaded leaves. Canopy assimilation is the sum of sunlit and shaded leaf photosynthesis over their respective LAI classes. Photosynthesis of sunlit and shaded leaves was computed with the asymptotic exponential equation, where quantum efficiency $\left(Q_{E}\right)$ and light-saturated photosynthesis rate $\left(\mathrm{P}_{\max }\right)$ were functions of intercellular $\mathrm{CO}_{2}\left(\mathrm{C}_{\mathrm{i}}\right), \mathrm{O}_{2}$, and temperature. The Farquhar and von Caemmerer equations for the ribulose 1,5 bisphosphate (RuBP)-regeneration limited region were used to compute the efficiency of electron conversion to $\mathrm{CO}_{2}$ fixation. The modeling approach is modular in that various mechanistic leaf photosynthesis equations can be substituted, with each receiving inputs of absorbed $\mathrm{PFD}$, temperature, and $\mathrm{CO}_{2}$ for each class of leaves.

\section{Light absorbance, reflectance, and transmittance processes}

Photosynthetically active irradiance arrives at leaf surfaces in crop canopies by several pathways: 1) direct beam, 2) diffuse skylight (scattered by atmosphere and clouds), 3) diffuse scattered from other foliage (e.g., reflected from and transmitted through foliage), and 4) diffuse scattered from the soil surface.

Green leaves have a high absorptance for photosynthetically active radiation. The leaf scattering coefficient for direct-beam irradiance $(\sigma$ $=$ fraction transmitted plus reflected) is $\approx 0.20$ (Goudriaan, 1977), with $\approx 10 \%$ of incident PFD reflected, $\approx 10 \%$ transmitted, and $\approx 80 \%$ absorbed. The scattering coefficient varies somewhat with leaf thickness, leaf chlorophyll content, and angle of incidence of the direct

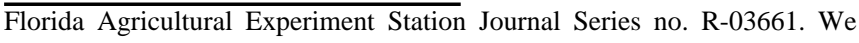
express appreciation to H. Gijzen and J. Goudriaan for their excellent suggestions for adapting the sunlit leaf area index approach for hedgerow canopies. We thank J. Norman for his advice on the model and E.B. Blazey and G. Bourgeois for their assistance with photosynthesis measurements. The cost of publishing this paper was defrayed in part by the payment of page charges. Under postal regulations, this paper therefore must be hereby marked advertisement solely to indicate this fact.

${ }^{1}$ Professor of Agronomy. To whom reprint requests should be addressed.

${ }^{2}$ Visiting Assistant in Agricultural Engineering.
}

beam. Scattering of direct-beam irradiance to lower leaves and penetration of diffuse skylight are important to canopy assimilation in two ways. First, in crop canopies, the lower, shaded leaves absorb $10 \%$ to $15 \%$ of the incident PFD that is scattered by the sunlit leaves. Second, lower leaves absorb a considerable fraction of the diffuse skylight since it is less directional than the direct beam. Diffuse-light flux absorbed by lower leaves, although fairly small, is important because, at low PFD, the apparent $\mathrm{Q}_{\mathrm{E}}$ will be high for lower leaves.

\section{Light interception by closed crop canopies}

For crop canopies that are closed and have their leaves randomly distributed horizontally, there are simple equations for light interception and for PFD striking a leaf at any given LAI depth. Because the leaves in crop canopies are not contiguous, there are gaps between adjacent leaves through which light penetrates farther down in the canopy. Assuming the gaps are randomly distributed horizontally, the area of direct-beam irradiance penetrating to any depth in the canopy is an exponential function of the cumulative LAI from the top of the canopy (analogous to the Beer-Lambert law):

where $I$ and $I_{o}$ are the total energies or areas of direct-beam fluxes on a horizontal plane at points within and above the canopy, respectively (Loomis and Williams, 1969; Monsi and Saeki, 1953). In the area context, the direct-beam extinction coefficient $\left(\mathrm{K}_{\mathrm{d}}\right)$ is the ratio of horizontally projected shadow area per unit land area per unit leaf area. The shadow projection of leaves depends on leaf angle and solar elevation angle $(\beta)$ from the horizontal. $K_{d}$ is 1.0 only when all leaves are distributed randomly in the horizontal plane and are perpendicular to the direct beam when the sun is directly overhead. Under these conditions, a canopy of LAI $=1$ intercepts $63 \%$ of the incident direct irradiance. Since $K_{d}$ includes $1 / \sin (\beta)$, it varies as the solar elevation angle $\beta$ changes. Leaf angle variations also affect $\mathrm{K}_{\mathrm{d}}$ because less light is intercepted when leaves are displayed obliquely to the direct beam. Equation [1] assumes random horizontal distribution of leaf area; however, that assumption does not hold for incomplete row crop stands or regularly spaced but incomplete plant stands. In addition to $\mathrm{K}_{\mathrm{d}}$, total light extinction by a crop canopy requires accounting for scattering (reflectance and transmittance), as was done by Duncan et al. (1967) and Goudriaan $(1977,1982)$. For these reasons, experimentally determined values for total light extinction would not necessarily be the same as $K_{d}$ calculated from Eq. [1]. See Loomis and Williams (1969), Ross (1981), and Campbell and Norman (1989) for further information on light interception relative to leaf angle, leaf pattern, LAI, and solar elevation.

\section{Simple models for predicting assimilation of closed canopies}

Two simple models for gross canopy assimilation $\left(\mathrm{P}_{\text {can }}\right)$ of horizontally uniform canopies are introduced here, so readers can compare them to the subsequent hedgerow photosynthesis model. Both simple models use light-response curves that can be defined by $\mathrm{Q}_{\mathrm{E}}$ and $\mathrm{P}_{\max }$. Acock et al. (1978) developed an analytical solution for $\mathrm{P}_{\text {can }}$ that considers the integral of the Michaelis-Menten equation for leaf photosynthesis over successive LAI depth (L) as PFD is absorbed:

Light attenuation through the canopy is assumed to follow the Beer-Lambert law, where $I_{o}$ is the PFD on a horizontal plane above the canopy. The actual PFD reaching the surface of a leaf and absorbed for 
photosynthesis $\left(\mathrm{I}_{\mathrm{i}}\right)$ at any LAI depth in the canopy requires consideration of $\sigma$ and $\mathrm{K}_{\mathrm{d}}$ (Charles-Edwards, 1981):

$\mathrm{I}_{\mathrm{i}}$ is the average irradiance absorbed at any given LAI depth and does not reflect the randomness of sunflecks penetrating to depth in the canopy. Upon combining the Michaelis-Menten leaf light-response equation and Eq. [3] for PFD absorbed by leaf area at any LAI depth, then integrating over LAI depth, the following equation is obtained:

Equation [4] tends to overpredict $\mathrm{P}_{\text {can }}$ slightly, possibly because of the use of average irradiance per layer and because one $P_{\max }$ value is used throughout the entire canopy. Reynolds et al. (1992) compared various model approaches and reported that using average irradiance for all leaves within a layer invariably overestimated canopy assimilation. This problem is inherent in the modeling approaches of Acock et al. (1978), Monsi and Saeki (1953), and Hirose and Werger (1987).

Another simple model for gross assimilation of closed crop canopies is based on the sunlit and shaded LAI approach and the exponential light-response equation (Boote and Jones, 1987; Boote and Loomis, 1991; Sinclair and Horie, 1989). This approach is based on light absorption by sunlit and shaded leaf classes, subsequent photosynthesis of these leaf classes, and summation of rates over the sunlit and shaded LAIs. The exponential light-response equation for leaf photosynthesis (P) is described:

First, consider photosynthesis by sunlit leaves. The amount of sunlit LAI ( $\mathrm{LAI}_{\text {sun }}$ ) is described analytically from $\mathrm{K}_{\mathrm{d}}$ and total LAI (Goudriaan, 1977):

If $\mathrm{K}_{\mathrm{d}}=1$ (leaves perpendicular to solar beam), then sunlit LAI approaches 1 as LAI approaches infinity. If $\mathrm{K}_{\mathrm{d}}<1$, say 0.5 , then the amount of sunlit LAI would approach 2 as LAI approaches infinity. The incident PFD on $\mathrm{LAI}_{\text {sun }}$ would be $\mathrm{K}_{\mathrm{d}}$ PFD. After accounting for $\sigma$ due to reflectance and transmittance, the absorbed PFD would be (1 $\sigma) \cdot K_{d} \cdot P F D$. Using the exponential leaf photosynthesis equation, the assimilation rate of sunlit leaves $\left(\mathrm{P}_{\text {sun }}\right)$ becomes

Next, consider photosynthesis by shaded leaves. Total canopy photosynthesis is increased by the photosynthetic contribution of lower, shaded leaves that absorb diffuse skylight and direct beam scattered and transmitted through the upper leaves. Shaded LAI $\left(\mathrm{LAI}_{\text {shd }}\right)$ is defined as any LAI that is not sunlit.

In a typical situation, $\approx 10 \%$ to $20 \%$ of the direct beam is scattered through sunlit leaves to shaded leaves. In the simple examples in Boote and Loomis $(1991)$, scattered direct beam $(\sigma=0.20)$ was assumed to include some diffuse skylight. As an approximation, Boote and Jones (1987) assumed that $\mathrm{LAI}_{\text {shd }}$ intercepted this scattered light using the same $\mathrm{K}_{\mathrm{d}}$ as for $\mathrm{LAI}_{\text {sun }}$, and that all shaded LAI shared equally in the use of this scattered PFD, once intercepted. Thus, PFD incident on, and available for, photosynthesis per unit shaded LAI ( $\left.\mathrm{PFD}_{\text {shd }}\right)$ is

and assimilation by shaded leaves $\left(\mathrm{P}_{\text {shd }}\right)$ is
The total canopy assimilation summed over both leaf categories is

Given inputs of field measurements of leaf $\mathrm{P}_{\max }, \mathrm{K}_{\mathrm{d}}$, and LAI, the sunlit plus shaded LAI photosynthesis model has adequately predicted total canopy assimilation response to PFD measured on closed canopies of soybean (Glycine max L.), peanut (Arachis hypogaea L.), and common bean (Phaseolus vulgaris L.) (Boote and Jones, 1987; Boote et al., 1988). Predictions with the sunlit plus shaded LAI approach (Eqs. [6-11]) have generally been closer to observed total canopy photosynthesis than predictions with the analytical equation of Acock et al. (1978). The analytical equation (Eq. [4]) gives comparable, but slightly higher, predictions than the sunlit plus shaded LAI approach (same $\mathrm{K}_{\mathrm{d}}$ and $\sigma$ ). These two approaches are satisfactory for closed crop canopies but do not work well for incomplete hedgerow canopies and lack a separate accounting for interception of direct beam and diffuse skylight. The sunlit plus shaded LAI approach has the advantage that any leaf photosynthesis equation (simple or complex) can be used.

\section{Row crop canopies and nonrandom horizontal distribution of LAI}

Many field and horticultural crops are grown in rows and the foliage is confined within a hedgerow. Even under equidistant plant spacing, leaves are usually clumped about the main axis of the plant. The canopy leaf area is then nonrandomly distributed horizontally, allowing greater light capture in clumped regions and greater light penetration to the soil where gaps in the canopy exist. If one looks at the canopy hedgerows at midday with the sun directly overhead, the impression may be that considerable light is not captured. Nevertheless, the effects of time of day and day of year on solar elevation causes considerably greater capture for lower solar elevations. It is possible to simulate the light interception by a hedgerow using three-dimensional geometry if one considers hedgerow dimensions, latitude, day of year, and time of day (Allen, 1974; Boote and Loomis, 1991; Gijzen and Goudriaan, 1989; Mutsaers, 1980).

\section{ASSIMILATION BY HEDGEROW CANOPIES}

A model to predict assimilation of row crop canopies was developed by Boote et al. $(1988,1989)$ based on a simplification of the hedgerow approach of Gijzen and Goudriaan (1989). The approach considers sunlit and shaded LAI similar to that for a horizontally uniform canopy, but with adaptations that apply to hedgerows. A simplified version of this approach is described by Boote and Loomis (1991). The version described below is a component of our crop growth simulation model, CROPGRO (Hoogenboom et al., 1992).

\section{Canopy envelope and light extinction coefficients}

The crop model predicts plant height and width over time, as a function of rate of increase in vegetative stage $(\mathrm{V}$; main stem node number) and internode length, which depends on temperature, water deficit, PFD, photoperiod, and plant vegetative stage (length per internode varies with $\mathrm{V}$ stage). Figure 1 illustrates prediction of width, height, and vegetative stage for a peanut crop canopy over the season. Plant canopy envelope is assumed to have an elliptical shape defined by the height and width. On an hourly basis, the shadow projected by individual plants is computed as a function of canopy height $(\mathrm{H})$, canopy width (W), time of day, day of year, latitude, and row azimuth. The shadow projections account for row spacing and spacing between plants in the row to allow computation of the fraction of the soil surface shaded by plant canopy at least once $\left(\mathrm{f}_{\mathrm{sh}}\right)$.

Solar azimuth and elevation are computed from standard equations as a function of latitude, day of year, and time of day (Spitters, 1986). Parameters such as latitude, row azimuth, row spacing, plant spacing in the row, leaf angle distribution, leaf scattering coefficient, soil albedo, and cultivar potential $\mathrm{P}_{\max }$ are assumed to remain constant during the season. Daily changes occur in day of year, height, width, LAI, leaf $\mathrm{N}$ concentration, specific leaf weight, and actual $\mathrm{P}_{\max }$.

The direct-beam extinction coefficient, $\mathrm{K}_{\mathrm{d}}$, is computed hourly as 

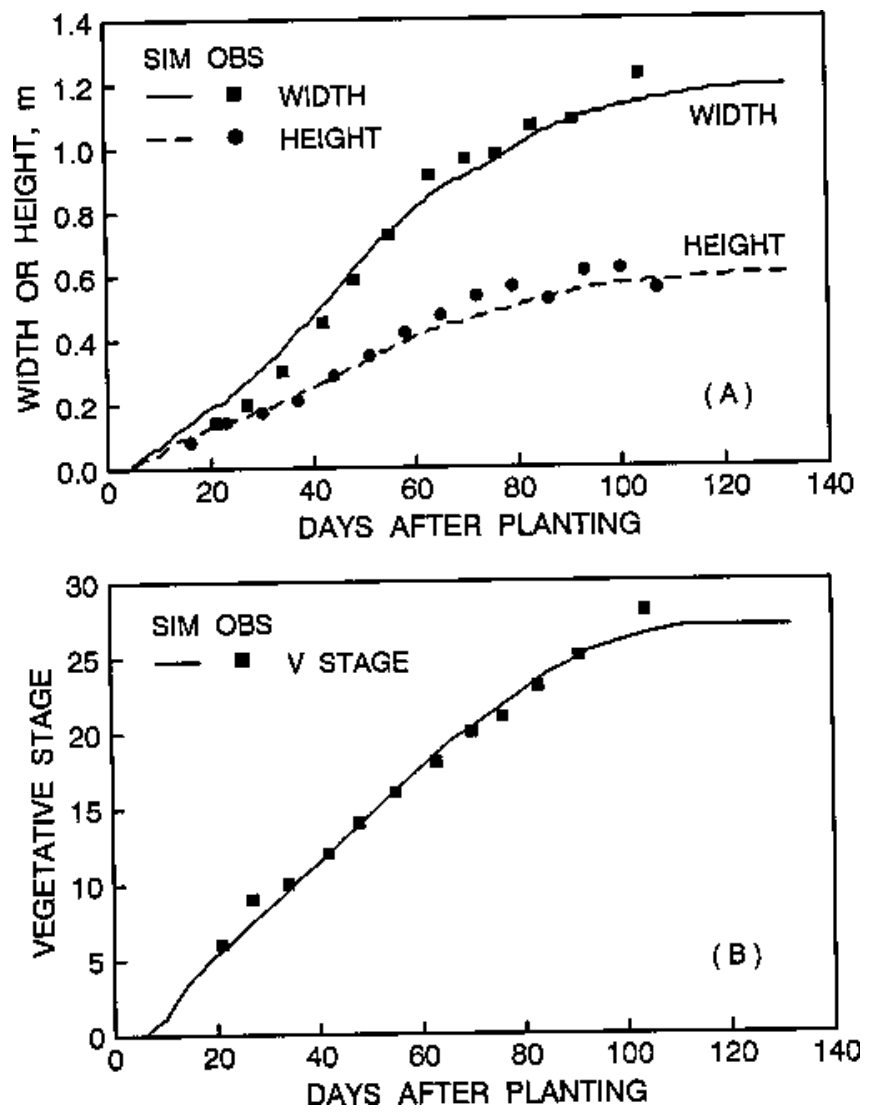

Fig. 1. (A) Predicted hedgerow width and height and (B) predicted vegetative stage of 'Florunner' peanut in 1990 at Gainesville, Fla. Solid points are field observations and line represents values simulated by PNUTGRO modelhedgerow version. $\mathrm{V}=$ vegetative.

a function of solar elevation and approximate leaf angle distribution among three angle classes ( 0 to 30, 30 to 60, and 60 to 90 degrees) using the approach of Goudriaan (1988). A similar, alternative approach has been proposed by Campbell and Norman (1989), whereby an ellipsoidal leaf angle distribution with a single parameter $(0.1=$ vertical, $10=$ horizontal) can be used to compute the proportion of leaves in each of three leaf angle classes. For simplicity, a spherical leaf-angle distribution could also be used, where the average horizontal projection of leaves relative to the direct-beam path is a constant 0.5 . Experience has shown that leaf angle distribution has only small effects on daily canopy photosynthesis, although a spherical leaf-angle distribution can underestimate light interception at midday for soybean and peanut. $\mathrm{K}_{\mathrm{d}}$ varies with $\beta$, because $\beta$ affects the effective pathlength through the canopy.

Light interception, photosynthesis, and LAI are restricted to the fraction of the soil surface shaded by the canopy $\left(f_{\text {sh }}\right)$, which depends on overlapping shadows of plant ellipses relative to row spacing and plant spacing.

The sunlit and shaded LAI are computed for the hedgerow canopy as

\section{Calculating hourly weather data}

Class A weather station data generally consist of daily maximum and minimum temperatures, daily rainfall, and, for a few stations, daily solar radiation and relative humidity. Hourly weather data are frequently not available, but can be used to drive the model if available. A function from Spitters (1986) is used to compute the hourly radiation values from daily values to distribute solar radiation and PFD throughout the day. Hourly temperatures are calculated from daily maximum and minimum air temperatures using a combined sine-exponential curve vs. time of day (Kimball and Bellamy, 1986; Parton and Logan, 1981). Hourly total and photosynthetic irradiance are split into direct $\left(\mathrm{PFD}_{\mathrm{dir}}\right)$ and diffuse $\left(\mathrm{PFD}_{\mathrm{dif}}\right)$ components using an algorithm for fraction diffuse vs. atmospheric transmission (Erbs et al., 1982; Spitters et al., 1986).

\section{Radiation absorption}

The PFD absorbed by sunlit and shaded LAI is computed as described by Spitters (1986). In this algorithm, a proportion of the direct-beam PFD is converted to diffuse within the canopy by scattering processes. The scattering coefficient $(\sigma)$ includes transmittance and reflectance down through the foliage. Reflectance $\left(\delta_{\text {dir }}\right.$ and $\left.\delta_{\text {dif }}\right)$ from the canopy to the sky depends on $\sigma$ and solar elevation. The use of $f_{\text {sh }}$ limits absorption of direct-beam PFD to the shaded soil surface area at any time of day. The relative LAI in the shaded zone is increased by dividing LAI by $\mathrm{f}_{\mathrm{sh}}$ as shown below:

Absorption of diffuse skylight $\left(\mathrm{A}_{\mathrm{dif}}\right)$ depends on row spacing $(\mathrm{R})$, plant spacing within the row $(\mathrm{S})$, canopy height $(\mathrm{H})$, and canopy width (W), based on an adaptation of Goudriaan (1977). The approach computes the path width [gap $(\mathrm{G})$ between hedges $=\mathrm{R}-\mathrm{W}$ ] or the path width $(\mathrm{G})$ between plants in the row $(\mathrm{S}-\mathrm{W})$ to compute the view factor (fraction of sky seen by the plants) for incomplete canopies. A diffuse extinction coefficient of 0.8 is assumed.

This approach assumes that diffuse irradiance originates from a uniformly overcast sky and that an incomplete canopy has a view factor $>1$. It is important that diffuse-light capture be computed in the two-dimensional manner above when plant canopy envelopes do not overlap within the row. This requirement was discovered by simulating single widely spaced plants, where, theoretically and in practice, photosynthesis and yield should reach a constant maximum per plant at some spacing at which single plants no longer compete for light.

Absorption of PFD reflected from soil $\left(\mathrm{A}_{\mathrm{ref}}\right)$ is handled in a similar manner to Eq. [25], based on total PFD incident on the soil surface (both direct and diffuse) and assuming that diffuse soil reflectance to $\operatorname{PFD}\left(\delta_{\text {soil }}\right)$ is 0.25 . 

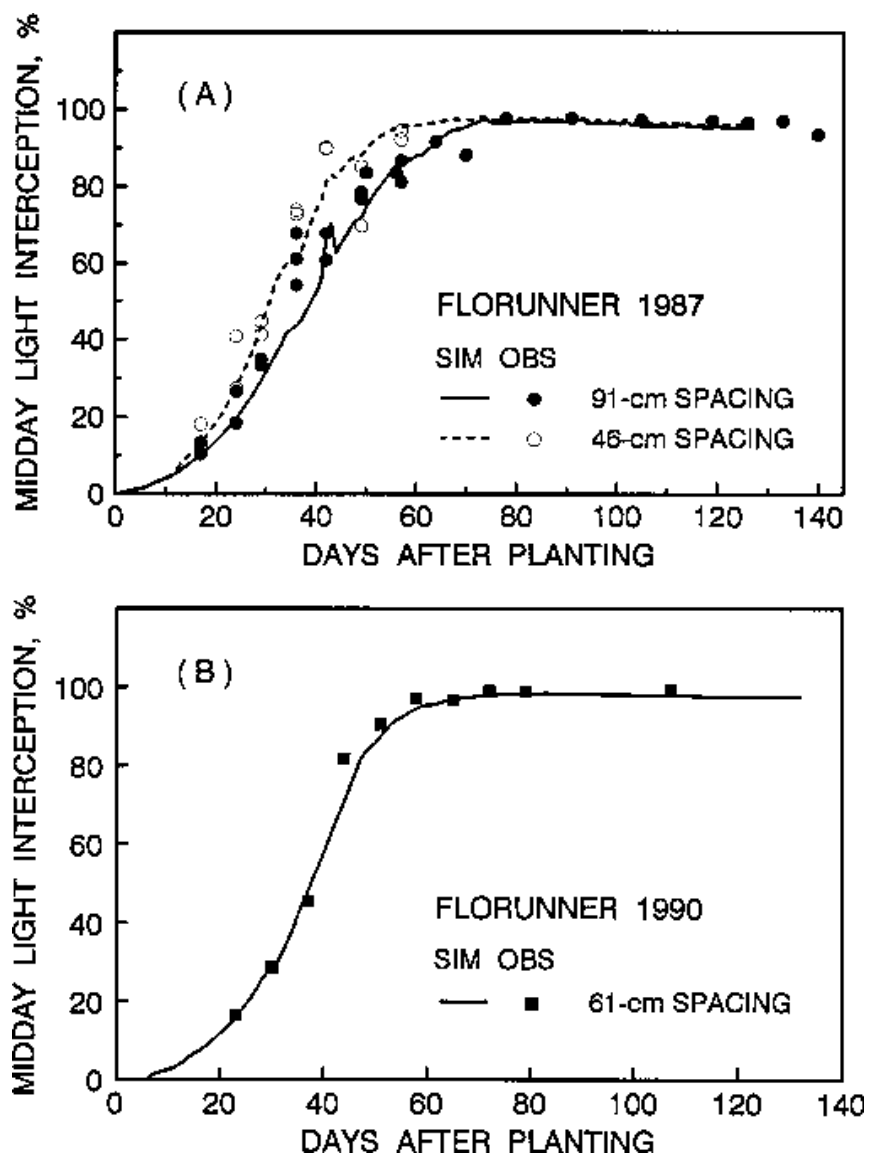

Fig. 2. Simulated and observed percent light interception at midday for 'Florunner' peanut canopies grown at Gainesville in (A) 46- and 91-cm row spacing in 1987 and (B) 61-cm row spacing in 1990. Plant population was 22.4 plants $/ \mathrm{m}^{2}$ for both row spacings in 1987 , and 15 plants $/ \mathrm{m}^{2}$ in 1990 .

\section{Comparison to canopy light interception}

Canopy light absorption $\left(\mathrm{PFD}_{\mathrm{abs}}\right)$ is calculated in Eq. [29] as the sum of direct-beam PFD absorbed by sunlit leaves, direct beam converted to diffuse and absorbed by all LAI, skylight absorbed by sunlit and shaded leaves, and light reflected and absorbed from the soil. Canopy light interception $\left(\mathrm{PFD}_{\text {int }}\right)$ is the sum of the first three components above and also includes reflectance of direct and diffuse from the canopy (Eq. [26]). Predicted and observed light interception is illustrated in Fig. 2 for peanut canopies with different row spacings. This figure illustrates that the hedgerow approach will predict light interception correctly if the geometry is adequately described (canopy height and width over time had been calibrated to field measurements).

\section{Allocation of diffuse PFD among LAI layers}

The PFD absorbed by the sunlit and shaded classes of leaves is computed for leaves in three LAI layers (each layer is one-third of total LAI). The flux of diffuse PFD absorbed by leaves in a given stratum, $\mathrm{PFD}_{\text {shd(i) }}$, is calculated from direct beam converted to diffuse within the canopy $\left(\mathrm{A}_{\mathrm{dir}, \mathrm{dif}}\right)$, absorbed skylight $\left(\mathrm{A}_{\mathrm{dif}}\right)$, and diffuse reflected from the soil, applying Eqs. [14, 15, 16, 25, and 28] over one-third, two-thirds, and three-thirds of the total LAI, respectively, then using differences to calculate PFD absorbed per layer and per unit LAI in each layer. The average flux of PFD absorbed by the shaded leaves in a given stratum is $\mathrm{PFD}_{\text {shd(i) }}$, whereas sunlit leaves additionally receive direct beam, $(1-\sigma) \cdot K_{d} \cdot P D_{\text {dir }}$, as shown in Eq. [30].

The need for layering diffuse-light absorption was documented by Reynolds et al. (1992) and is also supported by our comparison of model predictions to field data. We found canopy assimilation to be overpredicted $10 \%$ to $15 \%$ when nonlayered diffuse-light capture was used for high LAI canopies and when the Spitters'(1986) fraction
Table 1. Influence of number of canopy layers for diffuse-light absorption and the resulting effect on assimilation by sunlit leaves, shaded leaves, and the total canopy. Light-saturated photosynthesis rate $\left(\mathrm{P}_{\max }\right)=26 \mu \mathrm{mol} \mathrm{CO} \mathrm{CO}_{2} / \mathrm{m}^{2}$ per sec and leaf area index $=5$.

\begin{tabular}{|c|c|c|c|c|}
\hline \multirow{2}{*}{$\begin{array}{l}\text { Layers } \\
\text { (no.) }\end{array}$} & \multicolumn{3}{|c|}{$\begin{array}{c}\text { Assimilating leaves } \\
\left(\mu \mathrm{mol} \mathrm{CO} \mathrm{CO}_{2} / \mathrm{m}^{2} \text { per sec }\right)\end{array}$} & \multirow{2}{*}{$\begin{array}{l}\text { Deviation } \\
(\%)\end{array}$} \\
\hline & Sunlit & Shaded & Total & \\
\hline \multicolumn{5}{|c|}{ Midday, $P F D^{z}=1500 \mu \mathrm{mol} \cdot \mathrm{m}^{-2} \cdot \mathrm{s}^{-1}, 0.245$ fraction diffuse } \\
\hline 1 & 27.8 & 17.8 & 45.6 & 8.9 \\
\hline 2 & 28.3 & 14.8 & 43.2 & 3.0 \\
\hline 3 & 28.5 & 14.0 & 42.4 & 1.4 \\
\hline 5 & 28.6 & 13.4 & 42.1 & 0.4 \\
\hline 10 & 28.6 & 13.2 & 41.9 & 0 \\
\hline $1(\mathrm{SL} / \mathrm{SH})^{\mathrm{y}}$ & 29.2 & 11.4 & 40.6 & -3.2 \\
\hline \multicolumn{5}{|c|}{ Midday, $P F D=2000 \mu \mathrm{mol} \cdot \mathrm{m}^{-2} \cdot \mathrm{s}^{-1}, 0.245$ fraction diffuse } \\
\hline 1 & 30.7 & 23.0 & 53.7 & 11.0 \\
\hline 2 & 31.2 & 19.0 & 50.2 & 3.6 \\
\hline 3 & 31.3 & 17.9 & 49.2 & 1.6 \\
\hline 5 & 31.4 & 17.3 & 48.7 & 0.5 \\
\hline 10 & 31.4 & 17.0 & 48.4 & 0 \\
\hline $1(\mathrm{SL} / \mathrm{SH})$ & 31.8 & 14.8 & 46.7 & -3.7 \\
\hline \multicolumn{5}{|c|}{ Midday, $P F D=1500 \mu \mathrm{mol} \cdot \mathrm{m}^{-2} \cdot \mathrm{s}^{-1}, 0.490$ fraction diffuse } \\
\hline 1 & 25.0 & 26.5 & 51.5 & 13.7 \\
\hline 2 & 26.3 & 21.1 & 47.4 & 4.6 \\
\hline 3 & 26.7 & 19.5 & 46.2 & 2.0 \\
\hline 5 & 26.9 & 18.7 & 45.6 & 0.6 \\
\hline 10 & 27.0 & 18.4 & 45.3 & 0 \\
\hline $1(\mathrm{SL} / \mathrm{SH})$ & 28.3 & 15.6 & 43.9 & -3.0 \\
\hline \multicolumn{5}{|c|}{ Midday, $P F D=2000 \mu \mathrm{mol} \cdot \mathrm{m}^{-2} \cdot \mathrm{s}^{-1}, 0.490$ fraction diffuse } \\
\hline 1 & 28.4 & 33.6 & 62.0 & 16.6 \\
\hline 2 & 29.5 & 26.4 & 55.9 & 5.2 \\
\hline 3 & 29.8 & 24.6 & 54.3 & 2.2 \\
\hline 5 & 29.9 & 23.6 & 53.5 & 0.7 \\
\hline 10 & 30.0 & 23.2 & 53.2 & 0 \\
\hline 1(SL/SH) & 31.2 & 20.2 & 51.4 & -3.3 \\
\hline
\end{tabular}

${ }^{\text {zPFD }}=$ photon flux density.

${ }^{\text {y }} \mathrm{SL} / \mathrm{SH}$ assumes sunlit leaves over shaded leaves.

diffuse approach was followed. The overprediction was less pronounced on clear days and was minor in our earlier models in which we had arbitrarily limited the fraction of diffuse light and compared the models to data measured only on clear days (Boote et al., 1988, 1989). Reynolds et al. (1992) reported errors up to $15 \%$ when a single-layer model with one sunlit and one shaded leaf class was used, whereas a multilayer model with one sunlit and shaded leaf class per layer gave reasonable results. This finding indicates the need for layering LAI for diffuse-light absorption. We compared numbers of layers for diffuselight absorption (Table 1) and concluded that a model with three to five layers is adequate. A single-layer model (with sunlit and shaded leaves) gives $9 \%$ to $11 \%$ overprediction when the fraction of diffuse is low (0.245), but gives larger errors of $14 \%$ to $17 \%$ if the fraction of diffuse is higher. An assumption of sunlit leaves physically above shaded leaves for diffuse-light absorption underestimates $\mathrm{P}_{\text {can }}$ by $3 \%$ to $4 \%$ compared to a 10 -layer model. Ignoring sunlit and shaded leaf classes in each LAI layer and computing average PFD absorbed per unit LAI was a poor option, giving a $0 \%$ to $19 \%$ higher estimate of $\mathrm{P}_{\text {can }}$ than versions with sunlit and shaded leaf classes. These results concur with those of Reynolds et al. (1992), who reported that modeling approaches using average irradiance for all leaves within a layer invariably overestimated canopy assimilation. We conclude that canopy assimilation models must have layering for diffuse PFD absorption and must have sunlit vs. shaded leaf classes. In our approach, the multilayer strategy is valuable primarily for diffuse-light absorption, because the sunlit leaves, by definition, receive direct beam regardless of canopy position. Layering has a minor effect on total PFD absorbed by sunlit leaves because the diffuse PFD on sunlit leaves varies by layer.

\section{Summation of canopy rate over sunlit and shaded leaves}

Leaf photosynthesis is computed with single-leaf equations, described below, for sunlit and shaded leaf classes within each of three canopy layers ( $\mathrm{i}=1$ to 3 ). Because using an average leaf projection 
angle slightly overestimates leaf photosynthesis, we use a three-point Gaussian approach (Goudriaan, 1986) to integrate photosynthesis of sunlit leaves over the range of leaf angles expected. For simplification, we show only a constant leaf angle projection in Eq. [30]. This layering approach requires computing sunlit and shaded LAI within each stratum and then summing up assimilation over all layers (Eq. [33]). Using layers also allows using variation in $\mathrm{P}_{\max (\mathrm{i})}$ with canopy depth.

\section{Use of class divisions to reduce aggregation error}

One cannot merely compute leaf photosynthesis rate at the average leaf PFD and then multiply by the total LAI to obtain $\mathrm{P}_{\text {can }}$. This approach does not work because the photosynthetic light response is nonlinear and most leaves are either at higher or lower PFD. Light penetration into the crop canopy is nonlinear with canopy depth and time of day. Rastetter et al. (1992) described this as the "fallacy of the averages" (from Wagner, 1969) and illustrated the problem nicely and discussed ways to reduce aggregation error in predicting canopy photosynthesis. We approach the nonlinear integration (aggregation) from leaf-to-canopy photosynthesis in several ways: sunlit vs. shaded leaf classes, leaf angle classes, canopy layers, and hourly computations within the day. In our opinion, the sunlit and shaded leaf classes (and time of day) are the most important aggregation techniques, while leaf-angle classes are the least important. Canopy layers are useful for diffuse-light absorption and allowing $\mathrm{P}_{\max }$ to vary with depth. In the terminology of Rastetter et al. (1992), we have primarily partitioned the fine-scale components into relatively homogeneous subaggregates with respect to PFD and $\mathrm{P}_{\max }$. We discussed the relative importance of these techniques for minimizing aggregation error in the previous section on allocation of diffuse PFD among LAI layers and in a subsequent section on variation in $\mathrm{P}_{\max }$, specific leaf weight (SLW), and $\mathrm{N}$ concentration with LAI depth.

\section{LEAF PHOTOSYNTHESIS EQUATIONS USED IN THE HEDGEROW MODEL}

\section{Equations for light response}

A common equation used for single-leaf photosynthesis response to light is the nonrectangular hyperbola given below, including parameters, $\mathrm{P}_{\max }, \mathrm{Q}_{\mathrm{E}}$, and a curvature factor $(\Theta)$ :

Johnson and Thornley (1984) reviewed the use of the nonrectangular hyperbola for predicting photosynthetic response to PFD. When $\Theta=$ zero, the equation becomes a rectangular hyperbola (MichaelisMenten equation). With $\Theta=1.0$, the equation is a Blackman response of two intersecting straight lines. The asymptotic exponential equation (Eq. [5]) is similar to, but not exactly the same as, a nonrectangular hyperbola having a $\Theta$ of $\approx 0.7$. Most evidence suggests that the asymptotic exponential or a nonrectangular hyperbola with $\Theta=0.7$ to 0.9 provides a better fit than the Michaelis-Menten equation (Marshall and Biscoe, 1980; Peat, 1970). Evans and Farquhar (1991) used $\Theta=$ 0.7 to describe electron transport or photosynthesis response to PFD. The above equations are defined by initial slope, $Q_{E}$, and the asymptote ( $\mathrm{P}_{\max }$ at light saturation). Thus, it would be convenient if we could define environmental effects on $\mathrm{Q}_{\mathrm{E}}$ and $\mathrm{P}_{\max }$.

Incorporating leaf photosynthesis response to $\mathrm{CO}_{2}$ and temperature

The Farquhar and von Caemmerer (1982) approach is commonly used to predict leaf photosynthetic response to $\mathrm{C}_{\mathrm{i}}$. In their model, leaf $\mathrm{CO}_{2}$ assimilation rate takes the minimum of two equations: 1 ) rubiscolimiting equation (primarily at low $\mathrm{C}_{\mathrm{i}}$, where $\mathrm{CO}_{2}$ assimilation responds almost linearly to increasing $\mathrm{C}_{\mathrm{i}}$ and rate is limited by rubisco activity), and 2) RuBP-limiting equation (at ambient to superambient $\mathrm{C}_{\mathrm{i}}$, where assimilation responds less rapidly to increasing $\mathrm{C}_{\mathrm{i}}$ because rate is limited by electron transport). We use an adaptation based only on the RuBP-limiting equations for several reasons. First, the transition to the RuBP-limiting region begins near ambient $\mathrm{CO}_{2}$ and continues to higher $\mathrm{CO}_{2}$ levels. We are primarily interested in predictions only at and above ambient $\mathrm{CO}_{2}$. Second, assimilation in crop canopies is limited by light availability during much of the day, and lower parts of the crop canopy are light-limited all the time; thus, the RuBPlimiting equations apply more often. Last, our approach eliminates the need for independent estimates of the rubisco's maximum rate and its Michaelis constants.

In our hedgerow canopy photosynthesis model, we predict $\mathrm{Q}_{\mathrm{E}}$ as a function of $\mathrm{CO}_{2}, \mathrm{O}_{2}$, and temperature, while $\mathrm{P}_{\max }$ is modeled as a function of $\mathrm{CO}_{2}, \mathrm{O}_{2}$, temperature, SLW, and $\mathrm{N}$ concentration. In our approach, $\mathrm{CO}_{2}, \mathrm{O}_{2}$, and temperature effects on $\mathrm{Q}_{\mathrm{E}}$ and $\mathrm{P}_{\max }$ follow the approach of Farquhar and von Caemmerer (1982), assuming that $\mathrm{RuBP}$ is limiting; this includes the temperature effects on specificity factor $(\tau)$ and $\mathrm{CO}_{2}$ compensation point $\left(\Gamma^{*}\right)$ in absence of mitochondrial respiration.

Under limiting low light, where $\mathrm{Q}_{\mathrm{E}}$ is defined, the Farquhar and von Caemmerer (1982) equations, assuming electron transport is limiting, approach the limit of

where the latter part of the equation (1/2.1) represents 1 electron per 2.1 photons, and the first part of the equation is the efficiency of using electrons to fix and reduce $\mathrm{CO}_{2}$. This limiting equation for $\mathrm{Q}_{\mathrm{E}}$ is equation 16.63 of Farquhar and von Caemmerer (1982), assuming electron transport is limiting. At light saturation, the same equation holds for efficiency of using electrons for $\mathrm{CO}_{2}$ assimilation:

Fewer electrons, however, are produced per photon absorbed $\left(1 / \mathrm{QR}_{\mathrm{sat}}\right)$. In a practical sense, $1 / \mathrm{QR}_{\text {sat }}$ is related to the light-saturated rate of electron transport, $\mathrm{J}_{\max }$.

Equations [35] and [36] essentially describe the efficiency of electron use for $\mathrm{CO}_{2}$ fixation, from zero to saturating PFD. To calculate the effect of $\mathrm{CO}_{2}$ and temperature on $\mathrm{Q}_{\mathrm{E}}$, we use Eq. [35] with a scalar of 6.225 to compute a relative effect, $\mathrm{CO}_{2} \mathrm{Q}_{\mathrm{E}}(1.0$ at $30 \mathrm{C}$ and $350 \mathrm{ppm})$. $\mathrm{CO}_{2} \mathrm{Q}_{\mathrm{E}}$ is then multiplied by $0.0541(\mathrm{~mol} \mathrm{CO}$ fixed/mol PFD), which is the $\mathrm{Q}_{\mathrm{E}}$ (adjusted from 0.0524 at $325 \mathrm{ppm} \mathrm{CO}_{2}$ ) from observations on many $\mathrm{C}_{3}$ species (Ehleringer and Björkman, 1977; Ehleringer and Pearcy, 1983).

To compute $\Gamma^{*}$ and $\mathrm{C}_{\mathrm{i}}$, we need to know $\tau$, the specificity factor of rubisco for $\mathrm{CO}_{2}$ vs. $\mathrm{O}_{2}$. Harley and Tenhunen (1991) used the following exponential energy of activation equation to describe the response of $\tau$ to temperature based on data of Jordan and Ogren (1984):

The $\tau$ value decreases and $\Gamma^{*}$ increases similarly with temperature for most $\mathrm{C}_{3}$ species (Brooks and Farquhar, 1985; Jordan and Ogren, 1984). Then $\Gamma^{*}$ can be computed as a function of $\mathrm{O}_{2}$ concentration $\left(0.21 \mathrm{~mol} \cdot \mathrm{mol}^{-1}\right)$ and $\tau$ : 


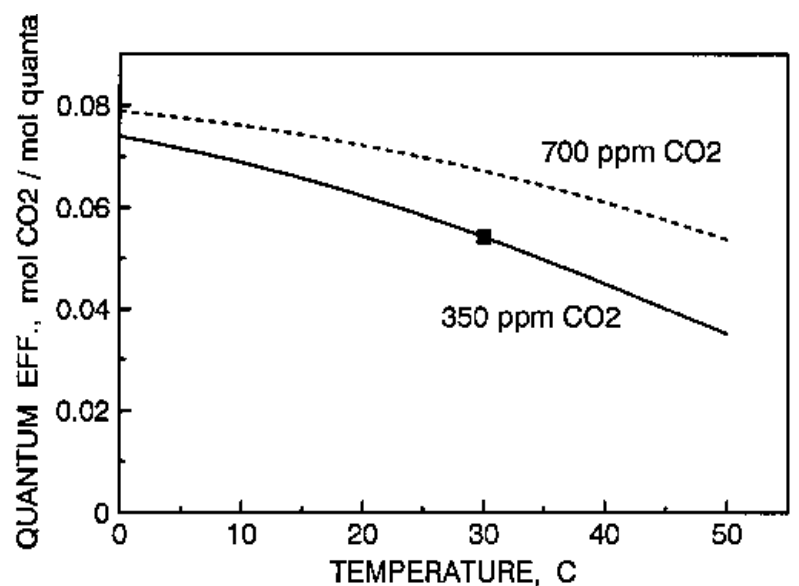

Fig. 3. Predicted quantum efficiency $\left(\mathrm{Q}_{\mathrm{E}}\right)$ at $\mathrm{CO}_{2}$ concentration of 350 and 700 $\mathrm{ppm}$ as affected by temperature. Point represents reference $\mathrm{Q}_{\mathrm{E}}$ of 0.0541 at $350 \mathrm{ppm} \mathrm{CO}$ based on Ehleringer and Björkman (1977).

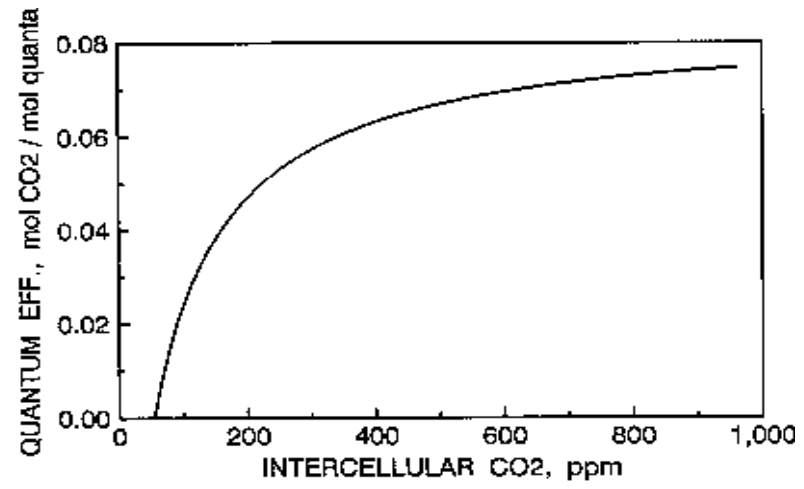

Fig. 4. Predicted quantum efficiency $\left(\mathrm{Q}_{\mathrm{E}}\right)$ at $30 \mathrm{C}$ as affected by $\mathrm{CO}_{2}$ concentration.

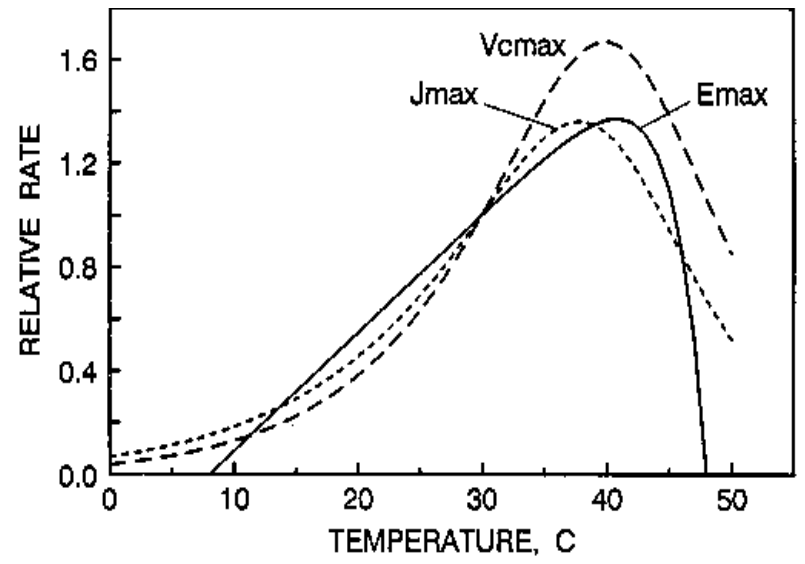

Fig. 5. Relative rate of electron transport $\left(\mathrm{E}_{\max }\right)$ vs. temperature. $\mathrm{J}_{\max }$ and $\mathrm{V}_{\text {cmax }}$ are electron transport and rubisco rate from Harley et al. (1985). All responses are normalized to 1.0 at $30 \mathrm{C}$.

Equation [36] is used to describe $\mathrm{C}_{\mathrm{i}}$ and temperature effects on the relative efficiency of $\mathrm{CO}_{2}$ fixation $\left(\mathrm{CO}_{2 \max }\right)$ in saturating light $\left(\right.$ at $\left.\mathrm{P}_{\max }\right)$ as follows:

Equation [41] is scaled to a relative effect of 1.0 at $30 \mathrm{C}$ and 350 ppm $\mathrm{CO}_{2}$. This requires $\mathrm{P}_{\max }$ input to the model to be described as $\mathrm{CO}_{2}$ fixation rate measured at saturating $\mathrm{PFD}, 30 \mathrm{C}, 350 \mathrm{ppm} \mathrm{CO}_{2}$, and $21 \% \mathrm{O}_{2}$.

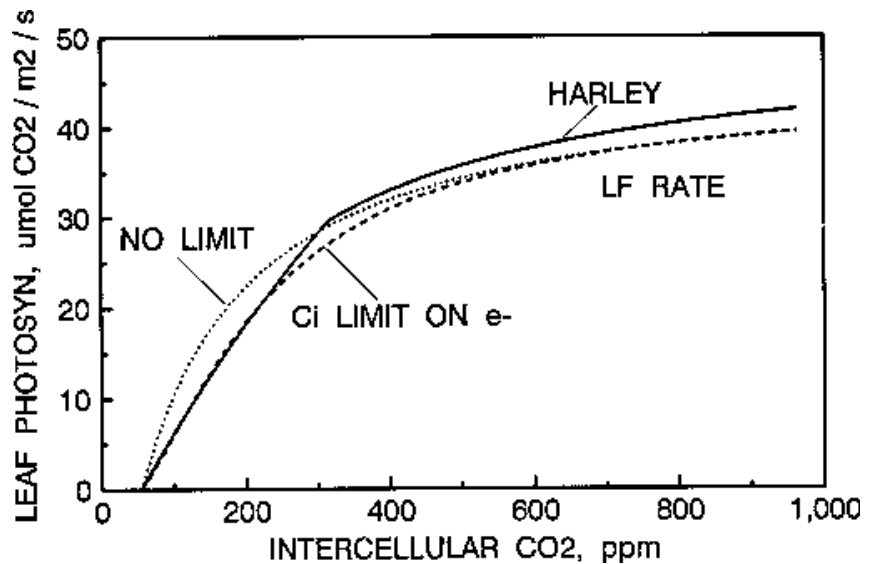

Fig. 6. Leaf photosynthesis response to intercellular $\mathrm{CO}_{2}\left(\mathrm{C}_{\mathrm{j}}\right)$ with and without $\mathrm{CO}_{2}$-substrate limitations on electron transport. Simulated at $30 \mathrm{C}$ and a photon flux density of $1500 \mu \mathrm{mol} \cdot \mathrm{m}^{-2} \cdot \mathrm{s}^{-1}$ using light-saturated photosynthesis rate $\left(\mathrm{P}_{\max }\right)=28 \mu \mathrm{mol} \mathrm{CO} \mathrm{C}_{2} / \mathrm{m}^{2}$ per sec. Harley equation was parameterized as described by Harley et al. (1985).

At the light compensation point, $\mathrm{C}_{\mathrm{i}}$ is assumed equal to $\mathrm{C}_{\mathrm{a}}$. In contrast, at high PFD, $\mathrm{C}_{\mathrm{i}}$ is computed with the following equation, where the ratio of 0.7 is the rate of change of $C_{i}$ with respect to $C_{a}$, which has held over a wide range of environmental conditions for many $\mathrm{C}_{3}$ species (Morison, 1987).

The $\mathrm{Q}_{\mathrm{E}}$ response to temperature and $\mathrm{CO}_{2}$, based on Eqs. [35-40], is shown in Figs. 3 and 4 . The responses closely mimic the sensitivity of $\mathrm{Q}_{\mathrm{E}}$ to temperature and $\mathrm{CO}_{2}$ reported for $\mathrm{C}_{3}$ species by Ehleringer and Björkman (1977). The shape of $\mathrm{CO}_{2 \max }$ vs. temperature and $\mathrm{CO}_{2}$ is very similar, but is normalized to 1.0 at $30 \mathrm{C}$ and $350 \mathrm{ppm} \mathrm{CO}_{2}$.

\section{Effect of temperature on $\mathbf{J}_{\max }$}

The $\mathrm{CO}_{2 \max }$ equation essentially describes the relative efficiency of converting electrons to $\mathrm{CO}_{2}$ fixed at high light intensity as influenced by $\mathrm{C}_{\mathrm{i}}, \mathrm{O}_{2}$, and temperature, but does not address temperature effects on electron transport itself. Temperature effects on light-saturated, $\mathrm{CO}_{2}-$ saturated leaf photosynthesis of soybean have been described with energy of activation-deactivation equations by Harley et al. (1985) and Harley and Tenhunen (1991). Since responses obtained by Harley et al. (1985) for soybean and by Tenhunen et al. (1976) for common bean (Phaseolus vulgaris L.) were almost linear and there were no data below $15 \mathrm{C}$, we used a straight line function, shown in Fig. 5, for increasing electron transport between 8 and 40C, scaled to a relative value of 1.0 at 30C (Pickering et al., 1995). Exponentially increasing heat damage to photosystem II is assumed, which reduces the rate $1.5 \%$ at $36 \mathrm{C}, 6 \%$ at $40 \mathrm{C}, 25 \%$ at $44 \mathrm{C}$, and $100 \%$ (to zero) at $48 \mathrm{C}$. Figure 5 compares our combined function to that of Harley et al. (1985).

\section{Effect of $\mathrm{CO}_{2}$ on electron transport}

If electron acceptors become limiting, as when $\mathrm{CO}_{2}$ declines below ambient, then electron transport is decreased because of inadequate $\mathrm{CO}_{2}$ or $\mathrm{O}_{2}$ to be fixed. Electron transport of $P$. vulgaris in high light flux $\left(\mathrm{PFD}>380 \mu \mathrm{mol} \cdot \mathrm{m}^{-2} \cdot \mathrm{s}^{-1}\right.$ ) was reported to decrease as $\mathrm{C}_{\mathrm{i}}$ fell below 300 ppm $\mathrm{CO}_{2}$, but there was no $\mathrm{C}_{\mathrm{i}}$ effect at a PFD of $175 \mu \mathrm{mol} \cdot \mathrm{m}^{-2} \cdot \mathrm{s}^{-1}$ (Sharkey et al., 1988). The authors explained this as the regulation of electron transport to match the rate of rubisco activity at low $\mathrm{C}_{\mathrm{i}}$ in the presence of high PFD. The excess energy was lost as chlorophyll fluorescence. Applying RuBP-limited equations to data on rice (Oryza sativa $\mathrm{L}$.) canopy assimilation at 160 to $900 \mathrm{ppm} \mathrm{CO}_{2}$ and solving for $\mathrm{P}_{\max }$ showed that $\mathrm{P}_{\max }$ declined as $\mathrm{C}_{\mathrm{a}}$ dropped below 330 or $500 \mathrm{ppm}$ (Boote et al., 1992).

To address this problem, we added an asymptotic equation $\left[1-\mathrm{e}\left(-\mathrm{z} * \mathrm{C}_{\mathrm{i}}\right)\right]$ that decreases $\mathrm{P}_{\max }$ as a function of $\mathrm{C}_{\mathrm{i}}$. This term describes substrate limitation for electron transport-RuBP generation. The 50\% response 
level was reached between $\mathrm{C}_{\mathrm{i}}=83$ to $137 \mathrm{ppm}$ for rice. This function accounts for the effects of the rubisco-limited phase in a simple way that is normalized to the original $\mathrm{P}_{\max }$ term. As illustrated in Fig. 6, this causes a sharper transition in response to $\mathrm{CO}_{2}$ than our original function, but gives an $\mathrm{A}: \mathrm{C}_{\mathrm{i}}$ curve that is more similar to the Farquhar and von Caemmerer approach [as parameterized by Harley et al. (1985)].

\section{Leaf and canopy photosynthesis response to temperature}

Leaf response to temperature. Despite a linear effect of temperature on $\mathrm{J}_{\max }$, leaf photosynthesis response to temperature shows a curvilinear trend with a broad optimum, even at high $\mathrm{CO}_{2}$ and a PFD of $1500 \mu \mathrm{mol} \cdot \mathrm{m}^{-2} \cdot \mathrm{s}^{-1}$ (Fig. 7A). At ambient $\mathrm{CO}_{2}(350 \mathrm{ppm})$, the response becomes flatter, with broad optimum between 32 and $40 \mathrm{C}$. The leaf $\mathrm{P}$ response to $\mathrm{CO}_{2}$ increases with temperature.

Canopy response to temperature. Simulated instantaneous canopy photosynthesis is illustrated in Fig. 7B for a closed canopy at solar noon $\left(\mathrm{LAI}=5.0, \mathrm{PFD}=1500 \mu \mathrm{mol} \cdot \mathrm{m}^{-2} \cdot \mathrm{s}^{-1}\right.$ on $1 \mathrm{July}$ at lat. $\left.30^{\circ} \mathrm{N}\right)$. Note that the optimum temperature for photosynthesis is quite broad, between 25 to $37 \mathrm{C}$ at $350 \mathrm{ppm} \mathrm{CO}$, but the optimum temperature increases as $\mathrm{CO}_{2}$ concentration increases. The broad temperature optimum for $\mathrm{P}_{\text {can }}$ at ambient $\mathrm{CO}_{2}$ is caused by two features: 1) in a canopy, many leaves operate at low light flux, which increases the effect of $\mathrm{Q}_{\mathrm{E}}$, and 2) leaf photosynthesis depends on temperature functions that influence $\mathrm{Q}_{\mathrm{E}}$ and $\mathrm{P}_{\max }$, and these two temperature functions operate in opposite directions. Using similar modeling approaches, Long (1991) also found broad optimums for daily $\mathrm{P}_{\text {can }}$ that shifted up several degrees with $\mathrm{CO}_{2}$ enrichment. The broad temperature optimum for $\mathrm{P}_{\text {can }}$ is consistent with field data showing little variation on crop growth rates despite variation in air temperature. It
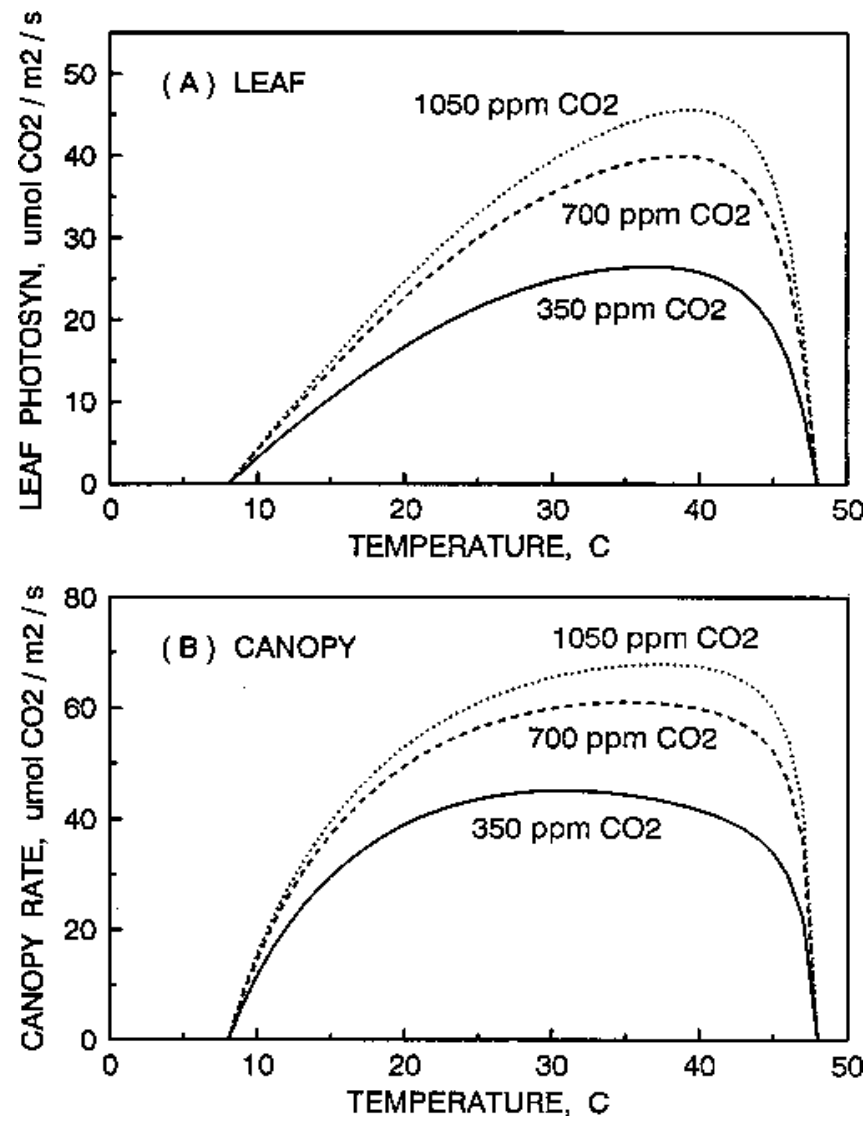

Fig. 7. (A) Leaf photosynthesis and (B) gross canopy assimilation $\left(\mathrm{P}_{\text {can }}\right)$ response to leaf temperature at three $\mathrm{CO}_{2}$ concentrations. Response simulated for leaf area index $=5.0$, closed canopy, at a photon flux density of $1500 \mu \mathrm{mol} \cdot \mathrm{m}^{-2} \cdot \mathrm{s}^{-1}$, at solar noon on $1 \mathrm{July}$ at lat. $30^{\circ} \mathrm{N}$, assuming fraction diffuse of 0.49 . Light-saturated photosynthesis rate $\left(\mathrm{P}_{\max }\right)=26 \mu \mathrm{mol} \mathrm{CO} /$ $\mathrm{m}^{2}$ per sec at $350 \mathrm{ppm} \mathrm{CO}_{2}$ and $30 \mathrm{C}$. is also supported by measurements in sunlit controlled-environment chambers, which showed no difference in $\mathrm{P}_{\text {can }}$ for rice at air temperatures of 25 to 37C (Baker and Allen, 1993) and for soybean at 28 to 35C (Jones et al., 1985a). The present model assumes that leaf temperature is equal to air temperature. When the model is used with canopy energy balance and stomatal sensitivity to $\mathrm{CO}_{2}$ and foliage temperature is predicted (Pickering et al., 1990, 1995), the optimum air temperature range becomes even broader because leaf temperature tends to be above air temperature if air temperature is low, and leaf temperature tends to be below air if air temperature is high.

\section{Leaf and canopy photosynthesis response to $\mathrm{CO}_{2}$}

Leaf response to $\mathrm{CO}_{2}$. Figure $8 \mathrm{~A}$ illustrates leaf photosynthesis response to $\mathrm{CO}_{2}$ for leaves at $10,20,30$, and $40 \mathrm{C}$, where the equations include the $\mathrm{CO}_{2}$ effect on electron transport as described above. Photosynthetic response to $\mathrm{CO}_{2}$ increases with temperature. These equations reproduce the well-known increase in $\mathrm{CO}_{2}$ compensation point as temperature increases.

Canopy response to $\mathrm{CO}_{2}$. The simulated $\mathrm{P}_{\text {can }}$ response to $\mathrm{CO}_{2}$ in Fig. $8 \mathrm{~B}$ shows that the response to $\mathrm{CO}_{2}$ depends on temperature and is limited at low temperature. The simulated $\mathrm{P}_{\text {can }}$ at $30 \mathrm{C}$ increased $35 \%$ as $\mathrm{CO}_{2}$ increased from 330 to $660 \mathrm{ppm}$. This compares to measured increases in $\mathrm{P}_{\text {can }}$ of $35 \%$ to $40 \%$ for rice (Baker et al., 1992, Boote et al., 1992 ) and $50 \%$ to $60 \%$ for soybean exposed to 660 vs. $330 \mathrm{ppm} \mathrm{CO}_{2}$ at 31C (Campbell et al., 1990). Jones et al. (1985b) observed that midday $\mathrm{P}_{\text {can }}$ of soybean measured at $800 \mathrm{ppm} \mathrm{CO}_{2}$ was $75 \%$ greater than the same canopy measured at $330 \mathrm{ppm} \mathrm{CO}_{2}$ (both at 31C). Predicted response for that comparison was a $42 \%$ increase. The predicted canopy responses to $\mathrm{CO}_{2}$ in these chambers appear to be somewhat less than those observed.
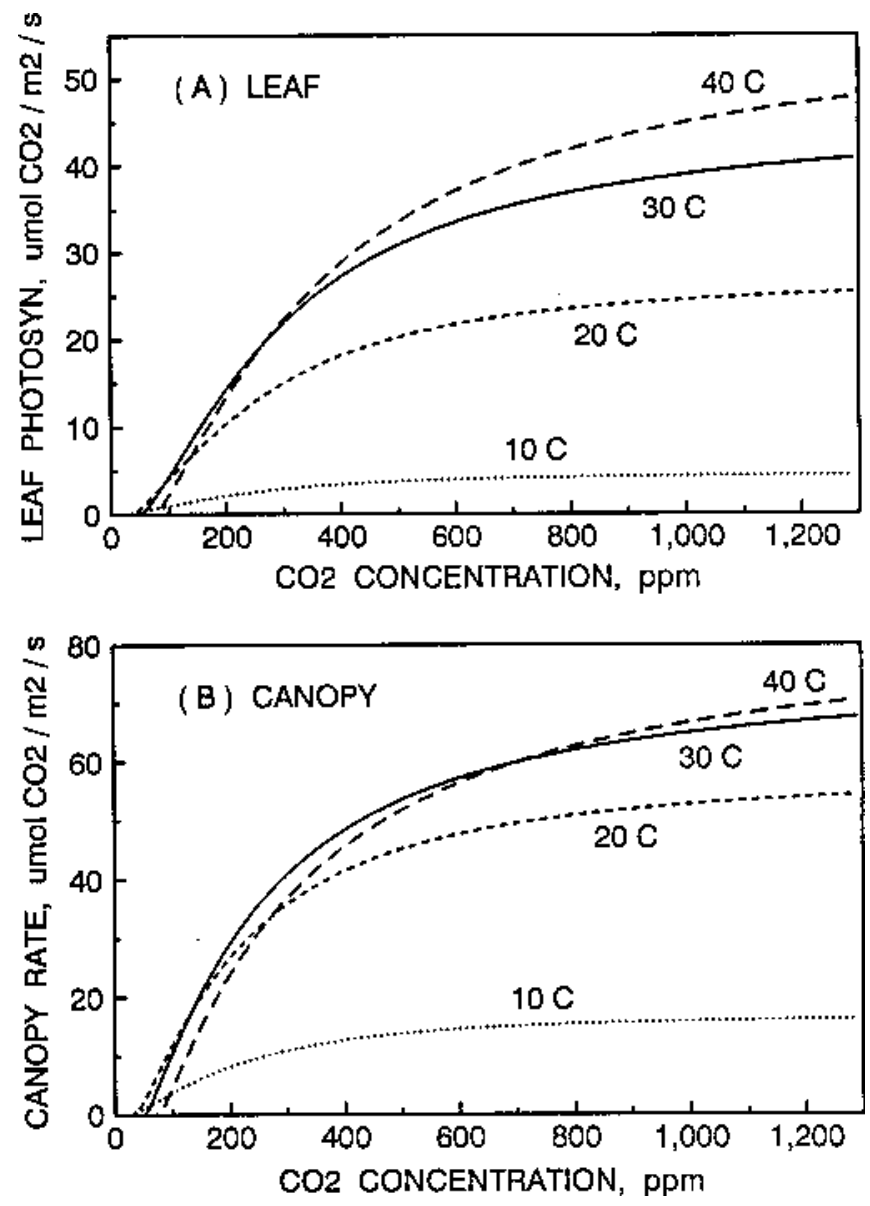

Fig. 8. (A) Leaf photosynthesis and (B) gross canopy assimilation response to $\mathrm{CO}_{2}$ at four temperatures. Response simulated for leaf area index $=5.0$, closed canopy, at a photon flux density of $1500 \mu \mathrm{mol} \cdot \mathrm{m}^{-2} \cdot \mathrm{s}^{-1}$, at solar noon on $1 \mathrm{July}$ at lat. $30^{\circ} \mathrm{N}$, assuming fraction diffuse of 0.49 . Light-saturated photosynthesis rate $\left(\mathrm{P}_{\max }\right)=26 \mu \mathrm{mol} \mathrm{CO} / \mathrm{m}^{2}$ per sec at $350 \mathrm{ppm} \mathrm{CO}$ and $30 \mathrm{C}$. 


\section{$P_{\max }$ as influenced by leaf $\mathbf{N}$ status and growth environment}

Under normal conditions, $\mathrm{P}_{\max }, \mathrm{J}_{\max }$, and maximum RuBP carboxylase activity $\left(\mathrm{V}_{\mathrm{cmax}}\right)$ on a leaf-area basis are reasonably well correlated to each other and are proportional to $\mathrm{N}$ concentration, $\mathrm{N}$ content per unit area, chlorophyll concentration, and leaf thickness (Field, 1983; Harley et al., 1992; Seemann et al., 1987). Evans and Farquhar (1991) proposed that $\mathrm{J}_{\max }$ and $\mathrm{P}_{\max }$ are proportional to the chlorophyll and $\mathrm{N}$ content per unit leaf area because these variables reflect the amount of photosynthetic apparatus per unit leaf area. Also, within a species, the amount of rubisco per unit leaf area is proportional to the amount of leaf $N$ per unit leaf area. Sinclair and Horie (1989) proposed that $\mathrm{P}_{\max }$ strongly depends on specific leaf N content (SLN).

Effects of growth environment (climate, nutrition, and $\mathrm{CO}_{2}$ ) are expressed at the morphological and biochemical level, e.g., SLW, N concentration of leaf tissue, and the amount of chlorophyll, thylakoid membranes, and rubisco per unit leaf area. Second-order environmental effects also occur. The portion of $\mathrm{N}$ in rubisco decreased under $\mathrm{N}$ deficiency and as irradiance declined (Seemann et al., 1987). Decline in total $\mathrm{N}$ per unit leaf mass and decline in rubisco per unit leaf area have been reported in response to increasing $\mathrm{CO}_{2}$ (Harley et al., 1992; Rowland-Bamford et al., 1991). Furthermore, Harley et al. (1992) observed a decline in the ratio of protein allocated to rubisco as $\mathrm{CO}_{2}$ increased.

In our modeling approach, $\mathrm{P}_{\max }$ (at standard $30 \mathrm{C}, 350 \mathrm{ppm} \mathrm{CO}_{2}$, and optimum $\mathrm{N}$ concentration) is allowed to be a linear function of SLW, based on the data of Dornhoff and Shibles (1970), adjusted to $350 \mathrm{ppm}$ $\mathrm{CO}_{2}$, and assuming a zero intercept (zero $\mathrm{P}_{\max }$ at zero SLW, and a $\mathrm{CO}_{2}$ uptake slope of $0.65 \mu \mathrm{mol} \cdot \mathrm{m}^{-2} \cdot \mathrm{s}^{-1}$ per gram leaf mass). $\mathrm{P}_{\max }$ is reduced

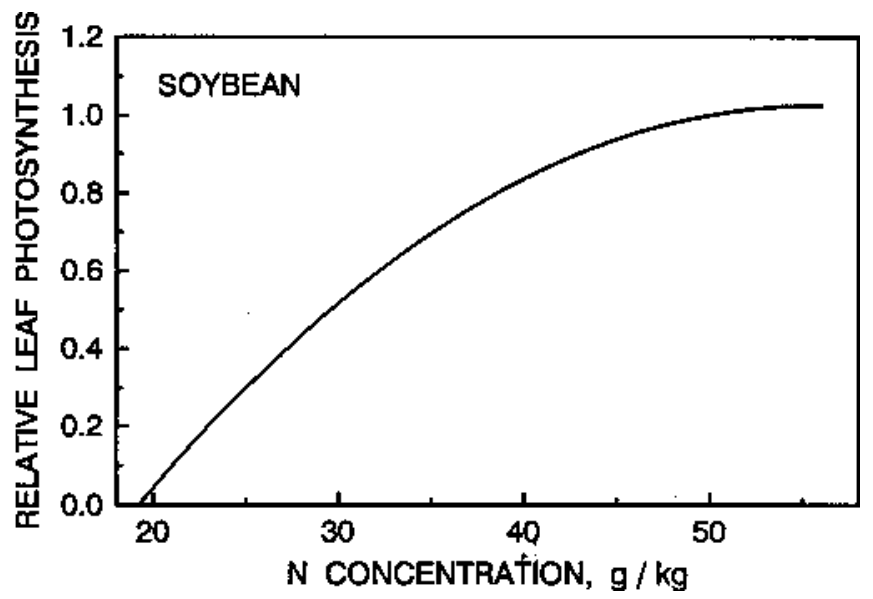

Fig. 9. Relative light-saturated photosynthesis rate $\left(\mathrm{P}_{\max }\right)$ response to leaf $\mathrm{N}$ concentration. if $\mathrm{N}$ concentration is not at optimum concentration (Fig. 9) (K.J. Boote, unpublished data).

\section{Variation in $P_{\max }$, SLW, and $N$ concentration with LAI depth}

SLW and leaf N concentration vary with depth in the crop canopy and, in turn, influence $\mathrm{P}_{\max }$ variation with depth in the canopy. Modeling vertical distribution in leaf photosynthetic characteristics is important for canopy assimilation models (Reynolds et al., 1992). Optimization analysis has shown higher $\mathrm{P}_{\text {can }}$ for closed crop canopies that have higher SLN (and $\mathrm{P}_{\max }$ ) for upper leaf layers at the cost of lower SLN and lower $\mathrm{P}_{\max }$ for lower leaf layers (Field, 1983; Hirose and Werger, 1987). Interestingly, crop canopies already tend toward an optimum distribution of SLN and SLW. Shiraiwa and Sinclair (1993) reported that SLN of soybean foliage declined linearly with increasing LAI depth, the slope ranging from 0.19 to 0.29 ( $\mathrm{g} \mathrm{N} / \mathrm{m}^{2}$ per unit LAI). Using a similar approach, we model decline in SLW and N concentration, each as linear functions of LAI depth. In our simulation examples, SLW declines $3.6 \mathrm{~g} \cdot \mathrm{m}^{-2}$ and $\mathrm{N}$ concentration declines $3.0 \mathrm{~g} \cdot \mathrm{kg}^{-1}$ per unit LAI depth increment. As a result of both features, we obtain variation in $\mathrm{P}_{\max }$ with LAI depth. For simulation purposes, standard light-saturated $\mathrm{P}_{\max }$ is defined at $30 \mathrm{C}$ and $350 \mathrm{ppm} \mathrm{CO}$ and at a defined SLW $\left(40 \mathrm{~g} \cdot \mathrm{m}^{-2}\right)$ and $\mathrm{N}$ concentration $\left(52 \mathrm{~g} \cdot \mathrm{kg}^{-1}\right)$ for soybean. These values are typical for upper soybean leaves and correspond to the calculated values for the upper third of the LAI of a soybean canopy $(\mathrm{LAI}=5.0)$ when average $\mathrm{SLW}=34 \mathrm{~g} \cdot \mathrm{m}^{-2}$, average $\mathrm{N}$ concentration $=$ $47 \mathrm{~g} \cdot \mathrm{kg}^{-1}$, and SLW and $\mathrm{N}$ decline with LAI depth as described above.

For the subsequent simulation examples, the input $\mathrm{P}_{\max }$ is assumed to apply to the upper one-third of the LAI, and $\mathrm{P}_{\max }$ of lower layers declines with LAI depth according to the functions described. In our crop model, canopy average SLW and N concentration are state variables and are used to compute SLW and N of the LAI layers. Layering SLW and N concentration increases $\mathrm{P}_{\text {can }}$ by $3 \%$ to $8 \%$ over an unlayered, uniform canopy that uses canopy average $\mathrm{P}_{\max }$, SLW, and $\mathrm{N}$ (Table 2). Researchers generally measure $\mathrm{P}_{\max }$ only for upper, sunlit leaves, which have greater SLW and higher N concentration than the canopy average. These upper leaves are the most relevant ones to measure because upper sunlit leaves receive most of the PFD and generate over half of the canopy $\mathrm{CO}_{2}$ assimilation. Using an input of $\mathrm{P}_{\max }$ for upper leaves and applying it to all LAI depths resulted in only a $1 \%$ to $4 \%$ overestimate of $P_{c a n}$. This result could be an argument that vertical gradient in $\mathrm{P}_{\max }$ is not really necessary, provided the input is upper-leaf $\mathrm{P}_{\max }$. Definitions of variables and abbreviations are provided in Table 3.

\section{Evaluating the hedgerow photosynthesis model}

Light interception and photosynthesis vs. time of day for closed and incomplete canopies. Crop canopies that are not closed are less able to respond to the high PFD at solar noon when the sun is directly

Table 2. Influence of vertical gradient in light-saturated photosynthesis rate $\left(\mathrm{P}_{\max }\right)$ upon canopy assimilation response to photon flux density $(\mathrm{PFD})$. The conditions are leaf area index $(\mathrm{LAI})=5.0$, canopy average specific leaf weight $(\mathrm{SLW})=34 \mathrm{~g} \cdot \mathrm{m}^{-2}$, and $\mathrm{N} \mathrm{concentration}=$ $47 \mathrm{~g} \cdot \mathrm{kg}^{-1}$. The gradients in SLW and $\mathrm{N}$ concentration are $3.6 \mathrm{~g} \cdot \mathrm{m}^{-2}$ and $3.0 \mathrm{~g} \cdot \mathrm{kg}^{-1}$ per unit LAI depth increment. For a three-layer canopy, $\mathrm{P}_{\max }$ of the upper one-third of LAI is $26 \mu \mathrm{mol} \mathrm{CO} \mathrm{Cm}^{2}$ per sec defined at SLW $=40 \mathrm{~g} \cdot \mathrm{m}^{-2}$ and N concentration $=52 \mathrm{~g} \cdot \mathrm{kg}^{-1}$. The comparison is made with canopies where all leaves are like upper leaves $\left(\mathrm{P}_{\max }=26\right)$ vs. canopies where all leaves are like average leaves $\left(\mathrm{P}_{\max }=21\right)$.

\begin{tabular}{|c|c|c|c|c|c|}
\hline \multirow[b]{2}{*}{$\begin{array}{l}\text { PFD } \\
\left(\mu \mathrm{mol} \cdot \mathrm{m}^{-2} \cdot \mathrm{s}^{-1}\right)\end{array}$} & \multicolumn{3}{|c|}{$\begin{array}{l}\text { Assimilation example } \\
\left(\mu \mathrm{mol} \mathrm{CO}_{2} / \mathrm{m}^{2} \text { per sec) }\right.\end{array}$} & \multirow{2}{*}{$\begin{array}{c}\text { Loss if } \\
\text { lower leaf } \\
\mathrm{P}_{\max }<\text { upper } \\
(\%)\end{array}$} & \multirow{2}{*}{$\begin{array}{c}\text { Benefit } \\
\text { from layering } \\
\text { vs. avg } \\
(\%)\end{array}$} \\
\hline & $\begin{array}{c}\text { All like } \\
\text { upper } \\
\left(\mathrm{P}_{\max }=26\right)\end{array}$ & $\begin{array}{c}\text { Layered } \\
\text { canopy } \\
\mathrm{f}(\mathrm{SLW}, \mathrm{N})\end{array}$ & $\begin{array}{c}\text { All like } \\
\text { avg } \\
\left(\mathrm{P}_{\max }=21\right)\end{array}$ & & \\
\hline \multicolumn{6}{|c|}{0.245 fraction diffuse } \\
\hline 500 & 20.1 & 19.8 & 19.2 & 1.4 & 3.2 \\
\hline 1000 & 33.3 & 32.5 & 30.8 & 2.5 & 5.5 \\
\hline 1500 & 42.5 & 41.1 & 38.4 & 3.2 & 7.0 \\
\hline 2000 & 49.2 & 47.4 & 43.9 & 3.7 & 7.9 \\
\hline \multicolumn{6}{|c|}{0.490 fraction diffuse } \\
\hline 500 & 20.8 & 20.6 & 20.0 & 0.9 & 3.0 \\
\hline 1000 & 35.5 & 34.9 & 33.1 & 1.7 & 5.2 \\
\hline 1500 & 46.2 & 45.1 & 42.3 & 2.4 & 6.7 \\
\hline 2000 & 54.3 & 52.7 & 48.9 & 3.0 & 7.7 \\
\hline
\end{tabular}


overhead, and a fraction of the PFD is lost directly to the soil. Figures 10 and 11 illustrate how incomplete peanut canopies $(92-\mathrm{cm}$ row spacing) intercepted a smaller fraction of the PFD toward midday and tended to light-saturate at a lower PFD than the closed canopies (46$\mathrm{cm}$ row spacing). As the canopy grew wider and increased in LAI, a greater fraction of PFD was intercepted. The diurnal time course of percent light interception (Fig. 10, top) and $\mathrm{P}_{\text {can }}$ (Fig. 10, center) are reasonably predicted for the different times of day and treatments. Despite a constant number of plants per square meter in both row spacings, there were persistent row-spacing effects on light interception and $\mathrm{P}_{\text {can }}$ until the widely spaced crop canopy closed at or about 29 July (57 days after planting). The Spitters (1986) function for PFD distribution (Fig. 10, bottom) adequately describes actual PFD mea-
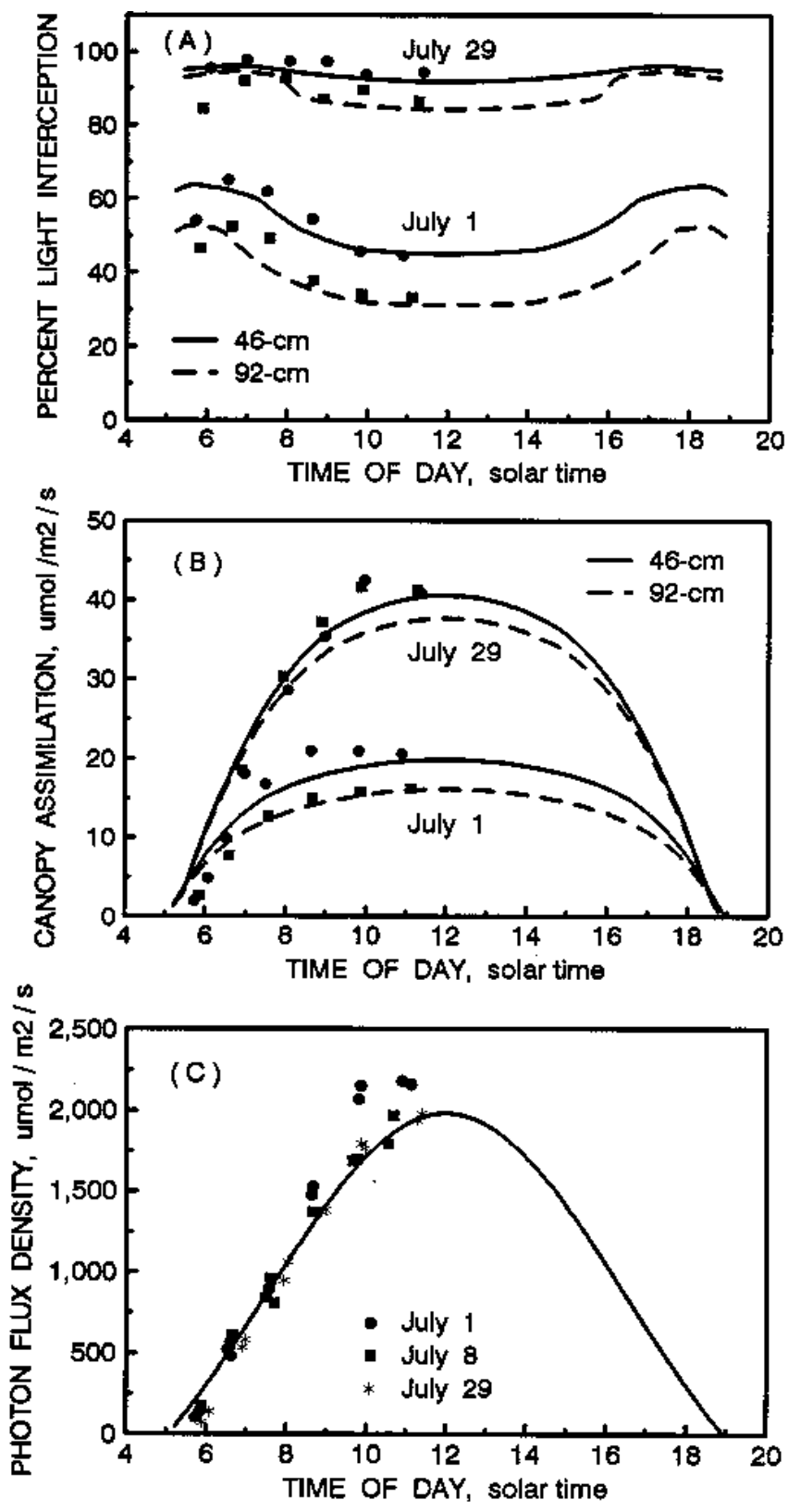

Fig. 10. (A) Light interception, (B) gross canopy assimilation, and (C) photon flux density (PFD) on 1 and 29 July 1987 for peanut canopies in 46- and $92-$ $\mathrm{cm}$ row spacing as the crop canopy closed. Canopy assimilation was simulated for actual experimental conditions [leaf area index, canopy width and height, and light-saturated photosynthesis rate $\left(\mathrm{P}_{\max }\right)$ measured on sunlit leaves], but using instantaneous PFD from the Spitters function, given a PFD of $58 \mathrm{~mol} \cdot \mathrm{day}^{-1}$ as input. Solid line for modeled PFD (bottom) is for 1 July. Points represent observed light interception, gross canopy assimilation $\left(\mathrm{P}_{\text {can }}\right)$, and PFD. surements, although it is a bit high near dawn or sunset and a bit low at midday. The alternative full-sine function of Charles-Edwards and Acock (1977) would underpredict near dawn and overpredict at midday. Because $\mathrm{P}_{\text {can }}$ and PFD point measurements were manually taken only for clear sunny conditions, the points are compared to a line predicted for a clear day in July with high daily PFD $\left(58 \mathrm{~mol} \cdot \mathrm{m}^{-2}\right)$ and minimum cloud cover.

Assimilation response to PFD at various degrees of canopy closure. Data for the above measurement dates are plotted in Fig. 11 as $\mathrm{P}_{\text {can }}$ vs. PFD. As expected, the incomplete canopies on 1 July were less able to respond to high PFD, whereas the closed canopies on 29 July increased $\mathrm{P}_{\text {can }}$ to the highest $\mathrm{PFD}$ value. The early season row spacing effects on $\mathrm{P}_{\text {can }}$ nearly disappeared with canopy closure. These results show that the hedgerow model will successfully predict canopy assimilation response to PFD for different row spacings, canopy widths, LAIs, times of day, and temperatures, based on only one input ( $\mathrm{P}_{\max }$ measured on upper leaves). We conclude that $\mathrm{P}_{\text {can }}$ can be predicted from single-leaf $\mathrm{P}_{\max }$. Actually, measured peanut $\mathrm{P}_{\max }$ was quite repeatable over seven successive dates in this study and over much of the season in data of Bennett et al. (1993), thus one $\mathrm{P}_{\max }$ value could have been used with only a small loss in accuracy.

Daily assimilation response to LAI at various degrees of canopy closure. Figure 12 illustrates the importance of degree of canopy closure on daily assimilation. With $80 \%$ apparent ground cover [width : row spacing $(\mathrm{W}: \mathrm{R})=0.8$ ], there is only a small reduction $(4.2 \%)$ in $\mathrm{P}_{\text {can }}$ even at high LAI. With progressively smaller canopy width (ratio

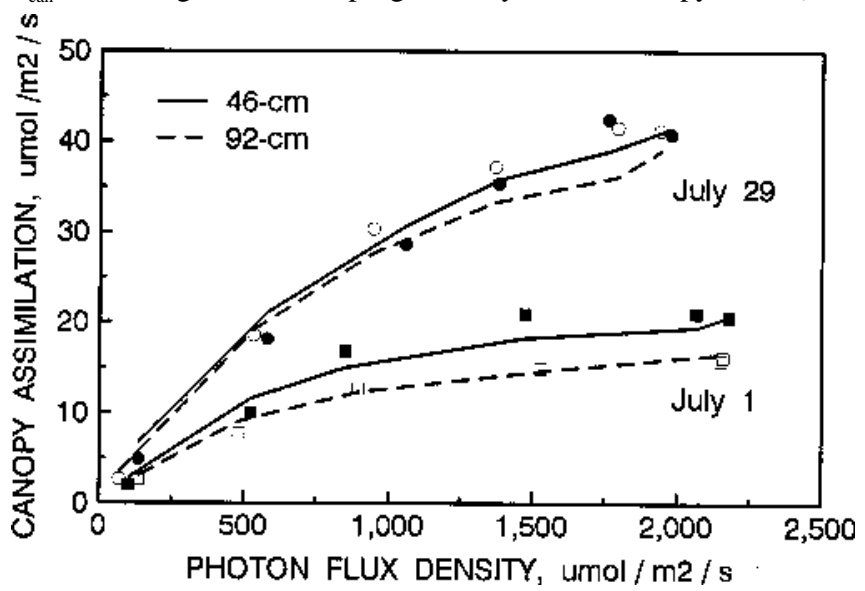

Fig. 11. Gross canopy assimilation $\left(\mathrm{P}_{\text {can }}\right)$ response to photon flux density (PFD) on 1 and 29 July 1987 for peanut in 46- and $92-\mathrm{cm}$ row spacings. $P_{\text {can }}$ was simulated for actual experimental conditions [leaf area index, canopy width and height, time of day, instantaneous PFD, and light-saturated photosynthesis rate $\left(\mathrm{P}_{\max }\right)$ measured on sunlit leaves].

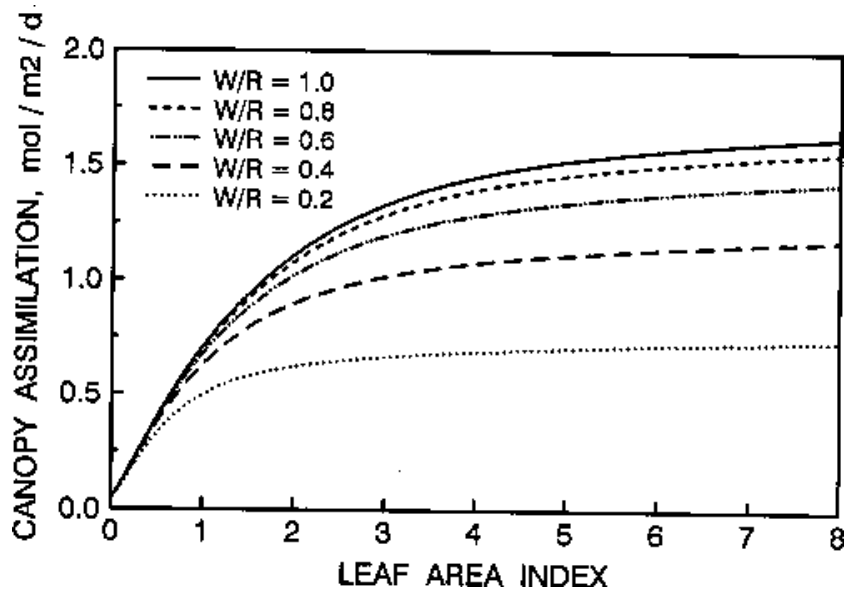

Fig. 12. Daily canopy assimilation vs. leaf area index at five degrees of canopy closure $\left(\mathrm{W} / \mathrm{R}=\right.$ canopy width/row spacing). Simulated at $30 \mathrm{C}, \mathrm{CO}_{2}=350$ ppm, light-saturated photosynthesis rate $\left(\mathrm{P}_{\max }\right)=26 \mu \mathrm{mol} \mathrm{CO} \mathrm{C}_{2} / \mathrm{m}^{2}$ per sec, photon flux density $=45 \mathrm{~mol} \cdot \mathrm{m}^{-2} \cdot \mathrm{day}^{-1}$, in east-west rows, at lat. $30^{\circ} \mathrm{N}$, on 1 July. 
Table 3. Definition of variables, symbols, and abbreviations used. Fluxes and rates are per square meter of land area, unless clearly stated as per unit leaf area.

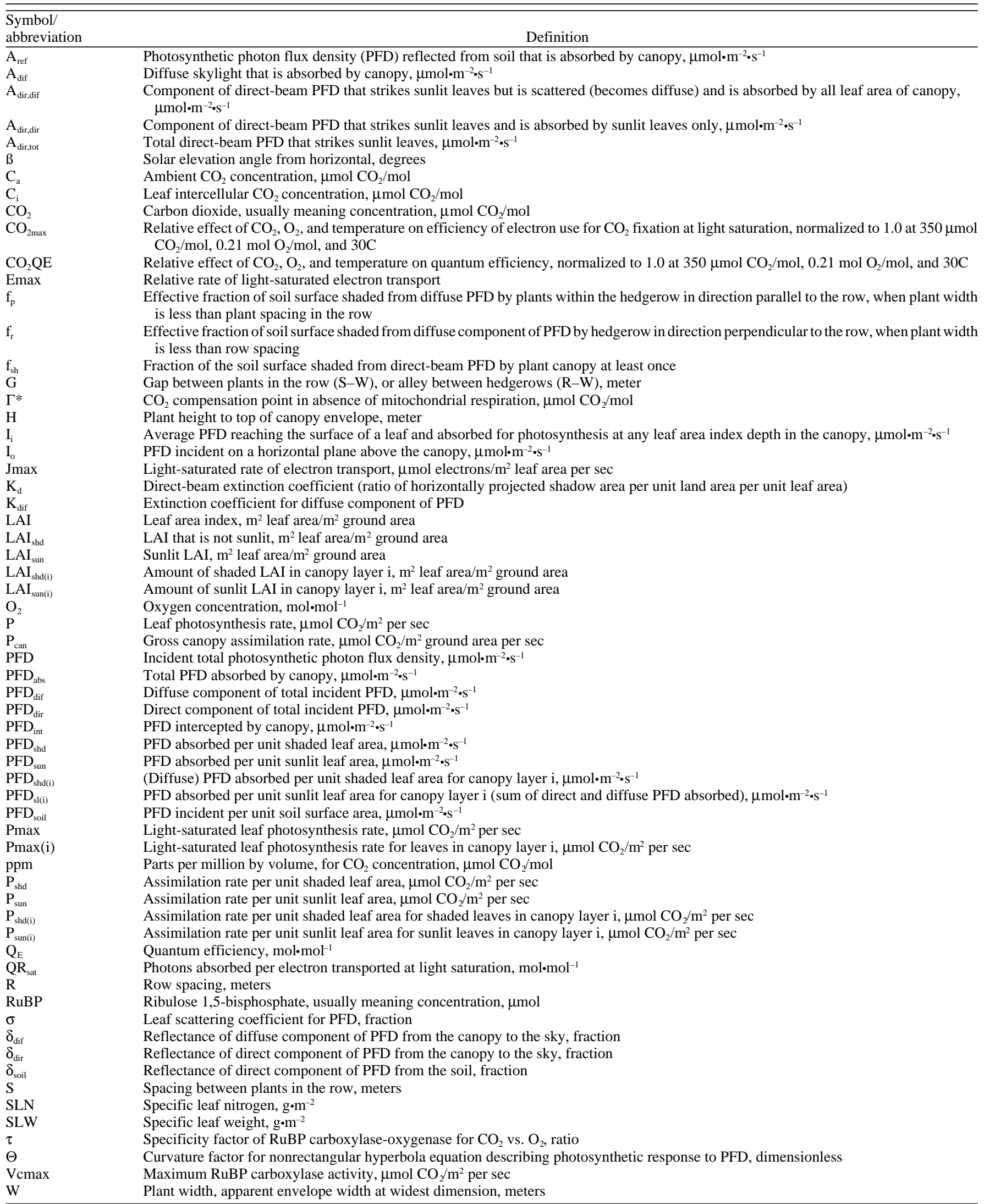

from 0.8 to 0.2$), \mathrm{P}_{\text {can }}$ is progressively reduced. A nonhedgerow model would follow the line for $\mathrm{W}: \mathrm{R}=1.0$ and would be in error by the difference between that line and the line for the given $\mathrm{W}: \mathrm{R}$ ratio. Figure 12 probably gives an overly optimistic impression of photosynthesis at incomplete cover, because it assumes that hedgerows with low $\mathrm{W}: \mathrm{R}$ ratio can achieve the same land-area LAI as a closed canopy.
The latter is not likely; thus, the reduction in $\mathrm{P}_{\mathrm{can}}$ will be somewhat more than represented in Fig. 12.

Response to row spacing. Figure 13 illustrates response of daily assimilation to variation in row spacing while holding a constant LAI (solid line) or leaf area (LA) per unit of canopy width (long dash line). In conjunction with the crop model, the hedgerow photosynthesis 


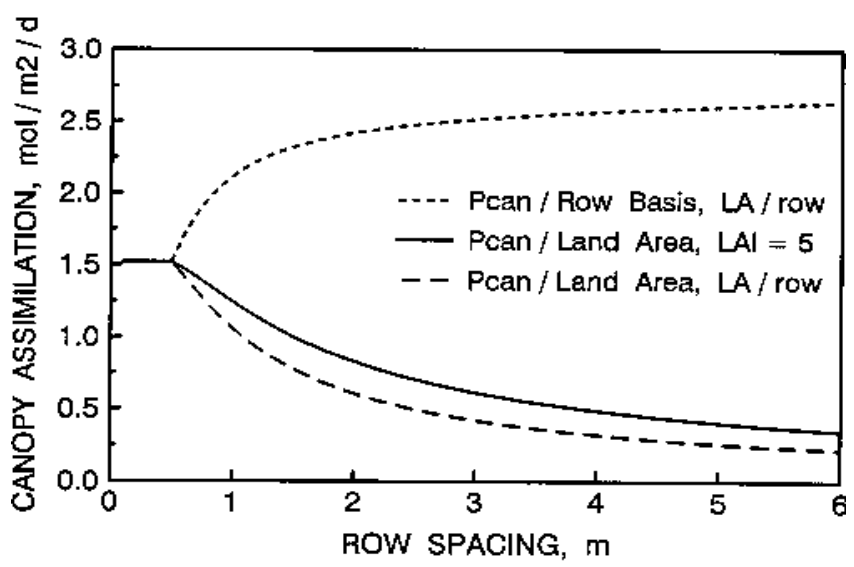

Fig. 13. Daily canopy assimilation vs. row spacing for a crop canopy $0.5 \mathrm{~m}$ tall and $0.5 \mathrm{~m}$ wide. Gross canopy assimilation $\left(\mathrm{P}_{\text {can }}\right)$ is expressed 1 ) per unit of canopy width (per row basis) for constant LAI of 5 per unit canopy width (------), 2) on a land-area basis with constant land-area-based leaf area index (LAI) of 5 ( - , or 3 ) on land-area basis with constant LAI of 5 per unit canopy width (- - - ). Simulated under same conditions as Fig. 12.

approach creates a somewhat more gradual decline in yield at the row spacing, where the canopy just begins to close. The curve labeled "PG / row basis" is the $\mathrm{P}_{\text {can }}$ per row where the LA is held constant at 5 per unit of canopy width. Constant LA per unit canopy width is probably the more realistic example, because the situation of a constant land-area LAI of 5 in a 5-m spacing would, for example, force a LA of 50 within the canopy envelope of $0.5 \mathrm{~m}$. The upper line of Fig. 13 also illustrates the maximum $\mathrm{P}_{\text {can }}$ possible for a $0.5-\mathrm{m}$-tall $\times 0.5-\mathrm{m}$ wide canopy with no competition. In this case, lack of a border or competition effects increased $\mathrm{P}_{\text {can }}$ by $77 \%$.

\section{SUMMARY OF HEDGEROW MODEL FEATURES}

The proposed hedgerow canopy photosynthesis approach offers the needed ability to model assimilation of incomplete canopies, yet allows use of leaf-level photosynthesis equations that mimic rubisco kinetics. Predicted leaf and $\mathrm{P}_{\text {can }}$ responses to $\mathrm{CO}_{2}$ were reasonable, but predicted response at subambient $\mathrm{CO}_{2}$ was improved by allowing electron transport to be limited as a function of $\mathrm{C}_{\mathrm{i}}$. Single-leaf $\mathrm{P}_{\max } / \mathrm{J}_{\max }$ was modeled as a linear function of SLW and as a quadratic function of leaf $\mathrm{N}$ concentration. As expected, predicted canopy assimilation response to PFD was limited by incomplete canopies, even at high land-area-based LAI. Canopy assimilation, parameterized for soybean at $350 \mathrm{ppm} \mathrm{CO}_{2}$, showed a broad temperature optimum between 25 and $37 \mathrm{C}$, even though leaf $\mathrm{P}_{\max }$ has a more pronounced peak between 32 to $40 \mathrm{C}$.

The sunlit and shaded LAI photosynthesis approach appears to be adaptable to the hedgerow model, provided diffuse-light absorption is handled in a multilayered manner. The sunlit and shaded LAI approach is simpler and less demanding of computer time than the mechanistic hedgerow photosynthesis model of Gijzen and Goudriaan (1989), which uses a ray-tracing approach and LAI layering. We conclude that canopy assimilation models must have layering for diffuse PFD absorption and must have sunlit and shaded leaf classes. Stockle (1992) and Reynolds et al. (1992) compared multilayered canopy photosynthesis models to a single-layer model and proposed that, in many instances, a single-layer model divided into sunlit and shaded LAI fractions yielded reasonable results with $<5 \%$ error. Their results support the sunlit and shaded LAI approach we have taken. Reynolds et al. (1992) confirmed the importance of including leaf energy balance and distinguishing between sunlit and shaded leaves. They provided evidence that a multilayered approach is best. We agree with this need, particularly for diffuse-light absorption. We conclude that the problem with the single-layer models is primarily related to diffuse-light absorption. We also agree with Reynolds et al. (1992) that leaf energy balance is needed. Including an energy balance actually makes the predicted air temperature optimum for photosynthesis even broader in most cases.
Application to horticultural crops. Horticultural commodities are probably grown more often in hedgerow or limited plant spacing than field crops. There are a number of application examples for using such a hedgerow photosynthesis model: 1) predicting optimum spacing for fruit and nut tree crops; 2) predicting yield effects of various hedgerow arrangements for trellised vineyards, staked tomatoes, or dwarfed dense hedgerow apples; 3 ) evaluating productivity of sweet corn (Zea mays L.), beans, and potatoes (Solanum tuberosum L.) grown in rows; and 4) evaluating productivity of single plants in response to various spacings in the field and greenhouse.

\section{Literature Cited}

Acock, B., D.A. Charles-Edwards, D.J. Fitter, D.W. Hand, L.J. Ludwig, J. Warren Wilson, and A.C. Withers. 1978. The contribution of leaves from different levels within a tomato crop to canopy net photosynthesis: An experimental examination of two canopy models. J. Expt. Bot. 29:815-827.

Allen, Jr., L.H. 1974. Model of light penetration into a wide-row crop. Agron. J. 66:41-47.

Baker, J.T. and L.H. Allen, Jr. 1993. Effects of $\mathrm{CO}_{2}$ and temperature on rice: A summary of five growing seasons. J. Agr. Meteorol. 48:575-582.

Baker, J.T., L.H. Allen, Jr., and K.J. Boote. 1992. Response of rice to $\mathrm{CO}_{2}$ and temperature. Agr. For. Meteorol. 60:153-166.

Bennett, J.M., T.R. Sinclair, L. Ma, and K.J. Boote. 1993. Single leaf carbon exchange and canopy radiation use efficiency of four peanut cultivars. Peanut Sci. 20:1-5.

Boote, K.J., G. Bourgeois, and J. Goudriaan. 1988. Light interception and photosynthesis of incomplete hedgerow canopies of soybean and peanut. 1988 Agron. Abstr. p. 105.

Boote, K.J. and J.W. Jones. 1987. Equations to define canopy photosynthesis from quantum efficiency, maximum leaf rate, light extinction, leaf area index, and photon flux density, p. 415-418. In: J. Biggins (ed.). Progress in photosynthesis research. vol. 4. Martinus Nijhoff Publ., The Netherlands.

Boote, K.J, J.W. Jones, and G. Hoogenboom. 1989. Simulating crop growth and photosynthesis response to row spacing. 1989 Agron. Abstr. p. 11.

Boote, K.J. and R.S. Loomis. 1991. The prediction of canopy assimilation, p. 109-140. In: K.J. Boote and R.S. Loomis (eds.). Modeling crop photosynthesis-From biochemistry to canopy. Crop Sci. Soc. Amer. Spec. Publ. 19. Amer. Soc. Agron., Madison, Wis.

Boote, K.J., N. Pickering, J.T. Baker, and L.H. Allen. 1992. Predicting canopy assimilation of rice in response to carbon dioxide concentration and temperature, p. 831-834. In: N. Murata (ed.). Research in photosynthesis. vol. 4. Kluwer Academic Publishers, Dordrecht, The Netherlands.

Brooks, A. and G.D. Farquhar. 1985. Effect of temperature on the $\mathrm{CO}_{2} / \mathrm{O}_{2}$ specificity of ribulose-1,5-bisphosphate carboxylase/oxygenase and the rate of respiration in the light. Estimates from gas-exchange measurements on spinach. Planta 165:397-406.

Campbell, G.S. and J.M. Norman. 1989. The description and measurement of plant canopy structure, p. 1-19. In: G. Russell, B. Marshall, and P.G. Jarvis (eds.). Plant canopies: Their growth, form and function. Cambridge Univ. Press, England.

Campbell, W.J., L.H. Allen, Jr., and G. Bowes. 1990. Response of soybean canopy photosynthesis to $\mathrm{CO}_{2}$ concentration, light, and temperature. J. Expt. Bot. 41:427-433.

Charles-Edwards, D.A. 1981. The mathematics of photosynthesis and productivity. Academic, London.

Charles-Edwards, D.A. and B. Acock. 1977. Growth response of a Chrysanthemum crop to the environment. II. A mathematical analysis relating photosynthesis and growth. Ann. Bot. 41:49-58.

Denison, R.F. and R.S. Loomis. 1989. An integrative physiological model of alfalfa growth and development. Bul. Div. Agr. Natural Resources, Univ. of California, Oakland.

de Wit, C.T. 1965. Photosynthesis of leaf canopies. Agr. Res. Rpt. 663. PUDOC, Wageningen, The Netherlands.

Dornhoff, G.M. and R.M. Shibles. 1970. Varietal differences in net photosynthesis of soybean leaves. Crop Sci. 10:42-45.

Duncan, W.G., R.S. Loomis, W.A. Williams, and R. Hanau. 1967. A model for simulating photosynthesis in plant communities. Hilgardia 38:181-205.

Ehleringer, J. and O. Björkman. 1977. Quantum yields for $\mathrm{CO}_{2}$ uptake in $\mathrm{C}_{3}$ and $\mathrm{C}_{4}$ plants: Dependence on temperature, $\left[\mathrm{CO}_{2}\right]$, and $\left[\mathrm{O}_{2}\right]$ concentration. Plant Physiol. 59:86-90.

Ehleringer, J. and R.W. Pearcy. 1983. Variation in quantum yield for $\mathrm{CO}_{2}$ uptake among $\mathrm{C}_{3}$ and $\mathrm{C}_{4}$ plants. Plant Physiol. 73:555-559.

Erbs, D.G., S.A. Klein, and J.A. Duffie. 1982. Estimation of the diffuse 
radiation fraction for hourly, daily and monthly-average global radiation. Solar Energy 28:293-302.

Evans, J.R. and G.D. Farquhar. 1991. Modeling canopy photosynthesis from the biochemistry of the $\mathrm{C}_{3}$ chloroplast, p. 1-15. In: K.J. Boote and R.S. Loomis (eds.). Modeling crop photosynthesis-From biochemistry to canopy. Crop Sci. Soc. Amer. Spec. Publ. 19. Amer. Soc. Agron., Madison, Wis.

Farquhar, G.D. and S. von Caemmerer. 1982. Modelling of photosynthetic response to environment, p. 549-587. In: O.L. Lange, P.S. Nobel, C.B. Osmond, and H. Ziegler (eds.). Encyclopedia of plant physiology. new series. vol. 12B. Physiological plant ecology II. Springer-Verlag, Berlin.

Farquhar, G.D., S. von Caemmerer, and J.A. Berry. 1980. A biochemical model of photosynthetic $\mathrm{CO}_{2}$ assimilation in leaves of $\mathrm{C}_{3}$ species. Planta 149:7890.

Field, C. 1983. Allocating leaf nitrogen for the maximization of carbon gain: Leaf age as a control on the allocation program. Oecologia (Berlin) 56:341347.

Gijzen, H. and J. Goudriaan. 1989. A flexible and explanatory model of light distribution and photosynthesis in row crops. Agr. For. Meteorol. 48:1-20.

Goudriaan, J. 1977. Crop micrometeorology: A simulation study. Centre for Agricultural Publishing and Documentation, Wageningen, The Netherlands.

Goudriaan, J. 1982. Potential production processes, p. 98-113. In: F.W.T. Penning de Vries and H.H. van Laar (eds.). Simulation of plant growth and crop production. Centre for Agricultural Publishing and Documentation, Wageningen, The Netherlands.

Goudriaan, J. 1986. A simple and fast numerical method for the computation of daily totals of crop photosynthesis. Agr. For. Meteorol. 38:249-254.

Goudriaan, J. 1988. The bare bones of leaf-angle distribution in radiation models for canopy photosynthesis and energy exchange. Agr. For. Meteorol. 43:155-169.

Harley, P.C. and J.D. Tenhunen. 1991. Modeling the photosynthetic response of $\mathrm{C}_{3}$ leaves to environmental factors, p. 17-39. In: K.J. Boote and R.S. Loomis (eds.). Modeling crop photosynthesis-From biochemistry to canopy. Crop Sci. Soc. Amer. Spec. Publ. 19. Amer. Soc. Agron., Madison, Wis.

Harley, P.C., R.B. Thomas, J.F. Reynolds, and B.R. Strain. 1992. Modelling photosynthesis of cotton grown in elevated $\mathrm{CO}_{2}$. Plant Cell Environ. 15:271-282.

Harley, P.C., J.A. Weber, and D.M. Gates. 1985. Interactive effects of light, leaf temperature, $\left[\mathrm{CO}_{2}\right]$ and $\left[\mathrm{O}_{2}\right]$ on photosynthesis in soybean. Planta 165:249263.

Hirose, T. and M.J.A. Werger. 1987. Maximizing daily canopy photosynthesis with respect to the leaf nitrogen allocation pattern in the canopy. Oecologia (Berlin) 72:520-526.

Hoogenboom, G., J.W. Jones, and K.J. Boote. 1992. Modeling growth, development, and yield of grain legumes using SOYGRO, PNUTGRO, and BEANGRO: A review. Trans. Amer. Soc. Agr. Eng. 35:2043-2056.

Johnson, I.R. and J.H.M. Thornley. 1984. A model of instantaneous and daily canopy photosynthesis. J. Theoretical Biol. 107:531-545.

Jones, P., L.H. Allen, Jr., and J.W. Jones. 1985a. Responses of soybean canopy photosynthesis and transpiration to whole-day temperature changes in different $\mathrm{CO}_{2}$ environments. Agron. J. 77:242-249.

Jones, P., L.H. Allen, Jr., J.W. Jones, and R. Valle. 1985b. Photosynthesis and transpiration responses of soybean canopies to short- and long-term $\mathrm{CO}_{2}$ treatments. Agron. J. 77:119-126.

Jordan, D.B. and W.L. Ogren. 1984. The $\mathrm{CO}_{2} / \mathrm{O}_{2}$ specificity of ribulose $1,5-$ bisphosphate carboxylase/oxygenase. Dependence on ribulose-bisphosphate concentration, $\mathrm{pH}$, and temperature. Planta 161:308-313.

Kimball, B.A. and L.A. Bellamy. 1986. Generation of diurnal solar radiation, temperature, and humidity patterns. Energy Agr. 5:185-197.

Long, S.P. 1991. Modification of the response of photosynthetic productivity to rising temperature by atmospheric $\mathrm{CO}_{2}$ concentrations: Has its importance been underestimated? Plant Cell Environ. 14:729-739.

Loomis, R.S. and W.A. Williams. 1969. Productivity and the morphology of crop stands: Patterns with leaves, p. 27-51. In: J.D. Eastin, F.A. Haskins, C.Y. Sullivan, and C H.M. Van Bavel (eds.). Physiological aspects of crop yield. Amer. Soc. Agron., Madison, Wis.
Marshall, B. and P.V. Biscoe. 1980. A model for $\mathrm{C}_{3}$ leaves describing the dependence of net photosynthesis on irradiance. J. Expt. Bot. 31:29-39.

Monsi, M. and T. Saeki. 1953. Über den Lickhtfaktor in den Pflanzengesellschaften und seine Bedeutung für die Stoffproduktion. Jpn. J. Bot. 14:22-52.

Morison, J.I.L. 1987. Intercellular $\mathrm{CO}_{2}$ concentration and stomatal response to $\mathrm{CO}_{2}$, p. 229-251. In: E. Zeiger, G.D. Farquhar, and I.R. Cowan (eds.). Stomatal function. Stanford Univ. Press, Stanford, Calif.

Mutsaers, H.J.W. 1980. The effect of row orientation, date and latitude on light absorption by row crops. J. Agr. Sci. 95:381-386.

Norman, J.M. and T.J. Arkebauer. 1991. Predicting canopy photosynthesis and light-use efficiency from leaf characteristics, p. 75-94. In: K.J. Boote and R.S. Loomis (eds.). Modeling crop photosynthesis-From biochemistry to canopy. Crop Sci. Soc. Amer. Spec. Publ. 19. Amer. Soc. Agron., Madison, Wis.

Parton, W.J. and J.A. Logan. 1981. A model for diurnal variation in soil and air temperature. Agr. For. Meteorol. 23:205-216.

Peat, W.E. 1970. Relationships between photosynthesis and light intensity in the tomato. Ann. Bot. 34:319-328.

Pickering, N.B., J.W. Jones, and K.J. Boote. 1990. A moisture- and $\mathrm{CO}_{2-}$ sensitive model of evapotranspiration and photosynthesis. Paper 90-2519. Amer. Soc. Agr. Eng., St. Joseph, Mich.

Pickering, N.B., J.W. Jones, and K.J. Boote. 1995. Adapting SOYGRO V5.42 for prediction under climate change conditions. In: C. Rosenzweig, S. Hollinger, J. Jones, and L. Harper (eds.). Climate change in agriculture: Analysis of potential international impacts. Spec. Publ., Amer. Soc. Agron., Madison, Wis. (In press.)

Rastetter, E B., A.W. King, B.J. Cosby, G.M. Hornberger, R.V. O'Neill, and J.E. Hobbie. 1992. Aggregating fine-scale ecological knowledge to model coarser-scale attributes of ecosystems. Ecol. Applications 2:55-70.

Reynolds, J.F. and B. Acock. 1985. Modeling approaches for evaluating vegetation responses to carbon dioxide concentration, p. 33-51. In: B.R. Strain and J.D. Cure (eds.). Direct effects of increasing carbon dioxide on vegetation. U.S. Dept. of Energy, Carbon Dioxide Res. Div., DOE/ER0283, Washington, D.C.

Reynolds, J.F., J. Chen, P.C. Harley, D.W. Hilbert, R.L. Dougherty, and J.D. Tenhunen. 1992. Modeling the effects of elevated $\mathrm{CO}_{2}$ on plants: Extrapolating leaf response to a canopy. Agr. For. Meteorol. 61:69-94.

Ross, J. 1981. The radiation regime and architecture of plant stands. Tasks for vegetative sciences. no. 3. Dr. W. Junk, The Hague, The Netherlands.

Rowland-Bamford, A.J., J.T. Baker, L.H. Allen, Jr., and G. Bowes. 1991. Acclimation of rice to changing atmospheric carbon dioxide concentration. Plant Cell Environ. 14:577-583.

Seemann, J.R., T.D. Sharkey, J.L. Wang, and C.B. Osmond. 1987. Environmental effects on photosynthesis, nitrogen-use-efficiency, and metabolite pools in leaves of sun and shade plants. Plant Physiol. 84:796-802.

Sharkey, T.D., J.A. Berry, and R.F. Sage. 1988. Regulation of photosynthetic electron-transport in Phaseolus vulgaris L., as determined by room-temperature chlorophyll $a$ fluorescence. Planta 176:415-424.

Shiraiwa, T. and T.R. Sinclair. 1993. Distribution of nitrogen among leaves in soybean canopies. Crop Sci. 33:804-808.

Sinclair, T.R. and T. Horie. 1989. Leaf nitrogen, photosynthesis, and crop radiation use efficiency: A review. Crop Sci. 29:90-98.

Spitters, C.J.T. 1986. Separating the diffuse and direct component of global radiation and its implication for modeling canopy photosynthesis. Part II. Calculation of canopy photosynthesis. Agr. For. Meteorol. 38:231-242.

Spitters, C.J.T., H.A.J.M. Toussaint, and J. Goudriaan. 1986. Separating the diffuse and direct component of global radiation and its implications for modeling canopy photosynthesis. I. Components of incoming radiation. Agr. For. Meteorol. 38:217-229.

Stockle, C.O. 1992. Canopy photosynthesis and transpiration estimates using radiation interception models with different levels of detail. Ecol. Modelling 60:31-44.

Tenhunen, J.D., J.A. Weber, C.S. Yocum, and D.M. Gates. 1976. Development of a photosynthesis model with an emphasis on ecological applications. II. Analysis of a data set describing the $\mathrm{P}_{\mathrm{m}}$ surface. Oecologia 26:101-109.

Wagner, H.M. 1969. Principles of operations research. Prentice-Hall, Englewood Cliffs, N.J. 


\title{
A Supply and Demand Approach to Modeling Annual Reproductive and Vegetative Growth of Deciduous Fruit Trees
}

\author{
Theodore M. DeJong and Yaffa L. Grossman \\ Department of Pomology, University of California, Davis, CA 95616
}

An approach to developing a simulation model of the annual $\mathrm{C}$ supply and demand for reproductive and vegetative growth in peach trees is presented. This modeling approach simulates photosynthetic $\mathrm{C}$ assimilation using seasonal canopy light interception and daily minimum and maximum temperature and solar radiation inputs. Simulating $\mathrm{C}$ partitioning and crop growth is based on the hypothesis that plants grow as collections of semi-autonomous, but interacting, organs. The plant genotype, triggered by internal and environmental signals, determines current organ-specific growth potentials. Daily environmental conditions interact with organ-specific growth potentials to determine the conditional growth capacity and maintenance respiration requirement (i.e., the daily $\mathrm{C}$ demand) of each organ type. Then, the daily $\mathrm{C}$ available for growth after maintenance requirements are met is partitioned to leaves, fruit, stems, and branches based on their relative conditional growth capacities. Remaining carbohydrate is partitioned to the trunk, based on its conditional growth capacity, and all residual carbohydrate is partitioned to roots after aboveground demands are met. The methods used to determine organ-specific growth potentials and the usefulness of using the supply and demand approach to modeling the $\mathrm{C}$ economy of deciduous fruit crops are discussed.

The relatively intensive management requirements of perennial horticultural crops probably offer more opportunities for practical applications of computer simulation models of crop growth and carbohydrate requirements than less intensively managed annual or biennial agronomic crops. However, there has been much less research on models for perennial horticultural crops than for annual and

We gratefully acknowledge the staff of Kearney Agricultural Center for horticultural operations and field assistance. The description of the model was adapted from a $\mathrm{PhD}$ dissertation by Y.L.G. The cost of publishing this paper was defrayed in part by the payment of page charges. Under postal regulations, this paper therefore must be hereby marked advertisement solely to indicate this fact. biennial crop species because the traditional approaches used for annual row crops, such as sequential harvests of total plant biomass, present a monumental task for tree crops. Furthermore, the many management variables (such as scion cultivars, rootstock cultivars, tree spacing, location, pruning, and training) and the normal environmental variables (such as daily photon flux, temperature, water availability, and fertility) make the value of spending large amounts of time and energy to collect site-specific data for a model questionable.

However, deciduous tree crops offer certain advantages for developing functionally based simulation models that are useful for studying whole-plant $\mathrm{C}$ partitioning. Since deciduous tree crops such as peach (Prunus persica L. Batsch), plum (Prunus spp.), or apple (Malus spp.) begin the growing season with synchronized bloom, the crop load can be manipulated without stimulating further reproductive development such as subsequent bloom or increased seed number. Also, the indeterminate nature of these plants means that there is no preset normal growth or $\mathrm{C}$ partitioning pattern as there may be in rapidly developing annual plants such as cereals or grain legumes. These factors led to our development of a simulation model based on organ-specific growth potentials.

\section{Conceptual approach}

Our modeling approach is based on fundamental supply and demand principles. Carbohydrate is the basic currency of the model. For the first 150 degree-days ( 2 to 3 weeks with $7 \mathrm{C}$ minimum and $35 \mathrm{C}$ maximum thresholds) of the growing season, carbohydrate is assumed to come from storage. After that period, the daily carbohydrate supply is determined by a canopy photosynthesis submodel, SUCROS ' 86 (van Keulen et al., 1982, van Kraalingen and Spitters, 1986), that has been modified to account for the discontinuous canopy and leaf characteristics of peach orchards. The output of the C supply model is a daily estimate of the amount of carbohydrate available for structural and storage growth and maintenance of all organ types (Fig. 1).

\section{CARBON SUPPLY MODEL}

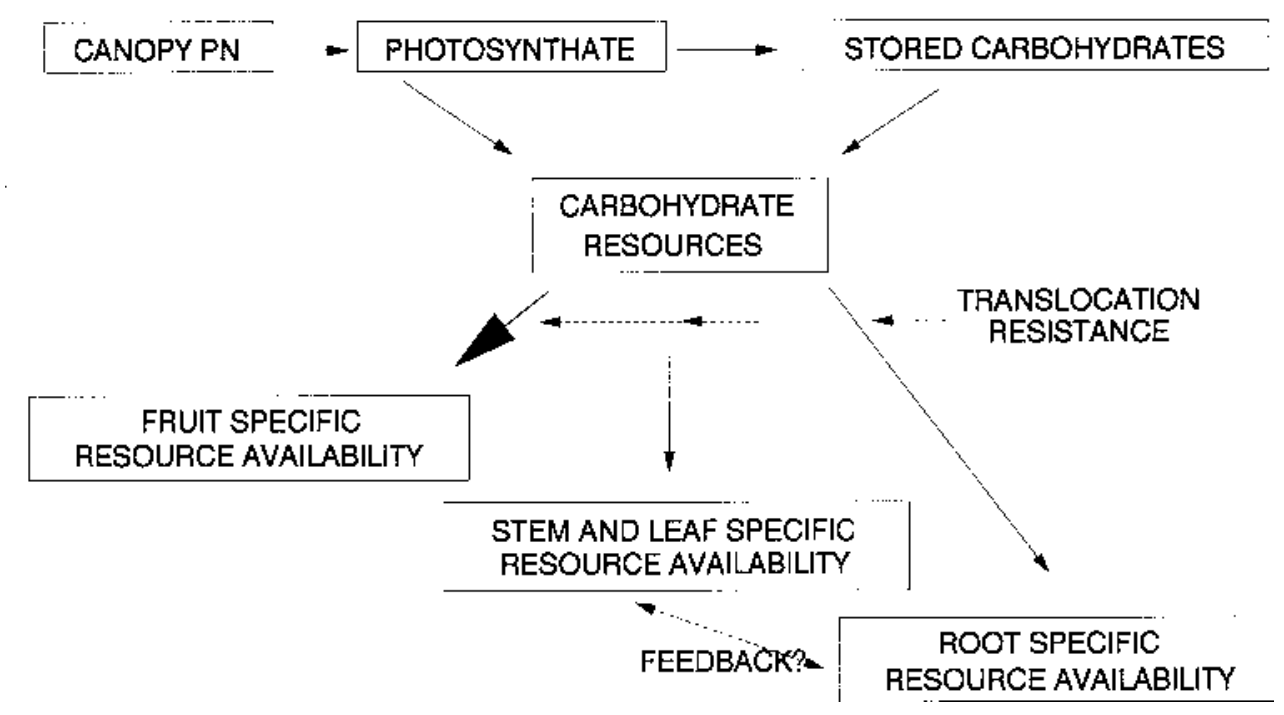

Fig. 1. A diagram of the $\mathrm{C}$ sources available to growing organs. The carbohydrate available for growth and maintenance of each organ type is determined by daily net photosynthesis, stored carbohydrate mobilization, translocation resistances between sources and sinks, and the relative competitive ability of the sinks for carbohydrates (DeJong and Grossman, 1992). 
Our approach to modeling carbohydrate use in deciduous tree crops is based on the observation that plant growth occurs in individual plant organs, including fruit, stems, leaves, and roots (Sprugel et al., 1991; Watson and Casper, 1984). With this approach, the daily carbohydrate demand is determined by the collective growth potentials of all individual growing organs on the tree. Observed carbohydrate partitioning is assumed to result from the dynamic equilibrium achieved by competition of individual sink organs for resources (Patrick, 1991) within constraints dictated by plant genotype, environmental thresholds, and ambient environmental conditions (Fig. 2). Competition between growing organs is mediated by the effect that growth has on resource availability and the relative ability of the translocation system to provide carbohydrates to the growing organs.

Although actual organ growth potentials are nearly impossible to determine experimentally, they can be estimated by measuring organ growth in response to crop load manipulation in species that may produce heavy crops naturally. In our work, we assume that measurements of individual fruit growth on trees that have had their initial crop load reduced by $\approx 90 \%$ are reasonable approximations of the potential fruit growth rate under the given environmental circumstances. Similarly, measurements of leaf, branch, and trunk growth of defruited trees are assumed to be adequate approximations of the growth potential of these organs relative to their growth potential with normal crop loads.

Respiration costs are dealt with in two ways. Maintenance respiration costs are assumed to have the highest priority for available $\mathrm{C}$ (Crapo and Ketellaper, 1981) and estimated maintenance respiration costs are met before any growth occurs. Growth respiration costs are calculated with dry-weight growth costs of the various organs.

\section{THE MODEL}

Carbohydrate supply. A diagram of the current version of the model is shown in Fig. 3, and details of the model and the computer program for the model are available in Grossman and DeJong (1994b). Daily $\mathrm{C}$ assimilation is calculated with a modified annual crop growth model, SUCROS '86 (Simple and Universal crop growth simulator) (van Keulen et al., 1982; van Kraalingen and Spitters, 1986), that explicitly simulates total daily canopy photosynthesis using Gaussian integration of the instantaneous leaf photosynthesis rate over canopy depth and diurnal light conditions (Goudriaan, 1986; Kropff et al., 1987).
The assimilation module of SUCROS ' 86 was modified to account for the discontinuous canopy in a peach orchard. The effective leaf area index during the day is adjusted using data on the daily pattern of light interception within peach orchards (DeJong and Goudriaan, 1989b). The light-saturated instantaneous photosynthetic rate is adjusted for the effect of air temperature (Y.L. Grossman, unpublished data), leaf age (DeJong and Doyle, 1984), and light exposure with canopy depth (DeJong and Doyle, 1985). Leaf area index is calculated from simulated leaf weight using an experimentally determined average specific leaf area (Y.L. Grossman, unpublished data).

Carbohydrate demand. The two components of carbohydrate demand, growth and respiration, are simulated daily. Maintenance respiration, the respiration associated with the upkeep of existing plant structures that is required for their persistence (Penning de Vries, 1975), is simulated explicitly. The carbohydrate requirement for growth is derived from the genetic potential for growth of each organ type, including the carbohydrate converted to dry matter and the respiratory cost of the conversion (Penning de Vries et al., 1974; Penning de Vries and van Laar, 1982).

Maintenance respiration cannot be experimentally separated from growth respiration on growing tissues. Several methods for distinguishing between maintenance and growth respiration have been developed (Amthor, 1989). In the mature-tissue method, maintenance respiration is estimated on a tissue that is no longer growing. In the regression method, the relationship between respiration rate and growth rate is measured, and respiration rate is extrapolated back to the point of no growth.

Leaf maintenance respiration rates were estimated from previously determined leaf-specific respiration rates using the mature-tissue method (Grossman and DeJong, 1994a). Stem, branch, and trunk maintenance respiration rates at $20 \mathrm{C}$ were estimated using the regression method:

$\mathrm{R}_{\mathrm{S}}=\mathrm{R}_{\mathrm{M}}+(\mathrm{G} * \mathrm{RGR})$

where $R_{S}$ is the specific respiration rate (grams of carbohydrate per gram dry weight per second), $R_{M}$ is the maintenance respiration rate (grams of carbohydrate per gram dry weight per second), $G$ is the growth respiration coefficient (grams of carbohydrate per gram dry weight), and RGR is the relative growth rate (grams dry weight per gram dry weight per second). $\mathrm{G}$ for peaches $(0.211 \mathrm{~g}$ carbohydrate $/ \mathrm{g}$ dry weight) was used in the calculation (DeJong and Goudriaan,

\section{SINK DEMAND MODEL}

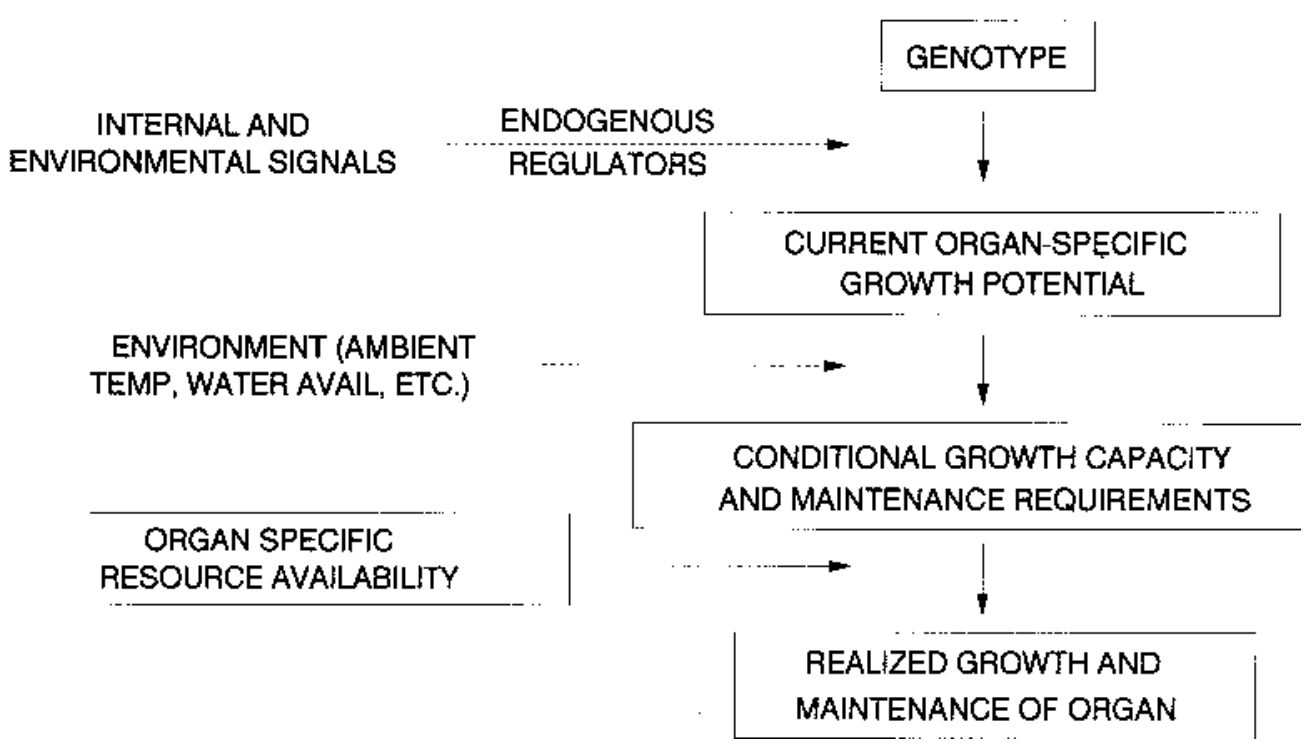

Fig. 2. A diagram of the potential and realized growth of an organ. Solid arrows indicate mechanisms, dotted arrows indicate information transfer (DeJong and Grossman, 1992). 


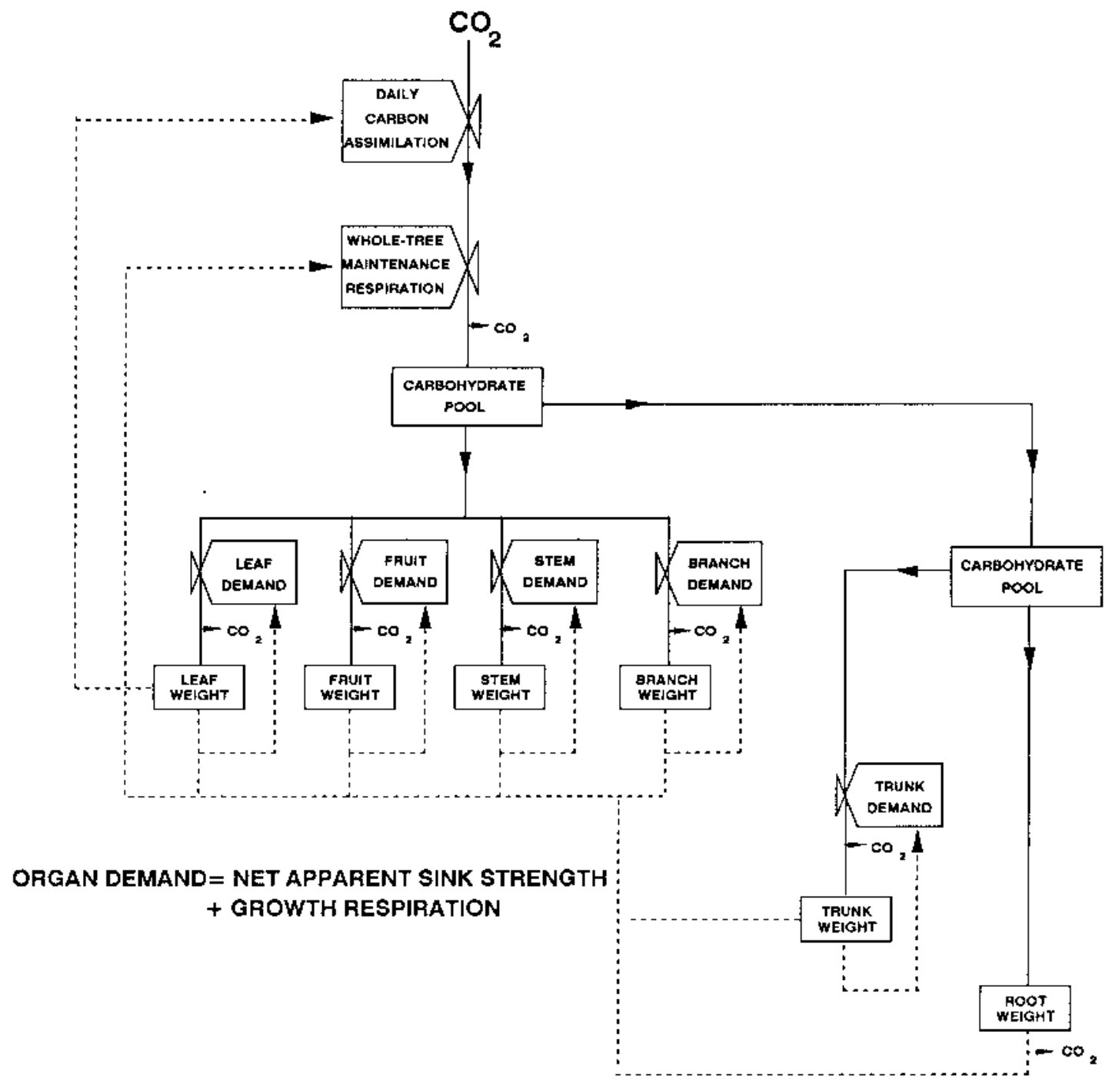

Fig. 3. Relational diagram illustrating $\mathrm{C}$ flow in the model. Boxes are state variables and valves are rate variables. Solid lines represent $\mathrm{C}$ flow and dashed lines represent information flow (Grossman and DeJong, 1994b).

1989a). Current-year stems, branches, and trunk specific respiration rates $\left(R_{S} s\right)$ and relative growth rates (RGRs) were obtained experimentally as previously described (Grossman, 1993; Grossman and DeJong,1994a). The fruit maintenance respiration rate was determined from DeJong and Goudriaan (1989a). The maintenance respiration rate for roots was set to the rate determined for branches of similar size.

Maintenance respiration is sensitive to temperature, approximately doubling when temperature increases from 20 to $30 \mathrm{C}$ (Grossman and DeJong, 1994a). For this reason, the model calculates temperature and maintenance respiration hourly. Hourly temperature is calculated from air and soil minimum and maximum temperatures assuming a sinusoidal temperature pattern during the day and an exponential temperature decline during the night (van Kraalingen and Rappoldt, 1987). The daily carbohydrate cost of maintenance respiration is determined as the sum of the products of the hourly respiration rates and the dry weights for each organ type.

The model determines daily potential net sink strength for each organ type from the seasonal patterns of organ growth potential (Grossman, 1993). The daily conditional net sink strength, reflecting the effect of temperature on growth, is determined from the potential net sink strength and the number of degree-days accumulated on each day. The carbohydrate cost of daily growth is calculated as the sum of the carbohydrate equivalent weight of the dry weight added by growth (sink strength) and the respiratory cost of that growth:
$\mathrm{C}_{\mathrm{G}}=\left(\mathrm{CE}_{\mathrm{DM}} * \mathrm{DM}\right)+(\mathrm{G} * \mathrm{DM})$

where $\mathrm{C}_{\mathrm{G}}$ is the carbohydrate cost of the dry matter added (grams of carbohydrate per day), $\mathrm{CE}_{\mathrm{DM}}$ is the carbohydrate content of the dry matter (grams of carbohydrate per gram dry weight), DM is the weight of the dry matter added (grams of dry weight per day), and G is the growth respiration coefficient (grams of carbohydrate per gram dry weight). The carbohydrate content of leaves, current-year stems, fruit, trunk, and roots was estimated from tissue $\mathrm{C}$ content measured by pyrolysis (Microanalytical Laboratory, Dept. of Chemistry, Univ. of California, Berkeley).

Carbohydrate partitioning. Carbohydrate partitioning is simulated daily. As it is generally accepted that an insufficient carbohydrate supply reduces growth before it reduces maintenance (Crapo and Ketellapper, 1981), the model supplies carbohydrate for maintenance respiration requirements before supplying carbohydrate for growth. The carbohydrate requirements for growth are satisfied based on the conditional net sink strengths of the growing organs and their proximity to the source. This approach is similar to that taken in modeling the growth of potatoes (Solanum tuberosum $\mathrm{L}$.) ( $\mathrm{Ng}$ and Loomis, 1984), grapevines (Vitis vinifera L.) (Wermelinger et al., 1991), and kiwifruit [Actinidia deliciosa (A. Chev.) C.F. Liang \& A.R. Ferguson var. deliciosa 'Hayward'] (Buwalda, 1991). All carbohydrate partitioning is characterized in terms of dry-weight gain, representing the weight of structural growth and carbohydrate storage reserves. 
The calculation of sink strength is simplified by grouping organs of the same type together, although it is recognized that transport occurs to individual growing organs. The fruit, leaves, stems, and branches are modeled as being closest to the source, followed by the trunk, and finally the roots. Daily carbohydrate availability is calculated after maintenance respiration and the carbohydrate cost of fruit, leaf, stem, and branch growth potential are calculated. Growth occurs at the potential rate if sufficient carbohydrate is available. If there is not enough carbohydrate available to support potential growth, these organs compete for carbohydrate based on their sink strength. The fraction of potential growth that can be supported is calculated as the ratio of carbohydrate available after maintenance respiration to the carbohydrate requirement for potential growth. This fraction is multiplied by the potential growth of each organ type to determine organ growth. Trunk growth is determined in the same manner by calculating the ratio of carbohydrate available after fruit, leaf, stem, and branch growth to the carbohydrate cost of trunk growth potential. Carbohydrate remaining after trunk growth supports root growth.

For the first 150 degree-days after bloom ( 2 weeks), fruit, leaves, stems, and branches are allowed to grow at their conditional growth rates, unrestricted by carbohydrate availability. The carbohydrate represented by the difference between $\mathrm{C}$ assimilation and carbohydrate required to support maintenance respiration and growth is assumed to come from stored carbohydrate and is deducted from the dry weight of the trunk and roots. During the rest of the season, carbohydrate demand is supplied only by daily $\mathrm{C}$ assimilation.

In this modeling approach, the daily $\mathrm{C}$ budget is balanced by assigning carbohydrate remaining after fruit, leaf, stem, branch, and trunk growth, and respiration demands are met to root growth. No attempt is made to account for carbohydrate loss from the roots by fine root turnover, exudation, and increased respiration during active nutrient transport. For this reason, although the model calculates root growth, the values should more reasonably be attributed to root activity, including structural and storage biomass gain and metabolic processes.

\section{MODEL SIMULATIONS}

Input data for model simulations included tree attributes (initial dry weights of fruit, leaves, stems branches, trunk, and roots; number of fruit at bloom and after thinning; thinning date) and environmental data (minimum and maximum air and soil temperatures, solar radiation).

Details concerning collecting input data, model calibration, and model accuracy are available elsewhere (Grossman, 1993; Grossman and DeJong, 1994b). We will concentrate only on demonstrating how model simulations may be used to study aspects of plant growth and development that are very difficult to study experimentally.

\section{CALIBRATION}
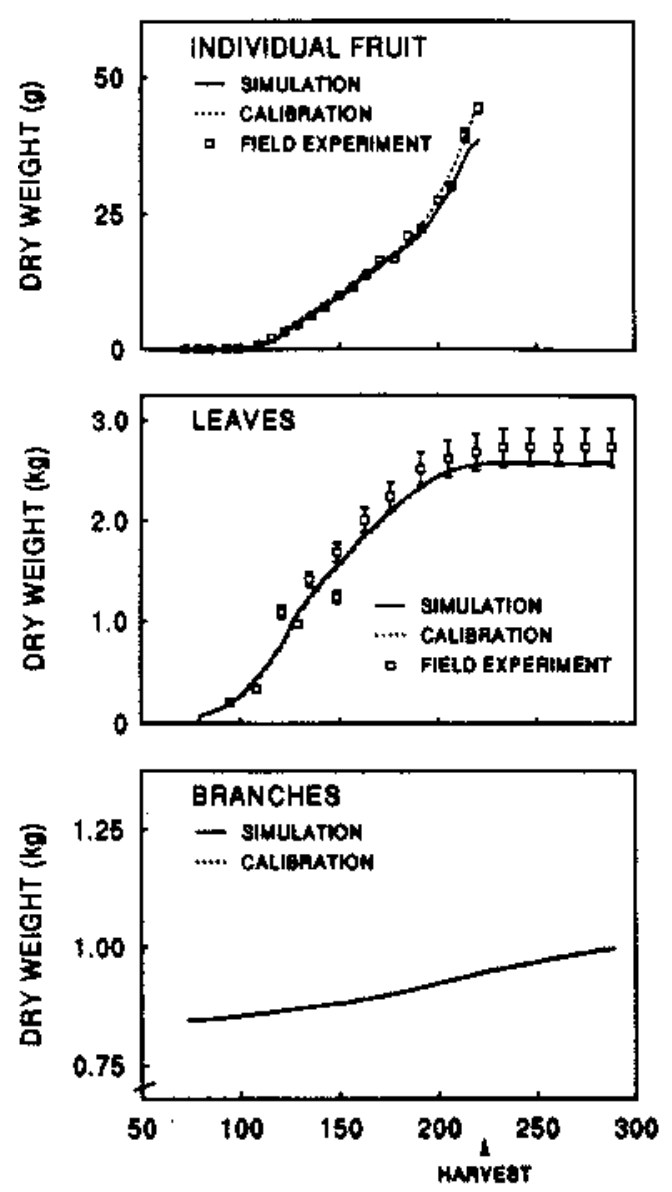
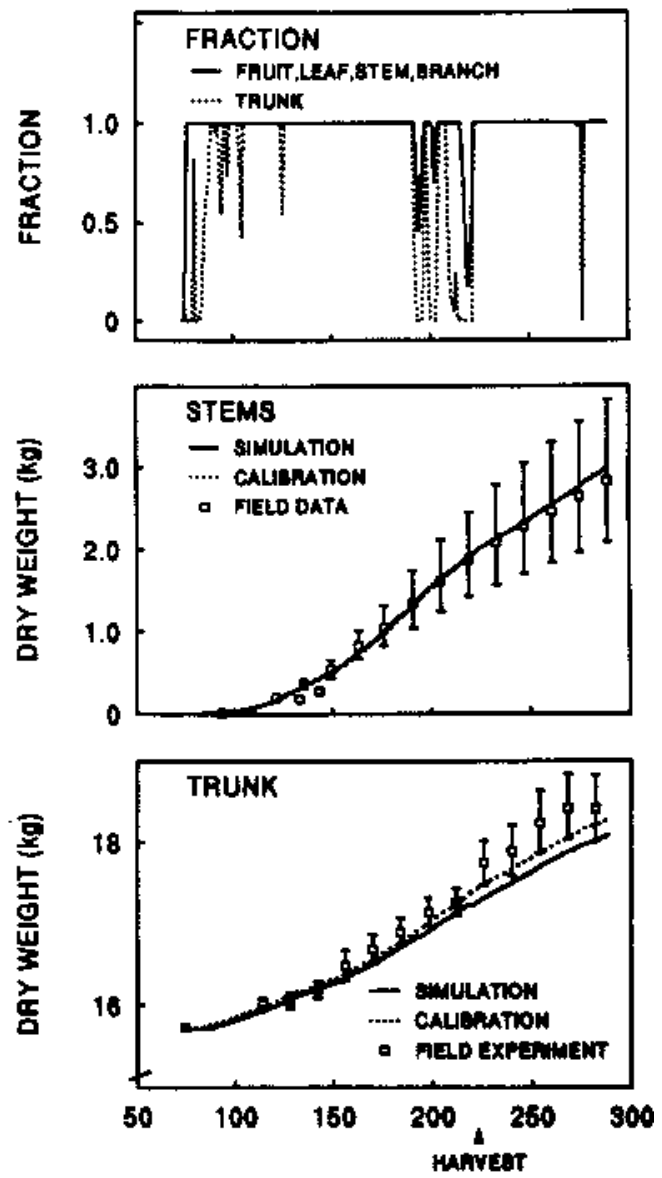

DAY OF THE YEAR

Fig. 4. Simulated, calibration, and experimental seasonal patterns of organ dry weight per tree under calibration conditions: individual fruit dry weight and the fraction of potential growth allowed by the model for peach trees that were heavily thinned at bloom, and leaf, stem, branch, and trunk dry weight per tree for defruited trees. Calibration curves for fruit and vegetative growth potentials were obtained from field data for growth on heavily thinned and defruited trees, respectively (Grossman, 1993). Calibration curves and simulation curves under calibration conditions differ because simulated carbohydrate availability restricted growth on several days. Where calibration curve is not distinguishable, it coincides with simulation curve. 


\section{THINNED AT EIGHT WEEKS}
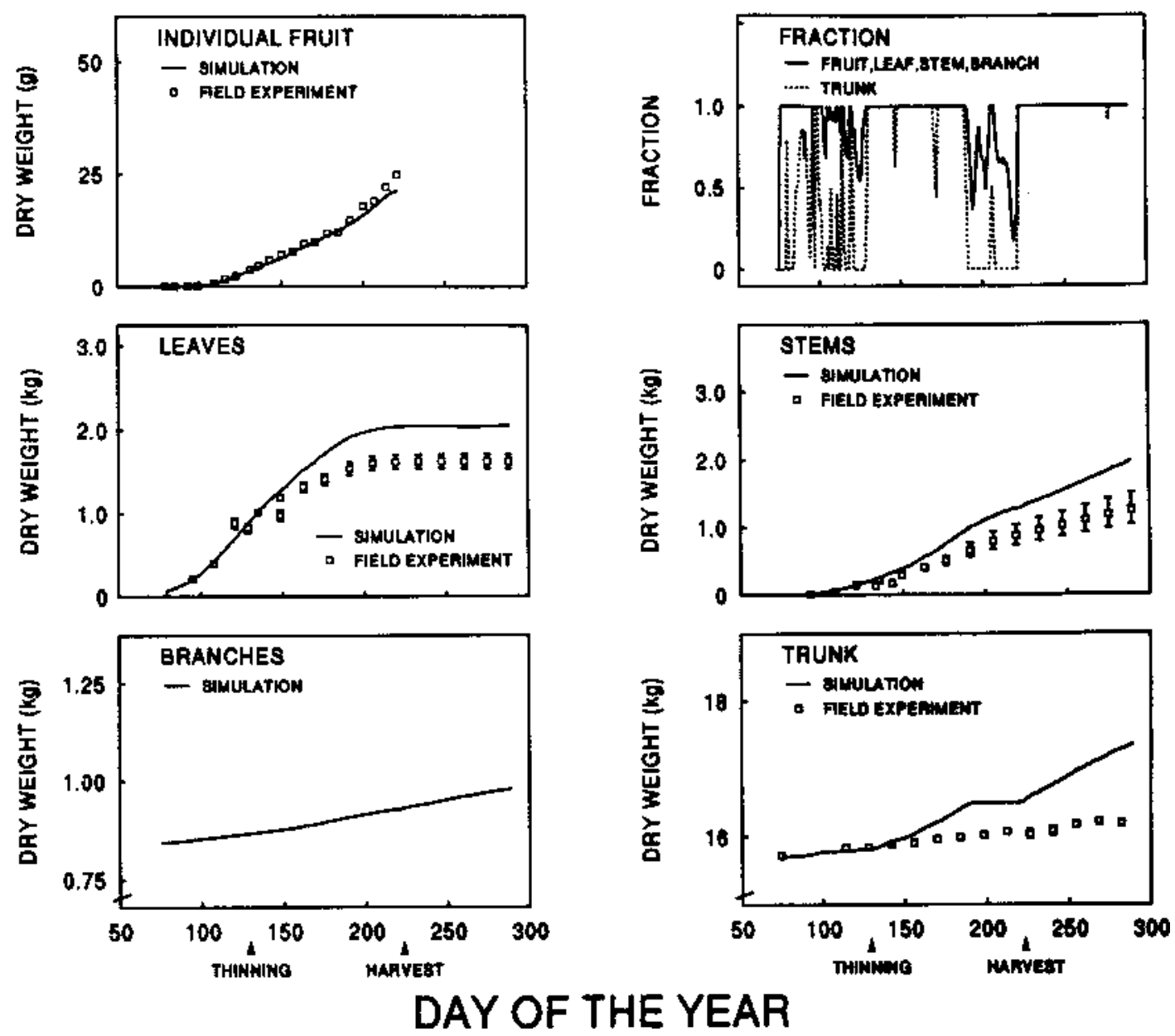

Fig. 5. Simulated and experimental seasonal patterns of individual fruit dry weight, the fraction of potential growth allowed by the model, and leaf, stem, branch, and trunk dry weight per tree for peach trees that were thinned 8 weeks after bloom (Grossman and DeJong, 1994b).

Although crop load can significantly influence vegetative drymatter production (Forshey and Elfving, 1989; Heim et al., 1979; Lenz, 1974), the timing and nature of these interactions are largely unknown. Simulations of seasonal dry-weight gain of the various plant organs and estimates of the daily carbohydrate investment costs associated with the growth of each organ (Figs. 4-6) on trees of a specific variety, crop load, and time of thinning indicate the nature of these interactions. As is generally known, fruit are the dominant sink for much of the time under normal cropping conditions. The model indicates that leaves are also a major sink during the early part of the season. The woody parts of the tree dominate the postharvest period.

Comparing simulations of organ growth under various cropping or environmental conditions allows the development of an integrated picture of the effects of changed conditions on that organ's growth (Fig. 7). This approach is particularly suitable for root activity because the model assumes that the root receives all of the residual carbohydrate available after the requirements of other organs are met. Although modeling carbohydrate partitioning to roots may overestimate root activity under certain conditions, the model clearly shows why cropping may have large effects on root growth (Heim et al., 1979; Lenz, 1974).

The model allows the calculation of quantitative estimates for daily C assimilation, respiration, and growth over the season (Fig. 8). Although these calculations depend on many assumptions and would vary greatly depending on environmental conditions, they clearly indicate the potential significance of maintenance respiration in the tree's overall C balance. They indicate seasonal C use vs. assimilation, previously unavailable for tree crops. An unusual feature of this modeling approach is that carbohydrate partitioning coefficients to the various organ types are a product of the model (Fig. 9) rather than the input since our modeling approach uses organ growth potentials as the primary determinants of carbohydrate use. In contrast, most plant simulation models partition carbohydrates according to assumed partitioning coefficients. The simulations indicate that almost all the carbohydrate is partitioned to fruit during the first few days before noticeable leaf activity begins. Then, as soon as leaf growth starts, partitioning shifts to leaf growth. The fruit regain dominance as the primary sink $\approx 1$ month later. Stems and branches receive a relatively small share of the carbohydrates until after harvest.

In retrospect, none of the results of these different types of simulations are particularly surprising. In fact, they seem to agree with many previous results and concepts regarding tree growth and crop productivity. Taken together, the modeling approach we have used describes tree and crop growth on a real-time basis and provides a conceptual basis for developing integrated working hypotheses for understanding tree function. Model predictions can be used as experimental hypotheses to be tested in the field. Alternatively, previous experimental results can be reexamined to determine if they substantiate model predictions. Furthermore, computer simulation allows dynamic integration of the effects of various input factors, such as crop load, fruit growth potential, and the environment, on tree growth and crop production. Thus, we believe that this modeling approach can be a powerful aid to developing and understanding some unifying concepts in horticultural crop production. 


\section{THINNED AT EIGHT WEEKS}
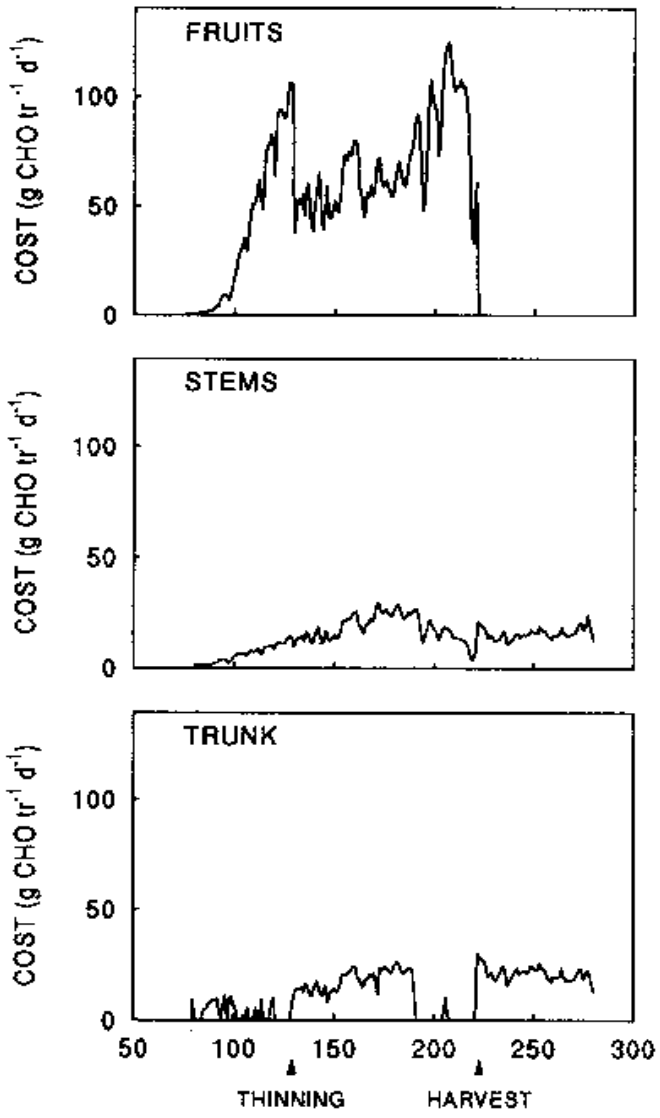
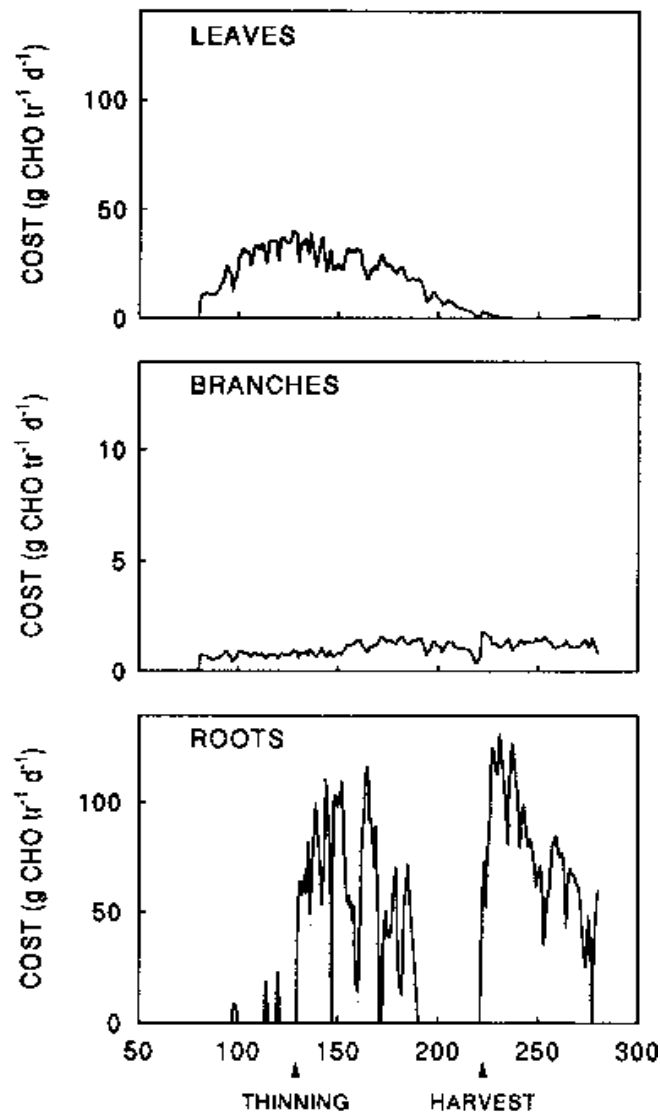

DAY OF THE YEAR

Fig. 6. Simulated seasonal patterns of daily carbohydrate investment costs of growth of fruit, leaves, stems, branches, trunk, and roots of peach trees that were thinned 8 weeks after bloom. Note scale change on graph pertaining to branches (Grossman and DeJong, 1994b).

\section{Literature Cited}

Amthor, J.S. 1989. Respiration and crop productivity. Springer-Verlag, New York. Buwalda, J.G. 1991. A mathematical model of carbon acquisition and utilization by kiwifruit vines. Ecol. Monogr. 57:43-64.

Crapo, N.L. and H.J. Ketellaper. 1981. Metabolic priorities with respect to growth and mineral uptake in roots of Hordeum, Triticum and Lycopersicon. Amer. J. Bot. 68:10-16.

DeJong, T.M. and J.F. Doyle. 1984. Leaf gas exchange and growth response of mature 'Fantasia' nectarine trees to paclobutrazol. J. Amer. Soc. Hort. Sci. 109:878-882.

DeJong, T.M. and J.F. Doyle. 1985. Seasonal relationships between leaf nitrogen content (photosynthetic capacity) and leaf canopy light exposure in peach (Prunus persica). Plant Cell Environ. 8:701-706.

DeJong, T.M. and J. Goudriaan. 1989a. Modeling peach fruit growth and carbohydrate requirements: Reevaluation of the double-sigmoid growth pattern. J. Amer. Soc. Hort. Sci. 114:800-804.

DeJong, T.M. and J. Goudriaan. 1989b. Modeling the carbohydrate economy of peach fruit growth and crop production. Acta Hort. 254:103-108.

DeJong, T.M. and Y.L. Grossman. 1992. Modeling the seasonal carbon economy of deciduous tree crops. Acta Hort. 313:21-28.

Forshey, C.G. and D.C. Elfving. 1989. The relationship between vegetative growth and fruiting in apple trees. Hort. Rev. 11:229-287.

Goudriaan, J. 1986. A simple and fast numerical method for the computation of daily totals of crop photosynthesis. Agr. For. Meteorol. 38:249-254.

Grossman, Y.L. 1993. The carbon economy of reproductive and vegetative growth of a woody perennial peach (Prunus persica (L.) Batsch): Growth potentials, respiratory demand and a simulation model. PhD Diss., Univ. of California, Davis.
Grossman, Y.L. and T.M. DeJong. 1994a. Carbohydrate requirements for dark respiration by peach vegetative organs. Tree Physiol. 14:37-48.

Grossman, Y.L. and T.M. DeJong. 1994b. PEACH: A simulation model of reproductive and vegetative growth in peach trees. Tree Physiol. 14:329345.

Heim, G., J.J. Landsberg, R.L. Watson, and P. Brain. 1979. Eco-physiology of apple trees, dry matter production and partitioning by young Golden Delicious trees in France and England. J. Applied Ecol. 126:179-194.

Kropff, M.J., L. Bastiaans, and J. Goudriaan. 1987. Implications of improvements in modeling canopy photosynthesis in SUCROS (a simple and universal crop growth simulator). Netherlands J. Agr. Sci. 35:192-194.

Lenz, F. 1974. Fruit effects on formation and distribution of photosynthetic assimilates. Proc. XIX Intl. Hort. Congr., Warsaw. p. 155-166.

$\mathrm{Ng}$, E. and R.S. Loomis. 1984. Simulation of growth and yield of the potato crop. Centre for Agricultural Publishing and Documentation, Wageningen, The Netherlands.

Patrick, J.W. 1991. Control of phloem transport to and short-distance transfer in sink regions: An overview, p. 167-177. In: J.L. Bonnemain, S. Delrot, W.J. Lucas, and J. Dainty (eds.). Recent advances in phloem transport and assimilate compartmentation. Oest Editions, Nantes, France.

Penning de Vries, F.W.T. 1975. The cost of maintenance processes in plant cells. Ann. Bot. 39:77-92.

Penning de Vries, F.W.T., A.H.M. Brunsting, and H.H. van Laar. 1974. Products, requirements and efficiency of biosynthesis: A quantitative approach. J. Theoretical Biol. 45:339-377.

Penning de Vries, F.W.T. and H.H. van Laar. 1982. Simulation of plant growth and crop production. Centre for Agricultural Publishing and Documentation, Wageningen, The Netherlands.

Sprugel, D.G., T.M. Hinckley, and W. Schaap. 1991. The theory and practice 
ROOTS
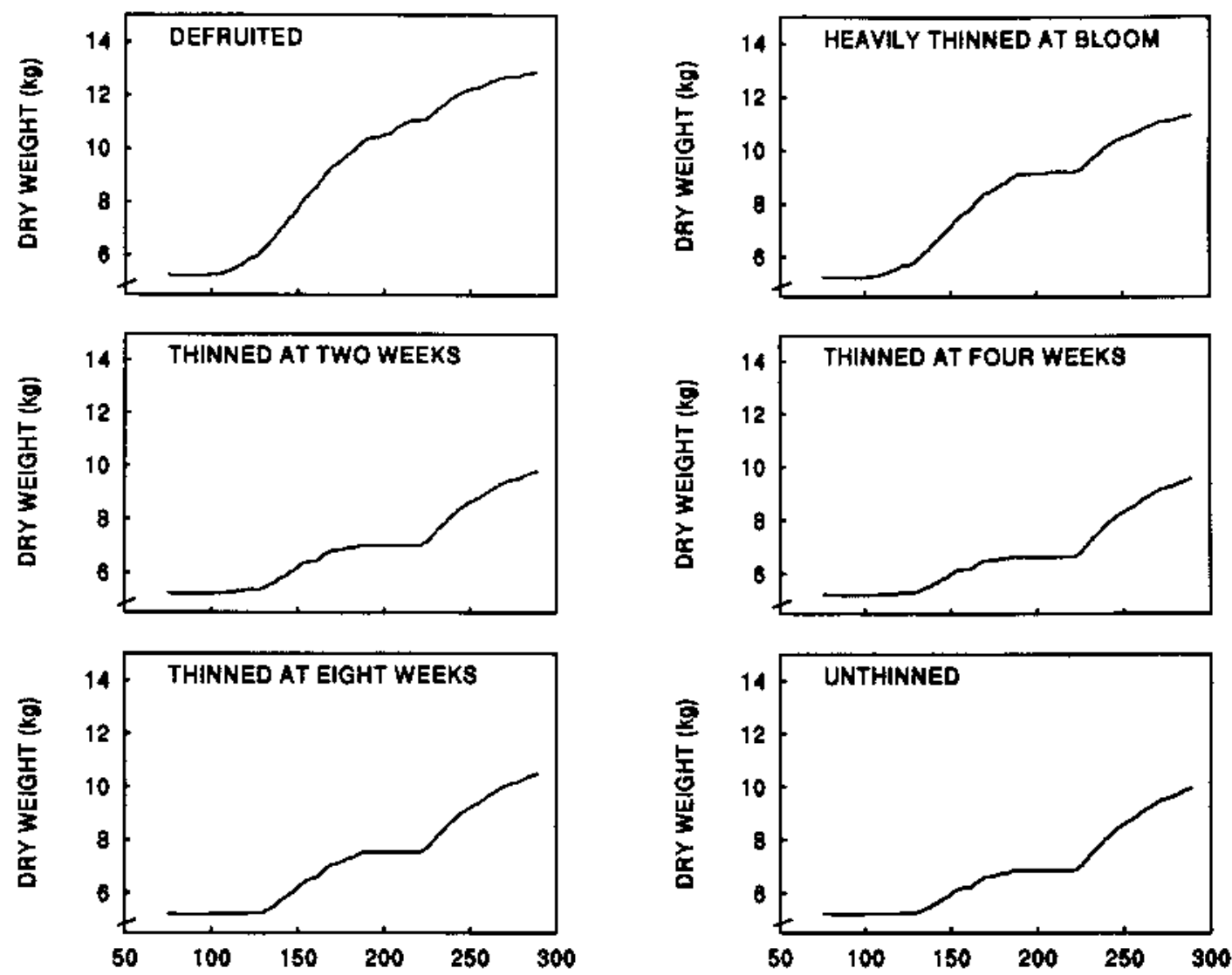

DAY OF THE YEAR

Fig. 7. Simulated seasonal pattern of dry-weight accumulation in roots per tree for peach trees that were defruited; heavily thinned at bloom; thinned 2,4 , or 8 weeks after bloom; and left unthinned (Grossman and DeJong, 1994b).

\section{SIMULATED CARBOHYDRATE SUPPLY AND DEMAND}
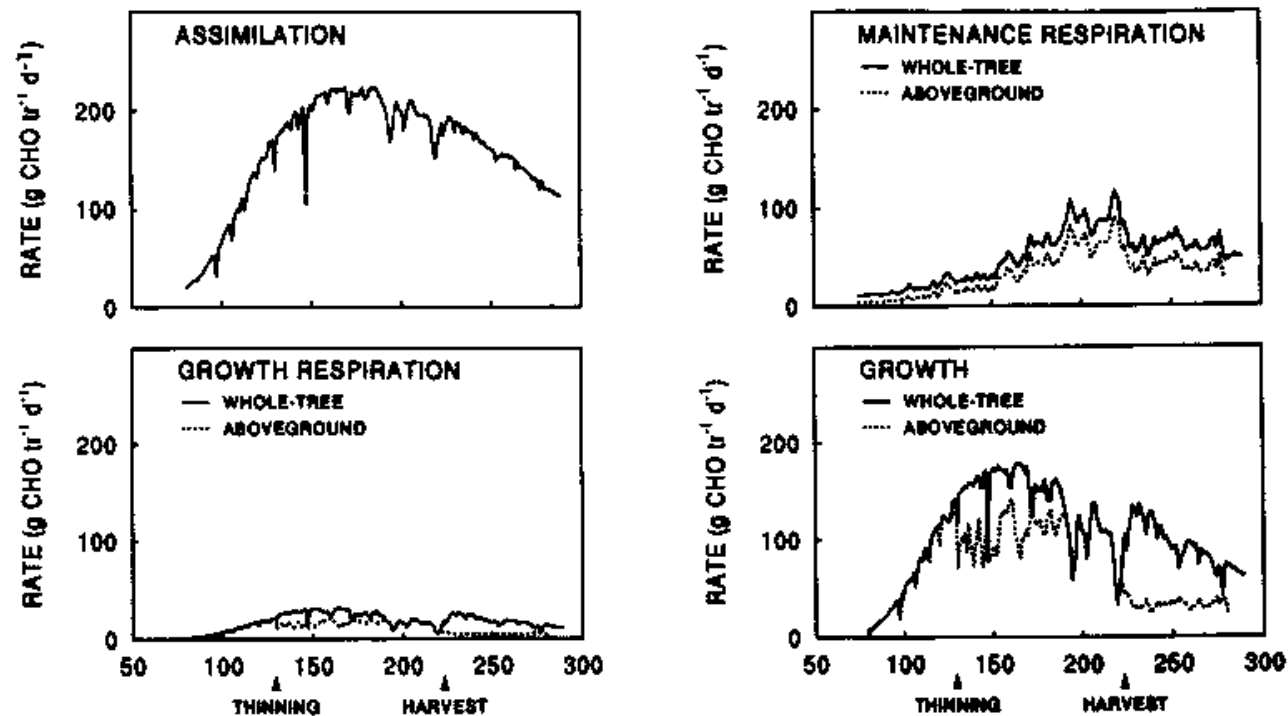

DAY OF THE YEAR

Fig. 8. Simulated seasonal pattern of daily $\mathrm{C}$ assimilation, maintenance respiration, growth respiration, and growth of peach trees that were thinned 8 weeks after bloom. Values can be converted to grams of carbohydrate per square meter per day dividing by 8 (Grossman and DeJong, 1994b). 


\section{SIMULATED PARTITIONING COEFFICIENTS}
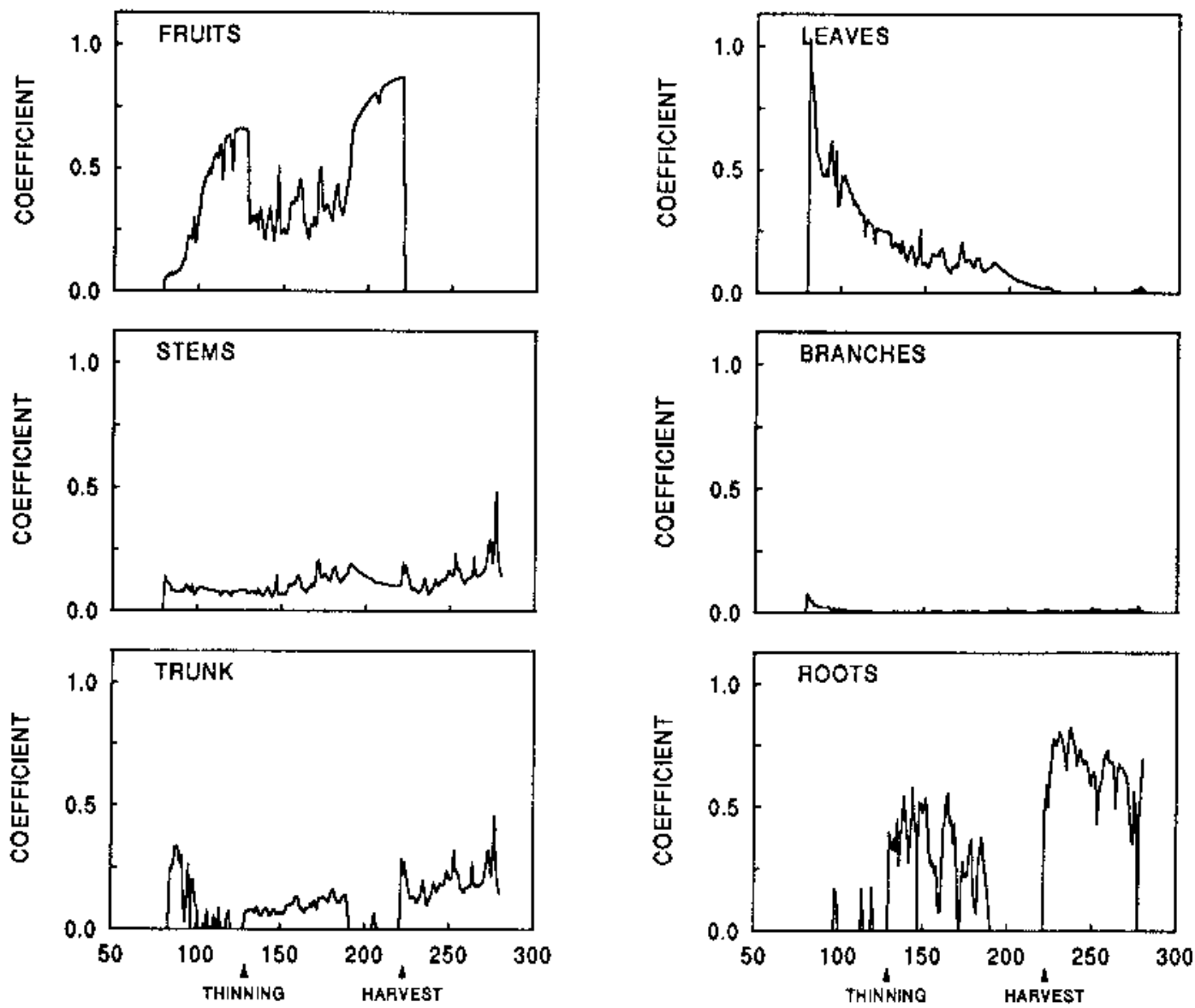

DAY OF THE YEAR

Fig. 9. Simulated seasonal patterns of the partitioning coefficients for fruit, leaves, stems, branches, trunk, and roots of peach trees that were thinned 8 weeks after bloom (Grossman and DeJong, 1994b).

of branch autonomy. Annu. Rev. Ecol. Systematics 22:309-334.

van Keulen, H., F.W.T. Penning de Vries, and E.M. Drees. 1982. A summary model for crop growth, p. 87-97. In: F.W.T. Penning de Vries and H.H. van Laar (eds.). Simulation of plant growth and crop production. Centre for Agricultural Publishing and Documentation, Wageningen, The Netherlands. van Kraalingen, D. and K. Rappoldt. 1987. Subprograms in simulation models. Internal Rpt. Center for Agrobiological Research/Dept. of Theoretical Production Ecology, Wageningen, The Netherlands. van Kraalingen, D. and C.J.T. Spitters. 1986. A simple and universal crop growth simulator: SUCROS '86. Internal Rpt. Center for Agrobiological Research/ Dept. of Theoretical Production Ecology, Wageningen, The Netherlands. Watson, M.A. and B.B. Casper. 1984. Morphogenetic constraints on patterns of carbon distribution in plants. Annu. Rev. Ecol. Systematics 15:233-258.

Wermelinger, B., J. Baumgärtner, and A.P. Gutierrez. 1991. A demographic model of assimilation and allocation of carbon and nitrogen in grapevines. Ecol. Modelling 53:1-26. 